\title{
Controlled Release of Alendronate from Polymeric Films
}

\author{
by \\ KAREN LONG \\ B.Sc., University of British Columbia, 1989 \\ A THESIS SUBMITTED IN PARTIAL FULFILLMENT OF \\ THE REQUIREMENTS FOR THE DEGREE OF \\ MASTER OF SCIENCE \\ in \\ THE FACULTY OF GRADUATE STUDIES \\ (Pharmaceutical Sciences)
}

THE UNIVERSITY OF BRITISH COLUMBIA

April 2006

(C) Karen Long, 2006 


\section{ABSTRACT}

Bisphosphonate drugs are used for bone disorders such as osteoporosis, hypercalcaemia of malignancy and Paget's disease. Bisphosphonates have been shown to reduce bone resorption and increase bone mass, but have low oral bioavailability. Localized delivery of bisphosphonates has the potential to improve efficacy and decrease side effects common to oral bisphosphonate therapy.

A sensitive high performance liquid chromatography method for the determination of the bisphosphonate, alendronate, was developed and validated. Novel alendronateloaded biodegradable polymeric films were prepared, which could be used as a targeted drug delivery device in areas where predictable bone ingrowth was desired. The drug release profiles of various formulations of alendronate in films composed of poly(lactic-co-glycolic acid) (PLGA) and polyethylene glycol or poly(DL-lactic acid)block-methoxy poly(ethylene glycol) (termed "diblock")' were determined. Increasing the proportion of diblock copolymer in the formulation decreased the glass transition temperature of PLGA, as measured by differential scanning calorimetry, and a miscible blend was formed. Controlled release over a 3 week period was observed for films composed of $10 \%$ diblock in PLGA.

Scanning electron microscopy and X-ray powder diffraction showed that grinding the alendronate prior to film preparation did not adversely affect the crystal structure. In addition, evidence from thermogravimetric analysis and powder diffraction patterns showed that preparation of the films in dichloromethane did not result in the formation of solvates.

Alendronate-loaded films were sterilized by glow discharge in preparation for in vitro studies with osteoblast cells. The drug release profiles of films that had and had not been glow discharged were the same and no difference in the mean molecular weight of the diblock was observed by gel permeation chromatography after 7 days at $37^{\circ} \mathrm{C}$ in phosphate buffered saline.

The effect of various concentrations $\left(10^{-4}\right.$ to $\left.10^{-8} \mathrm{M}\right)$ of alendronate on the proliferation of osteoblast cells in vitro was determined. Drug-loaded polymeric films containing $0.25 \%$ alendronate increased osteoblast proliferation after 4 days compared to polymer alone. However, films containing $0.5 \%$ alendronate appeared to inhibit proliferation. When these experiments were repeated using the MTS assay 
rather than manual counting, the results showed no significant effect of alendronate on osteoblast proliferation. 


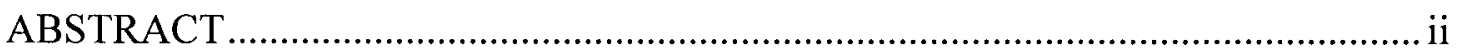

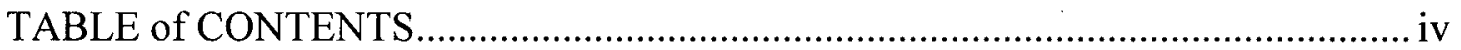

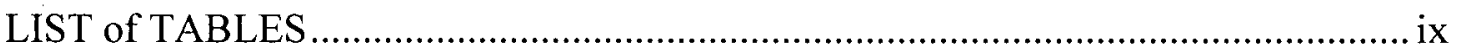

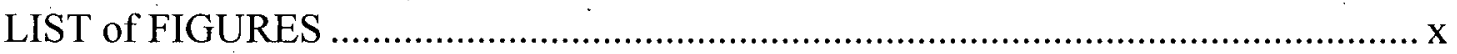

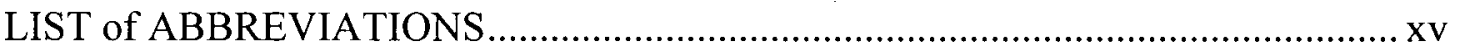

ACKNOWLEDGEMENTS ......................................................................................

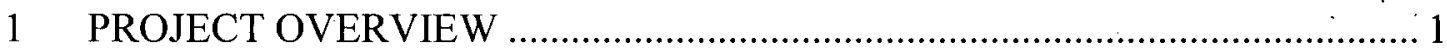

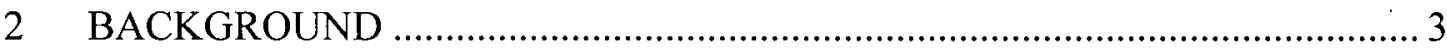

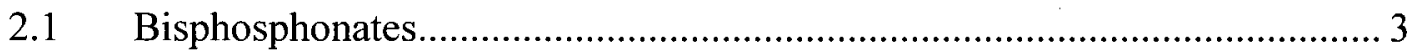

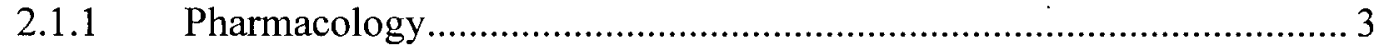

2.1.2 Structure-Activity Relationship .................................................... 5

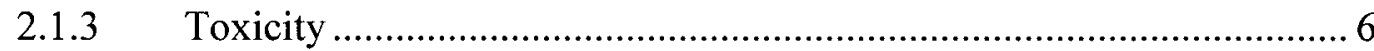

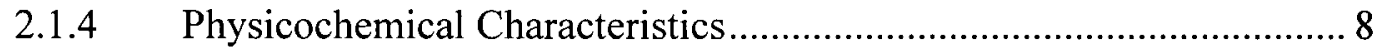

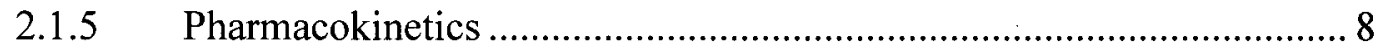

2.2 Therapeutic Applications of Delivery of Bisphosphonates to Bone Tissue .9

2.2.1 Topical or Subcutaneous Bisphosphonates with Implant Devices ..... 11

2.2.2 Bone Regeneration in Orthopaedic Procedures .................................. 12

2.2.3 Bone Regeneration in Periodontal Surgery ........................................... 14

2.2.4 Bone Void Fillers ............................................................................ 14

2.3 Polymeric Drug Delivery Systems............................................................ 15

2.3.1 Biodegradable Polymers as Biomaterials …………………................ 15

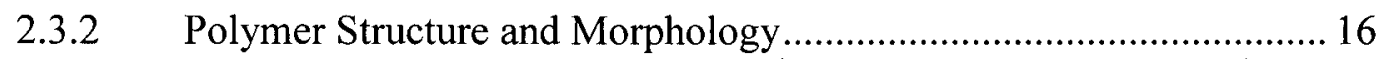




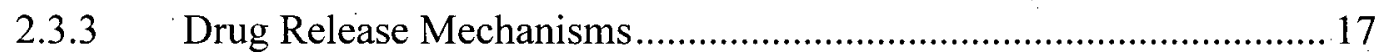

2.3.3.1 Diffusion Controlled Release....................................................... 17

2.3.3.2 Degradation Controlled Release ……………….......................... 18

2.3.4 Factors Influencing Drug Release _.................................................. 18

2.3.5 Polymers Used in Film Manufacture …………….............................. 19

2.3.5.1 Poly(DL-lactic-co-glycolic acid) (PLGA) ………………………..... 19

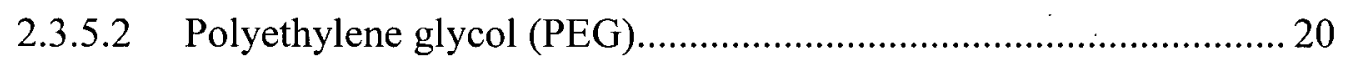

2.3.5.3 Amphiphilic Diblock Copolymer.................................................... 21

2.3.6 Controlled Release of Bisphosphonates from Polymers..................... 22

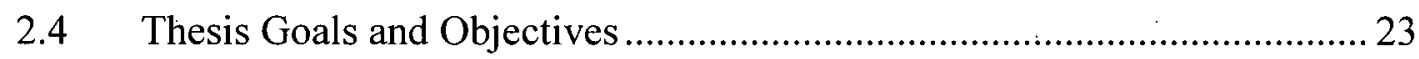

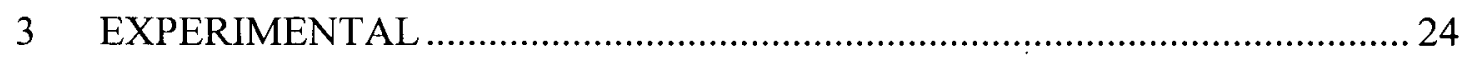

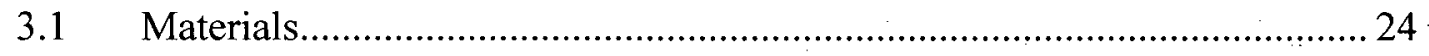

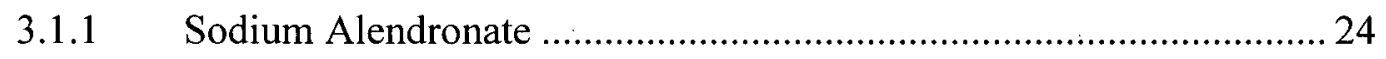

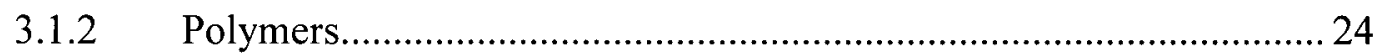

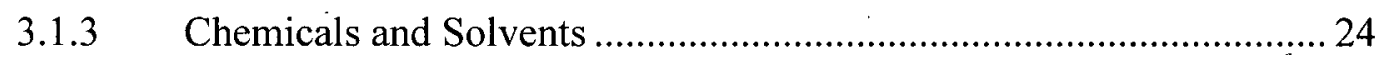

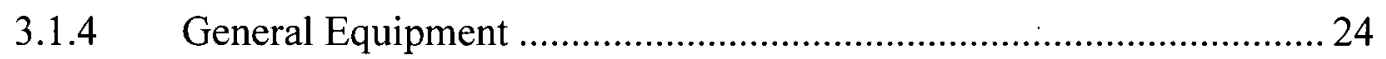

3.1.5 Stock Solutions for Drug Release Studies ……….............................. 25

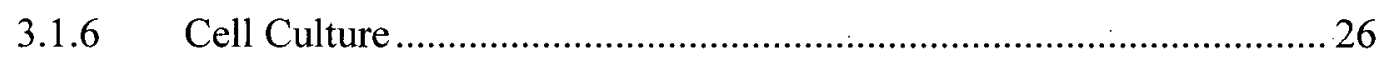

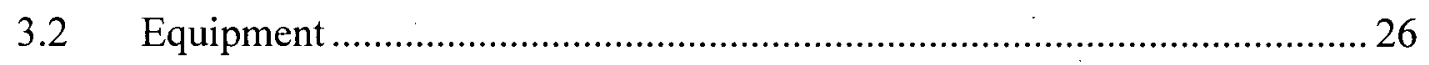

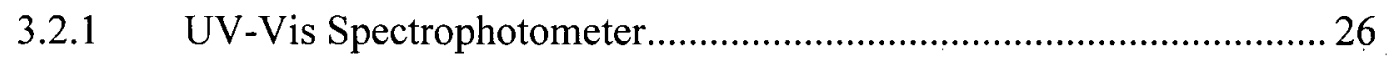

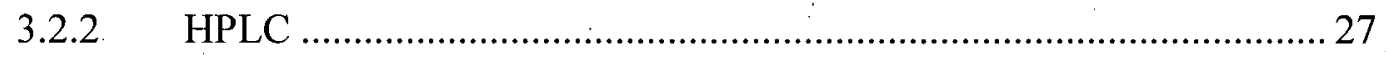

3.2.3 Liquid Chromatography/Mass Spectrometry …….............................. 27

3.2.4 Scanning Electron Microscope …………......................................... 27

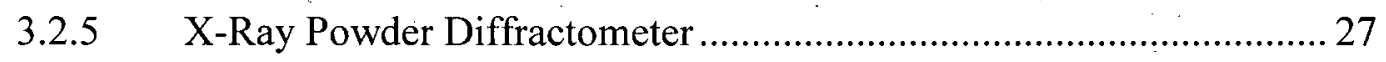




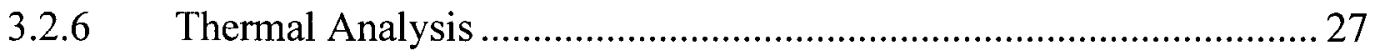

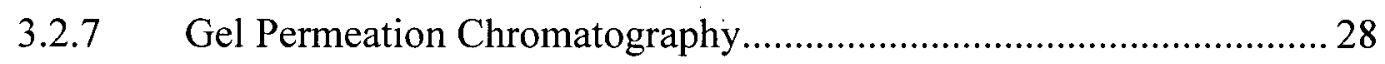

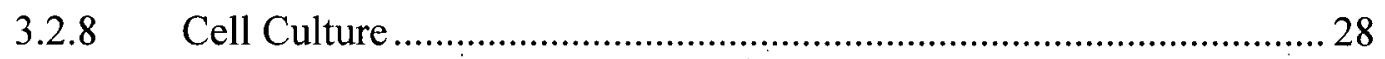

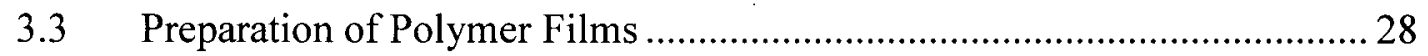

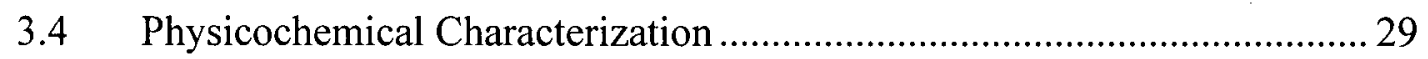

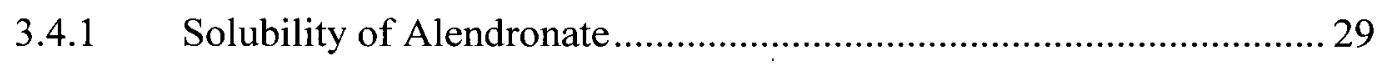

3.4.2 Alendronate Analysis by Spectrophotometry ..................................... 29

3.4.3 Alendronate Analysis by Ion Chromatography ……........................... 30

3.4.4 Alendronate Analysis by Fluorescence HPLC.................................... 31

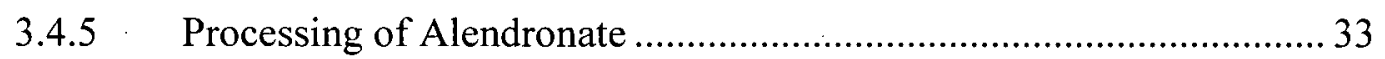

3.4.6 In vitro Release Studies................................................................. 33

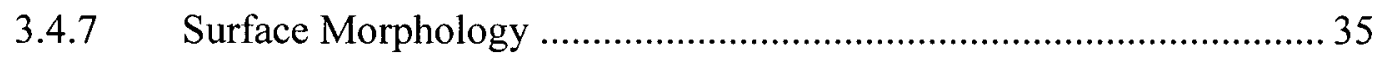

3.4.8 X-Ray Powder Diffraction ................................................................... 35

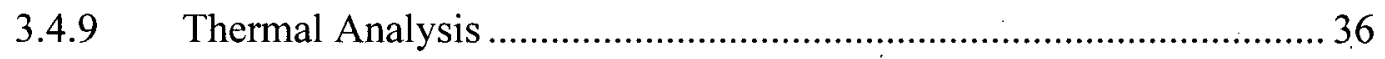

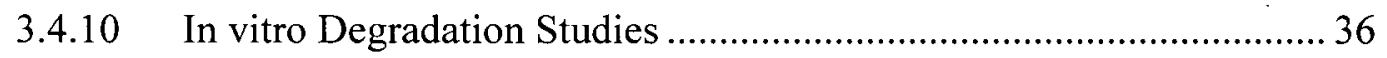

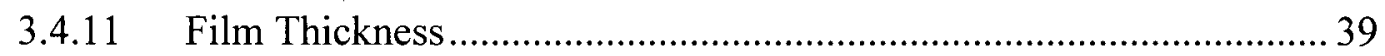

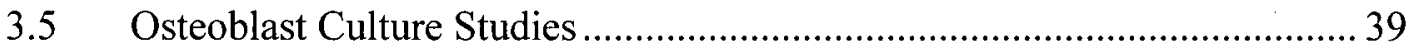

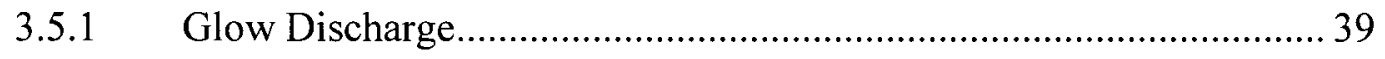

3.5.2 Cell Proliferation by Staining ………………………………............ 39

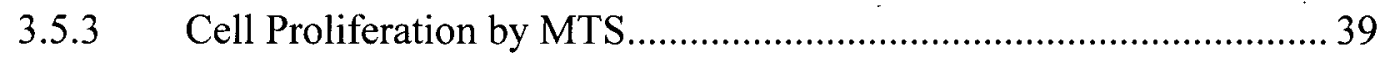

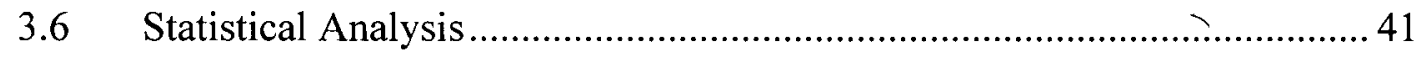

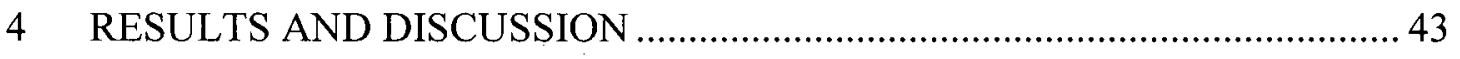

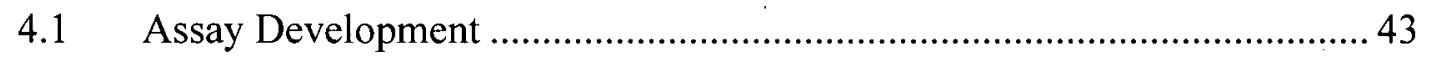

4.1.1 Sodium Alendronate Trihydrate..................................................... 43

4.1.2 Analytical Method Literature Review................................................. 44 
4.1.3 Alendronate Analysis by UV-Vis .................................................. 46

4.1.4 Alendronate Analysis by Ion Chromatography .................................... 46

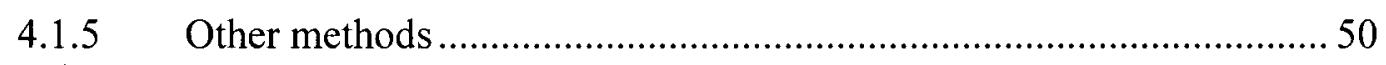

4.1.6 Alendronate Analysis by Fluorescence HPLC................................. 50

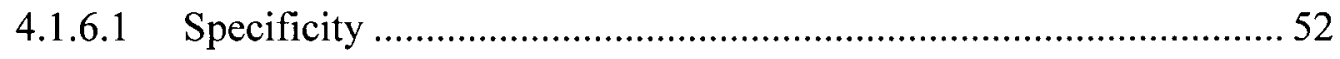

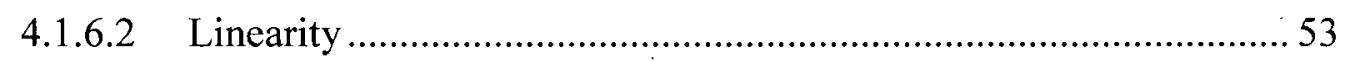

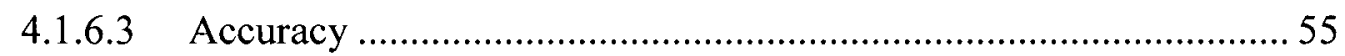

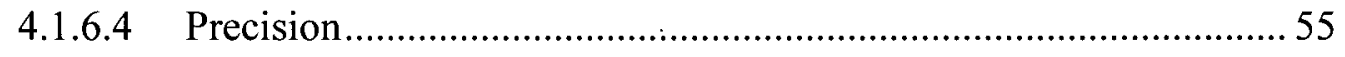

4.1.6.5 Detection Limit and Quantitation Limit.........................................56

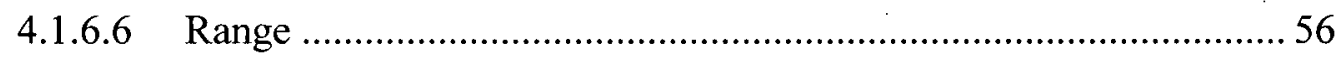

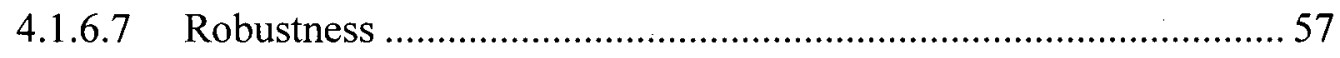

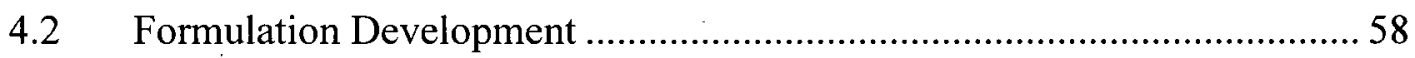

4.2.1 Preparation and Characterization of Polymer Films..........................58

4.2.2 Effect of Processing on Alendronate Powder ....................................... 58

4.2.2.1 Surface Morphology .................................................................... 58

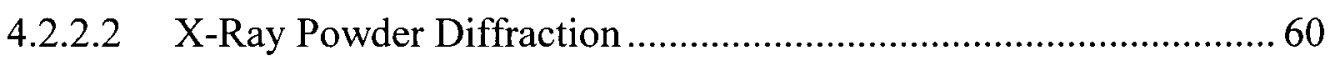

4.2.2.3 In Vitro Alendronate Release Profiles .............................................63

4.2.2.4 Investigation of Potential Solvate Formation..................................... 64

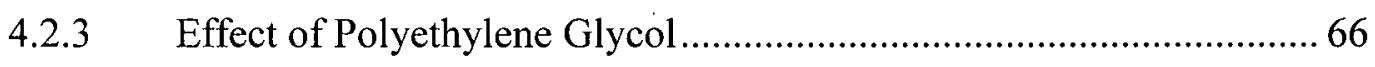

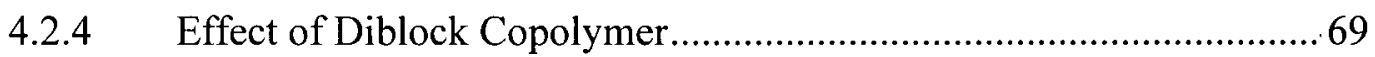

4.2.5 Mathematical Modeling ……………………................................. 70

4.2.6 Effect of Alendronate Concentration ................................................ 72

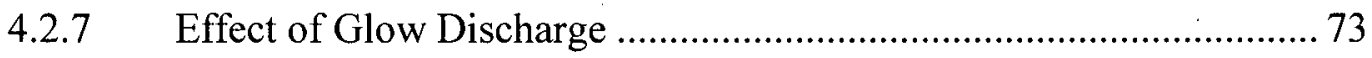

4.2.8 Characterization of 10\% Diblock in PLGA Blend Formulation.......... 76 


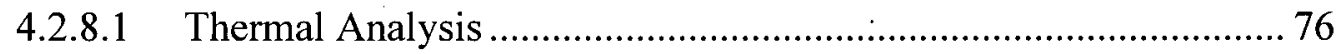

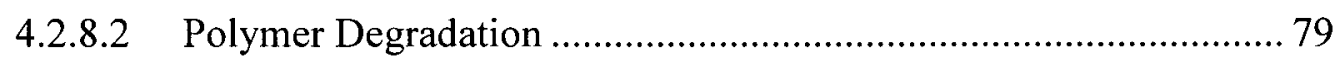

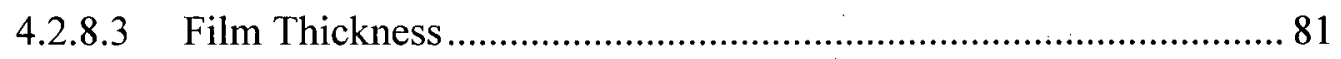

4.3 Osteoblasts Cell Culture Data ............................................................... 82

4.3.1 Effect of Alendronate Concentration .................................................. 82

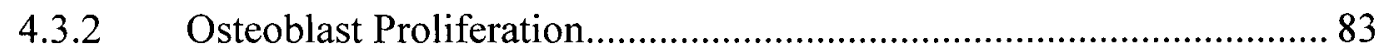

4.3.3 Cell Proliferation by MTS Assay …………......................................... 86

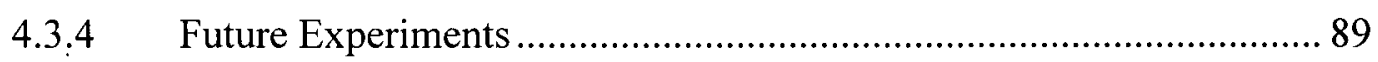

$5 \quad$ SUMMARY AND CONCLUSIONS ……………....................................... 91

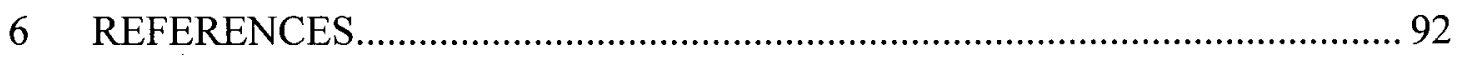




\section{LIST of TABLES}

Table 1 Commercially Available Bisphosphonate Drugs ................................... 6

Table 2 Local Bisphosphonate Use with Medical Implants.............................. 10

Table $3 \quad$ General Equipment and Supplies........................................................ 25

Table 4 Theoretical loadings of $0,0.1,0.25,0.5 \%$ alendronate into $10 \%$ diblock

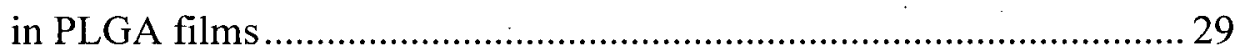

Table 5 Literature Review: Bisphosphonate Analytical Methods ...................... 45

Table 6 Specificity of Alendronate by Ion Chromatography: Retention Times of Common Ions.

Table 7 Method Validation Data for Fluorescence HPLC Analysis of

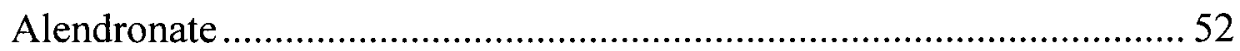

Table 8 Linearity of Alendronate Response by Fluorescence HPLC ................. 53

Table 9 Accuracy of Fluorescence HPLC Method for Determination of

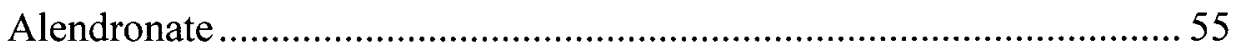

Table 10 Inter-Day Precision of Fluorescence HPLC Method for Determination of

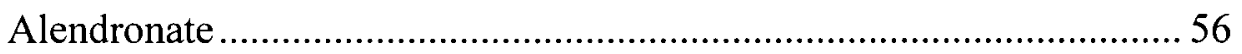

Table 11 Sample Solution Stability of Fluorescence HPLC Method for Determination of Alendronate .............................................................. 57

Table 12 X-Ray Diffraction Peak Positions and Relative Intensities of Theoretical, As Received and Ground Sodium Alendronate Trihydrate

Table 13 Similarity and Difference Factors (f1, f2) for Drug Release Curves of Glow Discharged and Control 10\% Diblock in PLGA Films Containing $0.1,0.25$ and $0.5 \%$ Alendronate. 75

Table 14 Observed Glass Transition Temperatures for PLGA and PLGA/Diblock Blends. 76

Table 15 Film Thicknesses and Weights of 4 Batches of Alendronate Loaded 10\% Diblock in PLGA Films. 82 


\section{LIST of FIGURES}

Figure 1 Chemical structure of the bisphosphonate alendronate bound to calcium. Carbon atoms are shown in grey, phosphorus in pink, oxygen in red, nitrogen in blue and hydrogen in white. 3

Figure 2 Bone remodelling cycle (Ralston 2005), used with permission................. 4

Figure 3 Structure of poly(lactic-co-glycolic acid) .............................................. 19

Figure 4 Structure of polyethylene glycol (PEG). PEG 600 is also known as PEG 12. 21

Figure 5 Structure of poly(DL-lactic acid)-block-methoxy poly(ethylene glycol), or "diblock" 21

Figure 6 UV-Vis spectra of alendronate standards in ceric nitrate solution containing $0,2.4,9.6$ and $28.8 \mu \mathrm{g} / \mathrm{ml}$ alendronate. Loss of signal at $320 \mathrm{~nm}$ is proportional to alendronate concentration 30

Figure 7 Representative chromatogram of $25 \mu \mathrm{g} / \mathrm{ml}$ alendronate standard by ion chromatography. Mobile phase: $0.5 \mathrm{mM}$ cupric nitrate, $1.0 \mathrm{mM}$ nitric acid, $1 \mathrm{ml} / \mathrm{min}$. UV-Visible detection at $245 \mathrm{~nm}$.

Figure 8 Sample preparation flow chart for the determination of alendronate by fluorescence HPLC 32

Figure 9 Fluorescence HPLC chromatogram of alendronate standard, concentration $0.01 \mathrm{mg} / \mathrm{ml}$. Mobile phase: 97:3 (1 mM EDTA $(\mathrm{pH}$ 6.5):methanol), $1 \mathrm{ml} / \mathrm{min}$. Excitation wavelength, $395 \mathrm{~nm}$, emission wavelength $480 \mathrm{~nm}$.

Figure 10. Scanning electron micrograph of sodium alendronate trihydrate as received from Dr. Wang. Mean particle size $\sim 30 \mu \mathrm{m}$ (range 9-97 $\mu \mathrm{m}$ ).

Figure 11 GPC elution profile of a 10\% diblock in 85:15 PLGA film (not glow discharged) after 3 days in PBS at $37^{\circ} \mathrm{C}$. Solvent: chloroform, $1 \mathrm{ml} /$ minute; injection volume $20 \mu \mathrm{l}$ 37

Figure 12 GPC standard curve for polystyrene standards with molecular weights from 300 to $30,000 \mathrm{~g} / \mathrm{mol}$. (Mobile phase: chloroform at $1.0 \mathrm{ml} / \mathrm{min}$. 
through two Styragel® columns (HR3 and HR1) connected in series with refractive index detection at $40^{\circ} \mathrm{C}$, injection volume: $20 \mu \mathrm{l}$ ). Equation: $y=-0.3103 x+7.6411, R 2=0.993$. 38

Figure 13 Schematic diagram of osteoblast cells proliferating over drug-loaded films and along walls of 12 -well plate 40

Figure 14 Chemical structure and ball-and-stick model of alendronate. Carbon atoms are shown in grey, phosphorus in pink, oxygen in red, nitrogen in blue and hydrogen in white. 43

Figure 15 Solubility of sodium alendronate trihydrate at $37^{\circ} \mathrm{C}$ in $(x)$ phosphate buffered saline $(\mathrm{pH} 7.5)$ and $(0)$ distilled water $(\mathrm{pH} 5.7)$. 44

Figure 16 Chromatogram of $0.5 \mathrm{mg} / \mathrm{ml}$ alendronate in phosphate buffer by ion chromatography. Mobile phase: $6 \mathrm{mM}$ nitric acid, flow rate: $0.5 \mathrm{ml} /$ minute, injection volume $20 \mu \mathrm{l}$, detection by A) refractive index or B) UV-Vis at $235 \mathrm{~nm}$. 47

Figure 17 Chromatogram of Alendronate in PBS by Ion Chromatography. Mobile phase: $0.5 \mathrm{mM}$ copper (II) nitrate, $1.0 \mathrm{mM}$ nitric acid, flow rate: $1.0 \mathrm{ml} /$ minute, injection volume $20 \mu \mathrm{l}$, detection by UV-Vis at $245 \mathrm{~nm}$.

Figure 18 Reaction of fluorescamine with an amino group creating a fluorescent fluorophore 51

Figure 19 Linearity of fluorescence HPLC standard curve for sodium alendronate standard solutions with concentrations of A) 0.5 to $2000 \mu \mathrm{g} / \mathrm{ml}$ $(\mathrm{R} 2=0.9936)$ or $\mathrm{B}) 0$ to $10 \mu \mathrm{g} / \mathrm{ml}(\mathrm{R} 2=0.9996)$. Mobile phase $97: 31$ mM EDTA(pH 6.5):Methanol, $1 \mathrm{ml} / \mathrm{min} ., 25 \mathrm{~cm} \mathrm{C1} 8$ column, $\lambda \mathrm{ex}=395$ $\mathrm{nm}, \lambda \mathrm{em}=480 \mathrm{~nm}$. 54

Figure 20 Scanning electron micrographs of sodium alendronate A) as received (trihydrate), mean particle size $30 \mu \mathrm{m}, \mathrm{B}$ ) ground (trihydrate), mean particle size $6 \mu \mathrm{m}, \mathrm{C}$ ) lyophilized, glassy anhydrous particles.

Figure 21 X-Ray Powder Diffraction Patterns of Alendronate A) ground, B) as received and C) lyophilized. 
Figure 22 Reference X-Ray Powder Diffraction Pattern of Sodium Alendronate Trihydrate, used with permission (Vickers 2004).

Figure 23 Cumulative Release of Alendronate from 10\% (w/w) drug-loaded 85:15 PLGA films containing: $(\Delta)$ lyophilized, $(\diamond)$ as received and $(\square)$ ground alendronate in PBS at $37^{\circ} \mathrm{C} .0 .1 \mathrm{mg} / \mathrm{mg}$ film represents $100 \%$ theoretical loading. Error bars indicate standard deviation among $n=5$ films of each type.

Figure 24 Thermogravimetric analysis of sodium alendronate trihydrate after 3 days in dichloromethane at $37^{\circ} \mathrm{C}$. The temperature ramp rate $=20^{\circ} \mathrm{C} /$ minute, unless a weight change of $>1.00 \% / \mathrm{min}$. was detected, in which case the temperature was held isothermal 65

Figure $25 \mathrm{X}$-ray powder diffraction pattern of sodium alendronate trihydrate as received (black) and after 3 days in dichloromethane at $37^{\circ} \mathrm{C}$ (red). ....66

Figure 26 Cumulative release of alendronate from 10\%-drug loaded 20\% PEG 600 in 85:15 PLGA films containing: $(\Delta)$ lyophilized, $(\diamond)$ as received, and () ground alendronate in PBS at $37^{\circ} \mathrm{C} .0 .1 \mathrm{mg} / \mathrm{mg}$ film represents $100 \%$ theoretical loading. Error bars indicate standard deviation among $n=5$ films of each type. 68

Figure 27 Cumulative release of alendronate from 5\%(w/w) drug-loaded films composed of 85:15 PLGA and the following amounts of diblock: $(\Delta)$ $0 \%$, (ㅁ) $10 \%,(\diamond) 20 \%$ or $(\times) 30 \%$ into PBS at $37^{\circ} \mathrm{C} .0 .05 \mathrm{mg} / \mathrm{mg}$ film represents $100 \%$ theoretical loading. Error bars indicate standard deviation among $\mathrm{n}=5$ films of each type.

Figure 34 Cumulative release of alendronate as a function of the square root of time from $5 \%(\mathrm{w} / \mathrm{w})$ drug-loaded films composed of 85:15 PLGA and the following amounts of diblock: $(\Delta) 0 \%,(\square) 10 \%,(\diamond) 20 \%$ or $(\times) 30 \%$ into PBS at $37^{\circ} \mathrm{C} .0 .05 \mathrm{mg} / \mathrm{mg}$ film represents $100 \%$ theoretical loading. Error bars indicate standard deviation among $\mathrm{n}=5$ films of each type. Lines shown are linear regressions of the given data points. 71

Figure 28 Cumulative release of alendronate from $(\Delta) 0.10 \%,(\diamond) 0.25 \%$ and (口) $0.50 \%$ drug-loaded $10 \%(\mathrm{w} / \mathrm{w})$ diblock in 85:15 PLGA films in PBS at $37^{\circ} \mathrm{C}$. Data expressed as mean $\pm \operatorname{SEM}(\mathrm{N}=3)$. 73 
Figure 29 Cumulative release of alendronate from $(\Delta) 0.10 \%,(\diamond) 0.25 \%$ and $(\square)$ $0.50 \%(\mathrm{w} / \mathrm{w})$ drug-loaded 10\% diblock in 85:15 PLGA films in PBS at $37^{\circ} \mathrm{C}$. Glow discharged data are indicated by open symbols and dashed lines. Control data are indicated by filled symbols and solid lines. Data are expressed as mean \pm SEM $(\mathrm{N}=3)$

Figure 30 Differential scanning calorimetry cooling/reheating scan of $10 \%$ Diblock in 85:15 PLGA following one heating cycle at a heating rate $10^{\circ} \mathrm{C} /$ minute. 77

Figure 31 Effect of blending increasing amounts of diblock into 85:15 PLGA films on glass transition temperature ( $\mathrm{Tg})$ of blend. Observed values $(\theta, \mathrm{n}=3)$ were obtained by differential scanning calorimetry at a heating rate of $10^{\circ} \mathrm{C} /$ minute. Error bars indicate standard deviation. Line shown is the linear regression of the given data points 78

Figure 32 Comparison of diblock molecular weights in glow discharged (solid) and not glow discharged (hatched) $10 \%$ diblock in 85:15 PLGA films agitated in PBS at $37^{\circ} \mathrm{C}$ for 3 or 7 days. Mean and SD for 3 batches determined by GPC, $\left({ }^{*}\right)$ statistically significant compared to time $0 \ldots 79$

Figure 33 Comparison of diblock to PLGA peak height ratios in glow discharged (solid) and not glow discharged (hatched) 10\% diblock in PLGA films agitated in PBS at $37^{\circ} \mathrm{C}$ for 3 or 7 days. Mean and SD for 3 batches determined by GPC. 81

Figure 35 Osteoblast proliferation in the presence of various concentrations of alendronate $(2.8 \times 10-4$ to $2.8 \times 10-8 \mathrm{M})$. Wells were seeded with $1 \mathrm{ml}$ of media containing 20,000 osteoblasts and an aliquot of alendronate solution. The relative osteoblast proliferation after 2 days at $37^{\circ} \mathrm{C}, 5 \%$ $\mathrm{CO} 2$ was measured by the MTS assay. Data expressed as mean \pm SEM $(\mathrm{N}=3)$.

Figure 36 Fluorescence microscope images of rat osteoblasts on $0.25 \%$ alendronate-loaded 10\% diblock in 85:15 PLGA Films, using the rhodamine (left) or DAPI (right) filters. 84

Figure 37 Osteoblast proliferation after 1, 2 or 4 days incubation with control Thermanox ${ }^{\mathrm{TM}}$ cover slips or 10\% diblock in 85:15 PLGA films loaded 
with $0,0.1,0.25$ or $0.5 \%$ alendronate. Proliferation is expressed as mean \pm SEM ( $\mathrm{N}=3$ experiments) of stained osteoblasts visible per representative microscope image (10X magnification). ........................ 85

Figure 38 Chemical structure of MTS tetrazolium reagent being reduced to its formazan product 86

Figure 39 Osteoblast proliferation data from experiment 1 on $0,0.1,0.25$ and $0.5 \%$ alendronate-loaded 10\% diblock in 85:15 PLGA films after incubation at $37^{\circ} \mathrm{C}$ for $1,3,4$ or 6 days. Proliferation was measured by the MTS assay $(n=3)$ and normalized to untreated control wells. A) Osteoblast proliferation on films only, B) osteoblast proliferation on films and wells. 87

Figure 40 Osteoblast proliferation data from experiment 2 on $0,0.1,0.25$ and $0.5 \%$ alendronate-loaded 10\% diblock in 85:15 PLGA films after incubation at $37^{\circ} \mathrm{C}$ for $1,3,4$ or 7 days. Proliferation was measured by the MTS assay $(n=3)$ and normalized to untreated control wells. A) Osteoblast proliferation on films only, B) osteoblast proliferation on films and wells. 88 


\section{LIST of ABBREVIATIONS}

$\alpha$-MEM Minimal essential medium

Absorbance units

${ }^{\circ} \mathrm{C}$

Degrees Celsius

$\mathrm{C}_{18}$

Octadecylsilane

$\mathrm{CO}_{2}$

Carbon dioxide

CPS Counts per second

DAPI 4',6-diamidino-2-phenylindole

DCM Dichloromethane, or methylene chloride

DSC Differential scanning calorimetry

EDTA Ethylenediamine tetraacetic acid

GPC Gel permeation chromatography

HPLC High performance liquid chromatography

$\mathrm{Hz} \quad \mathrm{Hertz}$

ICH International Conference on Harmonization

$\mathrm{kV} \quad$ Kilovolt

$\lambda_{\mathrm{em}} \quad$ Emission wavelength

$\lambda_{\mathrm{ex}} \quad$ Excitation wavelength

MePEG Methoxy polyethylene glycol

Mn Number average molecular weight

mPA MilliPascals

MTS 3-(4,5-dimethylthiazol-2-yl)-5-(3-carboxymethoxyphenyl)-2-(4sulfophenyl)-2H-tetrazolium, inner salt)

Mw Weight average molecular weight

M.W. Molecular weight

PBS Phosphate buffered saline

PEG Polyethylene glycol

PLGA Poly (lactic-co-glycolic acid)

PDLLA Poly(DL-lactic acid)

RF Radiofrequency 
Rhod Rhodamine

RSD Relative standard deviation (standard deviation/mean x 100)

SEM Scanning electron microscope

$\mathrm{Tg} \quad$ Glass transition temperature

TGA Thermogravimetric analysis

TRIS Tris(hydroxymethyl)methylamine buffer

UV-Vis Ultraviolet-visible

w/w Weight to weight

XRD X-ray powder diffraction 


\section{ACKNOWLEDGEMENTS}

I would like to thank my supervisor, Dr. Helen Burt, for her guidance, encouragement and patience over the course of my study. I would also like to thank my committee members for their interest and direction: Drs. Urs Häfeli, Richard Liggins, and Rizhi Wang. Thank you to Dr. Larry Lynd for chairing my committee.

I am grateful to Drs. Douglas Hamilton, Donald Brunette and Babak Cheroudi from the Faculty of Dentistry for providing osteoblast cells and technical assistance. Thanks also to Ke Duan from Metals and Materials Engineering for supplying alendronate and tantalum samples.

Special thanks to Dr. Katherine Haxton for drawing the chemical structures; and to Anita Lam of the X-Ray Crystallographic Services of the UBC Chemistry department for her help in collecting and interpreting the powder diffraction patterns.

Thank you to the many members of the Burt group: Karen Chu, Barb Conway, Tobi Higo, John Jackson, Kevin Letchford, Linda Liang, John Lu, Mable Shi, Chris Springate, Jennifer Tam, Suzi Topic, Melanie ter Borg, Wes Wong, Chiming Yang, and Jason Zastre, for making this fun.

Finally, thank you to my sons, Charlie and Andy, for understanding when Mummy had to do her homework. 


\section{PROJECT OVERVIEW}

Bisphosphonate drugs are used for bone disorders such as osteoporosis, hypercalcaemia of malignancy and Paget's disease. Bisphosphonate drugs are potent inhibitors of osteoclastic bone resorption and there is evidence that they may trigger the proliferation of bone-building osteoblast cells (Fleisch 1998). This alters the balance of bone resorption and formation, leading to a net increase in bone density.

The oral bioavailability of the bisphosphonates is low (1-6\%) and decreases dramatically in the presence of food because they form insoluble complexes with calcium or iron. Oral bisphosphonates must be taken after an overnight fast, and then the patient must sit upright for at least 30 minutes to prevent irritation to the esophagus (Suri et al. 2001), and continue fasting for 30 minutes to 2 hours, depending on the bisphosphonate drug. Localized and controlled delivery of bisphosphonates has the potential to improve efficacy by targeting the site of action. Local delivery would also avoid the inconvenience of fasting and the potential complication of gastrointestinal disturbance.

Alendronate was selected from the class of bisphosphonates for this work because it is readily available and has been used in other studies in film coating formulations for porous tantalum implants for orthopaedic applications. Of the different bisphosphonates, alendronate has one of the lowest oral bioavailabilities $(0.7 \%)$ and highest incidence of gastrointestinal side effects.

Recent studies have shown that local delivery of bisphosphonates can improve bone growth around dental (Yaffe et al. 1995; Yaffe et al. 1997;Meraw et al. 1999;Meraw and Reeve 1999;Binderman et al. 2000; Yoshinari et al. 2002) and orthopedic implants (Astrand and Aspenberg 2004). Most of these studies have applied the bisphosphonate either topically into the implant cavity or as a drug coating to the implant itself; but neither of these approaches affords controlled drug release. In a periodontal procedure called guided tissue regeneration, a barrier film is inserted under the gum and over damaged : bone in order to guide bone regeneration. A potential application for bisphosphonate-loaded polymer films might be as biodegradable barrier films in guided tissue regeneration (Tengvall et al. 2004;Skoglund et al. 2004). (Kajiwara et al. 2005;Eberhardt et al. 2005; Peter et al. 2005a;Peter et al. 2006). There are a very limited number of reports of the development and characterization of polymer-based, controlled release delivery systems for bisphosphonates. Although polymeric microsphere preparations of other bisphosphonates, clodronate (Perugini et al. 2001) and pamidronate (Weidenauer et al. 2003; Weidenauer et al. 2004) have been reported, there has been no 
work on the development of biodegradable films for the controlled and localized delivery of alendronate for periodontal applications. This would represent a potentially important advancement in therapy.

In this work, poly(lactic-co-glycolic acid) (PLGA) was selected as the polymer vehicle because it is biodegradable, biocompatible and commercially available in a series of different molecular weights and copolymer ratios that would allow for modulating the drug release characteristics. In addition, previous work in this laboratory has shown that PLGA forms suitable film formulations for drugs such as paclitaxel (Jackson et al. 2004).

The goals of this project were to develop and characterize a biodegradable, controlledrelease film formulation for alendronate that would release alendronate over a period of 2-4 weeks and to determine the effects of alendronate release from the formulations on osteoblast proliferation.

Since alendronate is a very hydrophilic drug and PLGA is a hydrophobic polymer, our experimental approach to formulation development was to reduce the solid alendronate particle size and employ polymer blends to achieve homogenous dispersions of the drug in the matrix and modulate drug release rates. Lead formulations were selected for indepth characterization and for determination of osteoblast proliferation effects. 


\section{BACKGROUND}

\subsection{Bisphosphonates}

\subsubsection{Pharmacology}

The bisphosphonates are a group of compounds analogous to pyrophosphate, but characterized by a stable phosphate-carbon-phosphate (P-C-P) bond. They are used to treat bone disorders such as osteoporosis, osteolytic bone metastases, and Paget's disease (Fleisch 1998). Bisphosphonates bind avidly to calcium as shown in Figure 1.

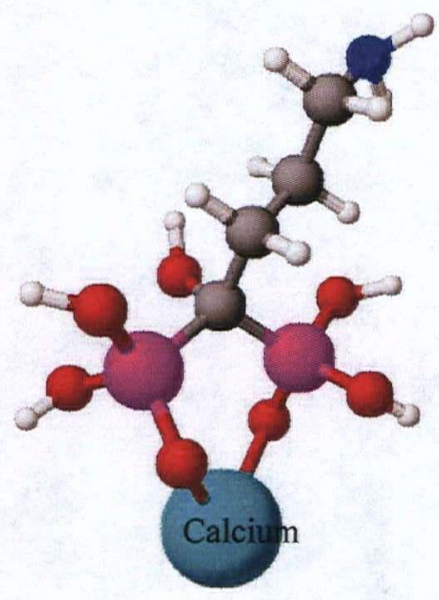

Figure 1 Chemical structure of the bisphosphonate alendronate bound to calcium. Carbon atoms are shown in grey, phosphorus in pink, oxygen in red, nitrogen in blue and hydrogen in white.

Bone is the major site of action of bisphosphonates. Bone tissue consists of $\sim 65 \%$ mineral layers (hydroxyapatite, $\mathrm{Ca}_{10}\left(\mathrm{PO}_{4}\right)_{6}(\mathrm{OH})_{2}$ ), and $\sim 35 \%$ protein layers (primarily collagen) (Fleisch 1997). At any time, approximately $10 \%$ of bone surface in the adult skeleton is undergoing active remodelling, whereas the remaining $90 \%$ is quiescent (Hughes et al. 1989; Fleisch 1997). Remodelling can be divided into four phases: resorption, reversal, formation and quiescence, as shown in Figure 2. Activated osteoclasts migrate to the bone where they secrete acid that dissolves a shallow trench in the hydroxyapatite (resorption). Then there is a reversal phase in which there may be degradation of the collagen, and the release of growth factors to initiate the formation phase. The resorption cavity is filled in by successive layers of osteoblast cells that also deposit a mineralizable matrix (Raisz 1999). The balance of bone resorption and 
formation may be disrupted by factors such as age, immobilization, inflammation or disease (Raisz 1999).

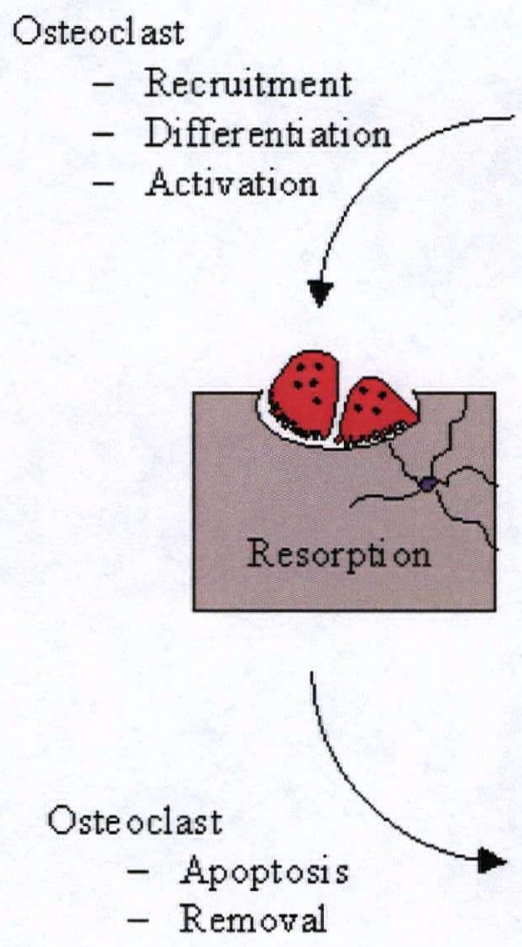

\section{Lining cells}
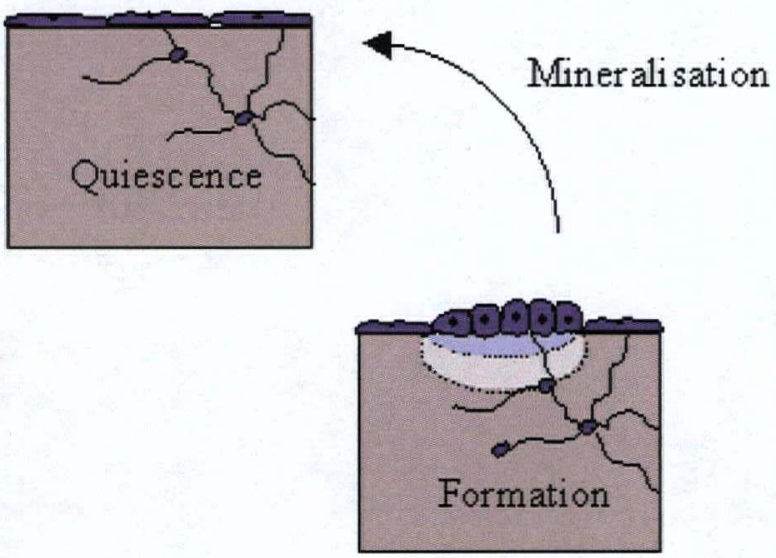

- Removal
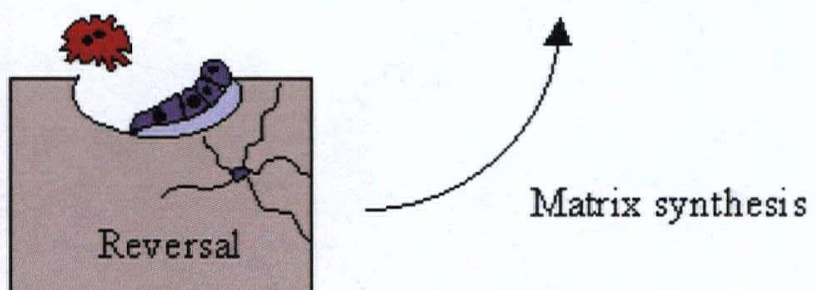

Osteoblast

- Recruitment

- Differentiation

- Activation

Figure 2 Bone remodelling cycle (Ralston 2005), used with permission.

The principal effect of bisphosphonates is the inhibition of osteoclast-mediated bone resorption. Bisphosphonates have a high affinity for calcium in hydroxyapatite (Fleisch 1985). Calcium-bound drug is dissolved under the acidic conditions created by the osteoclasts during resorption. The solubilised bisphosphonate is then taken up by the osteoclast where it triggers various biochemical effects. At the molecular level, nitrogencontaining bisphosphonates inhibit the mevalonate pathway, which perturbs cell activity and can induce apoptosis (Reszka and Rodan 2004). At the cellular level, there is a decrease in osteoclast recruitment and adhesion (Cecchini et al. 1987). The loss of the ruffled border on the osteoclast renders it inactive for further resorption, resulting in shallower resorption sites (Tenenbaum et al. 2002). Other effects include: prevention of 
the development of osteoclast precursors (Hughes et al. 1989); stimulation of the production of osteoclast inhibitory factor (Vitte et al. 1996), and ultimately, induction of osteoclastic apoptosis (Hughes et al. 1995). In addition to direct effects on the osteoclasts, bisphosphonates also promote osteoblast proliferation and maturation (Im et al. 2004; Von Knoch et al. 2005). The net effect is a reduction in bone resorption leading to a net gain in bone density.

\subsubsection{Structure-Activity Relationship}

The administration of bisphosphonates varies with compound and indication. The Canadian Pharmacists Association Compendium of Pharmaceuticals and Specialties (2005) reports that the drug is taken orally either daily, weekly or monthly. For hypercalcemia of malignancy and Paget's disease, it is given as an intravenous infusion (Hillner et al. 2003).

There are several bisphosphonate drugs with various substitution groups, relative potencies, routes of administration, and indications, as shown in Table 1. Bone affinity and antiresorptive abilities appear to depend on separate properties of the bisphosphonate structure. Where the $\mathrm{R}_{1}$ side group is $-\mathrm{OH}$, the affinity for calcium ions increases due to tridentate rather than bidentate chelation to the calcium atom. The $\mathrm{R}_{2}$ side chain determines antiresorptive potency. The addition of an amino alkyl group increases the potency 10 fold and increases selectivity for inhibiting bone resorption over reducing mineralization (Rodan and Fleisch 1996). Compounds containing a tertiary nitrogen group or a nitrogen-containing heterocyclic ring are even more potent (Fleisch 1998). 


\section{Table 1 Commercially Available Bisphosphonate Drugs}

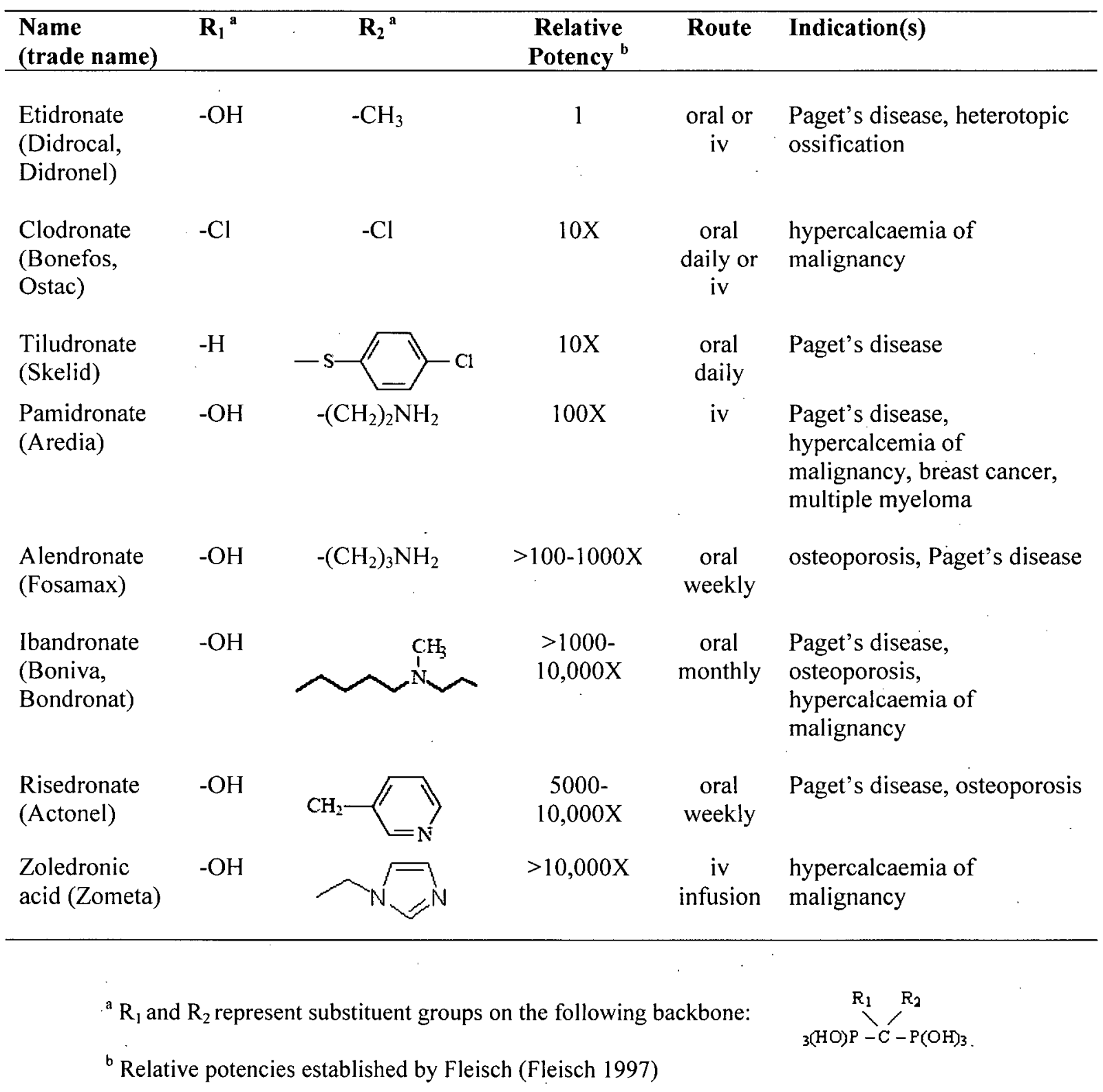

\subsection{3'Toxicity}

Reported toxicities include mild gastrointestinal disturbances and diarrhoea (Russell et al. 1999). Severe esophagitis and upper gastrointestinal events have been also reported, particularly for alendronate (Greenspan et al. 2000; Suri et al. 2001).

Recently, rare reports of osteonecrosis of the jaw have been reported in patients treated with bisphosphonates ( $>95 \%$ of cases were attributed to pamidronate and zoledronate); most cases have been in cancer patients undergoing dental procedures (Cheng et al. 
2005;Marx et al. 2005). The labelling of all bisphosphonates was recently updated to reflect this.

The incidence of gastrointestinal events in bisphosphonate clinical trials was lower than that observed post-marketing (Marshall 2002). The number of upper gastrointestinal disorders observed in the randomized comparative trials for alendronate in 2027 women over 3 years was $8(2.0 \%)$ patients receiving placebo and $9(4.6 \%)$ patients taking alendronate, $10 \mathrm{mg}$. None of these events was defined as serious (Greenspan et al. 2000). The New England Journal of Medicine reported that as of March 5, 1996, alendronate had been prescribed for $\sim 475,000$ patients worldwide, and a total of 199 patients had adverse effects related to the esophagus (51 categorized as serious or severe). Thirty-two patients were hospitalized, and two were temporarily disabled. Endoscopic findings generally indicated chemical esophagitis, with erosions or ulcerations and exudative inflammation accompanied by thickening of the esophageal wall. Esophagitis was associated with swallowing alendronate with little or no water, lying down during or after ingestion of the tablet, continuing to take alendronate after the onset of symptoms, and having pre-existing esophageal disorders (Suri et al. 2001).

The cause of this gastrointestinal damage may be linked to the mechanism of action for this class of drugs. Bisphosphonates can cause apoptosis in a variety of cell types in vitro, such as macrophage-like cells (Rogers et al. 1996), osteoclasts (Hughes et al. 1995), and myeloma cells (Shipman et al. 1998). Nitrogen-containing bisphosphonates can cause apoptosis and inhibit growth of gut epithelial cells due to inhibition of the mevalonate pathway, following loss of prenylated proteins and sterols (Suri et al. 2001). In a Caco-2 cell model in the presence of bisphosphonates, proliferating cells were more susceptible to apoptosis than confluent cells (Suri et al. 2001). In addition, nitrogen-containing bisphosphonates may compromise the surface hydrophobicity barrier of the gastrointestinal lining, which could trigger mucosal injury or ulceration (Lichtenberger $e t$ al. 2000).

The toxicity of bisphosphonates in a local delivery application, therefore, is dependent on the concentration of drug and the type of cells. Cells such as osteoclasts or gastric epithelial cells, which depend on the products of the mevalonate pathway to function, would be more susceptible to toxicity from nitrogen-containing bisphosphonates than other cells surrounding an orthopaedic or dental implant. 


\subsubsection{Physicochemical Characteristics}

Bisphosphonates are negatively charged at the normal intestinal $\mathrm{pH}$ range. For example, alendronate has $5 \mathrm{pKa}$ values $(0.8,2.2,6.3,10.9$ and 12.2). At the $\mathrm{pH}$ of the small intestine ( $\mathrm{pH}=6$ to 8$)$, it has a net negative charge (-2, including the positively charged amino group). Etidronate has $4 \mathrm{pKa}$ values $(1.7,3.1,7.5$ and 11.5) and also carries a negative charge (-3) in the intestine (Ezra and Golomb 2000).

The poor intestinal absorption is likely due to the low lipophilicity and negative charge of bisphosphonates. Alendronate has an octanol/buffer partition coefficient of 0.0017 (independent of $\mathrm{pH}$ values ranging from 2 to 11) (Boulenc et al. 1993; Lin et al. 1994).

Bisphosphonates are generally supplied as the sodium salt; the acid form has been found to be irritating, and the calcium salts (particularly of alendronate and pamidronate) are highly insoluble and more toxic than their free acid forms (Twiss et al. 1999). There was one report in the literature on the development of a gel formulation of calcium alendronate for subcutaneous or intramuscular administration (Ostovic and Brenner 1995); but it was not pursued. The various crystalline forms of alendronate have different solubilities. Alendronic acid monohydrate, alendronate monosodium salt trihydrate and alendronate monosodium salt anhydrous have solubilities in water of 8, 40 and 300 $\mathrm{mg} / \mathrm{mL}$, respectively (Ezra and Golomb 2000). The marketed compound is alendronate monosodium trihydrate. It is insoluble in liquids other than water.

\subsubsection{Pharmacokinetics}

Oral absorption of bisphosphonates is low (1-6\%) under fasting conditions and negligible in the presence of food. Bisphosphonates are transported across the intestinal lining by passive diffusion. They are highly polar and charged at physiological $\mathrm{pH}$, so absorption across the gastrointestinal mucosa is primarily by the paracellular, rather than the transcellular route (Lin 1996). Bisphosphonates can sequester calcium ions from the tight junctions of the gastrointestinal epithelium, resulting in increased paracellular transport (Suri et al. 2001).

Upon absorption, $70-80 \%$ of the drug is bound to albumin in the plasma, and then rapidly distributed throughout the body. It is then either taken up and sequestered into bone or eliminated by renal excretion (Lin et al. 1991). Uptake into the bone is greatest in areas of high physiological activity i.e., in active sites of bone resorption (Sato et al. 1991;Barrett et al. 2004). Approximately $65 \%$ of alendronate is present in non-calcified tissues within 5 minutes of administration of the drug. This is reduced to $5 \%$ within an hour and $<1 \%$ within 6-24 hours (Lin et al. 1991). 
Bisphosphonates are not metabolized. The P-C-P bond is completely resistant to hydrolysis by enzymes such alkaline phosphatase and pyrophosphatase (Lin et al. 1991).

The elimination of alendronate by urinary excretion has several phases. In the first phase, more than $90 \%$ of the drug (that has not been retained on the bone surface) is excreted within the first 24 hours; in the second elimination phase, alendronate has a half life of $\sim 10$ days (Reszka and Rodan 2004). Once the bisphosphonate has localized on the bone resorption surface, it becomes embedded in the bone until it is eventually released back into circulation as part of normal bone turnover. The average terminal elimination half life of alendronate from the skeleton is $\sim 10$ years (Lin et al. 1991).

\subsection{Therapeutic Applications of Delivery of Bisphosphonates to Bone Tissue}

The inconvenience of fasting and the risk of esophagitis may reduce patient compliance with oral delivery of bisphosphonates. Localized or targeted bisphosphonate delivery at the site of orthopaedic or dental implants offers several key benefits:

- higher bioavailability

- decreased toxicities

- convenience

Development of localized delivery systems for therapeutic applications would represent an important advancement in therapy.

Previous research on local delivery of bisphosphonates has taken a variety of forms. Several groups have explored topical or subcutaneous application of the drug prior to inserting an implant device. Other groups have used bisphosphonates as a coating on an orthopaedic implant, in order to improve the rate and extent of bone fixation. Bisphosphonates have also been used in periodontal implant applications and finally, bisphosphonates might be of use in conjunction with bone void fillers. A summary of the literature accounts of each type of local bisphosphonate delivery-including the drugs, doses and delivery methods-is shown in Table 2, and discussed in detail in the following sections. 
Table 2 Local Bisphosphonate Use with Medical Implants

(Page 1 of 2)

\begin{tabular}{llll}
\hline Drug (Reference) & Device & Concentration & Model \\
\hline
\end{tabular}

\section{Topical or Subcutaneous Delivery}

\begin{tabular}{|c|c|c|c|c|}
\hline $\begin{array}{l}\text { Alendronate (Astrand } \\
\text { and Aspenberg 2004) }\end{array}$ & $\begin{array}{l}\text { titanium bone } \\
\text { screws }\end{array}$ & $\begin{array}{l}20 \mu \mathrm{l} \text { of } 1 \\
\mathrm{mg} / \mathrm{ml} \text { solution } \\
\text { applied for } 1 \\
\text { minute }\end{array}$ & $\begin{array}{l}\text { rat tibia } \\
\text { implant }\end{array}$ & $\begin{array}{l}\text { Reduced soft tissue } \\
\text { damage and bone } \\
\text { resorption } \\
\text { following } 5 \text { days } \\
\text { oscillating fluid } \\
\text { pressure }\end{array}$ \\
\hline $\begin{array}{l}\text { Ibandronate (Skoglund } \\
\text { et al. 2004) }\end{array}$ & $\begin{array}{l}\text { stainless steel } \\
\text { bone screws }\end{array}$ & $\begin{array}{l}0.1 \mathrm{mg} \text { applied } \\
\text { locally or daily } \\
3 \mu \mathrm{g} \\
\text { subcutaneous } \\
\text { injections }\end{array}$ & $\begin{array}{l}\text { rat tibia } \\
\text { implant }\end{array}$ & $\begin{array}{l}\text { after } 2 \text { weeks, } \\
\text { pullout force } \\
\text { increased } 15 \% \\
\text { (local application) } \\
\text { or } 30 \% \text { (IM } \\
\text { injection) }\end{array}$ \\
\hline $\begin{array}{l}\text { Ibandronate } \\
\text { (Eberhardt et al. 2005) }\end{array}$ & $\begin{array}{l}\text { uncoated and } \\
\text { hydroxyapatite } \\
\text { coated titanium } \\
\text { implants }\end{array}$ & $\begin{array}{l}\text { saline, } 1 \mu \mathrm{g} / \mathrm{kg} \\
\text { or } 25 \mu \mathrm{g} / \mathrm{kg} \\
\text { subcutaneous } \\
\text { injection }\end{array}$ & $\begin{array}{l}\text { rat } \\
\text { femur } \\
\text { implant }\end{array}$ & $\begin{array}{l}\text { high dose } \\
\text { significantly } \\
\text { enhanced extent of } \\
\text { osseointegration }\end{array}$ \\
\hline
\end{tabular}

\section{Implant Coatings}

\begin{tabular}{|c|c|c|c|c|}
\hline $\begin{array}{l}\text { Alendronate (Meraw } \\
\text { and Reeve } \\
\text { 1999; Meraw et al. } \\
\text { 1999) }\end{array}$ & $\begin{array}{l}\text { hydroxyapatite } \\
\text { coated or } \\
\text { titanium dental } \\
\text { implants }\end{array}$ & $\begin{array}{l}\text { soak in } 0.1 \\
\mathrm{mM}, 1 \text { week at } \\
37^{\circ} \mathrm{C} \text { or } 2.8 \mu \mathrm{g}\end{array}$ & $\begin{array}{l}\text { dog } \\
\text { dental } \\
\text { implant }\end{array}$ & $\begin{array}{l}\text { increased amount } \\
\text { of bone around } \\
\text { implants }\end{array}$ \\
\hline $\begin{array}{l}\text { Pamidronate } \\
\text { Ibandronate (Tengvall } \\
\text { et al. } 2004)\end{array}$ & $\begin{array}{l}\text { cross-linked } \\
\text { fibrinogen coated } \\
\text { stainless steel } \\
\text { screws }\end{array}$ & $\begin{array}{l}0.12 \mu \mathrm{g} / \mathrm{cm}^{2} \text { or } \\
10 \AA \text { thick }\end{array}$ & $\begin{array}{l}\text { rat tibia } \\
\text { implant }\end{array}$ & $\begin{array}{l}\text { increased pullout } \\
\text { force after } 2 \text { weeks }\end{array}$ \\
\hline $\begin{array}{l}\text { Pamidronate } \\
\text { (Kajiwara et al. 2005) }\end{array}$ & $\begin{array}{l}\text { titanium } \\
\text { implants }\end{array}$ & $\begin{array}{l}\text { Soak in } 3 \\
\mathrm{mg} / \mathrm{mL}, 24 \mathrm{hr}, \\
37^{\circ} \mathrm{C}\end{array}$ & $\begin{array}{l}\text { rat tibia } \\
\text { implant }\end{array}$ & $\begin{array}{l}\text { significantly } \\
\text { accelerates } \\
\text { formation of new } \\
\text { bone }\end{array}$ \\
\hline $\begin{array}{l}\text { Zoledronic acid (Peter } \\
\text { et al. 2005a;Peter et } \\
\text { al. 2006) }\end{array}$ & $\begin{array}{l}\text { hydroxyapatite } \\
\text { coated titanium } \\
\text { implants }\end{array}$ & $\begin{array}{l}0,0.2,2.1,8.5 \\
\text { and } 16 \\
\mu \mathrm{g} / \text { implant }\end{array}$ & $\begin{array}{l}\text { rat } \\
\text { femoral } \\
\text { implants }\end{array}$ & $\begin{array}{l}\text { Mechanical } \\
\text { fixation and bone } \\
\text { density increased } \\
\text { with dose (up to } \\
8.4 \mu \mathrm{g} / \text { implant) }\end{array}$ \\
\hline
\end{tabular}


Table 3 Local Bisphosphonate Use with Medical Implants (Continued)

(Page 2 of 2)

\begin{tabular}{|c|c|c|c|c|}
\hline Drug (Reference) & Device & Concentration & Model & Effect \\
\hline \multicolumn{5}{|c|}{ Periodontal Applications } \\
\hline $\begin{array}{l}\text { Alendronate (Yaffe et } \\
\text { al. 1995;Yaffe } \text { et al. } \\
\text { 1997) }\end{array}$ & surgical pellet & $\begin{array}{l}0.15,0.75, \text { and } \\
1.5 \mathrm{mg} / \mathrm{ml}\end{array}$ & $\begin{array}{l}\text { rat } \\
\text { dental } \\
\text { surgery }\end{array}$ & $\begin{array}{l}\text { reduces bone } \\
\text { resorption } \\
\text { activated by dental } \\
\text { surgery }\end{array}$ \\
\hline $\begin{array}{l}\text { Alendronate } \\
\text { (Binderman et al. } \\
2000 \text { ) }\end{array}$ & $\begin{array}{l}\text { insert } \\
\text { drug/gelatin } \\
\text { sponge after } \\
\text { periodontal } \\
\text { surgery }\end{array}$ & $\begin{array}{l}10,50,200 \\
400 \mu \mathrm{g}\end{array}$ & $\begin{array}{l}\text { rat } \\
\text { dental } \\
\text { surgery }\end{array}$ & $\begin{array}{l}\text { reduced bone loss } \\
(\text { esp. } 400 \mu \mathrm{g})\end{array}$ \\
\hline $\begin{array}{l}\text { Pamidronate } \\
\text { (Yoshinari et al. 2002) }\end{array}$ & $\begin{array}{l}\text { titanium }+ \\
\text { Calcium } \\
\text { phosphate } \\
\text { implants }\end{array}$ & $\begin{array}{l}\text { Soak in } 0.01 \mathrm{M}, \\
\mathrm{pH} 6.2,24 \mathrm{hr}, \\
37^{\circ} \mathrm{C}\end{array}$ & $\begin{array}{l}\text { dog } \\
\text { dental } \\
\text { implant } \\
\end{array}$ & $\begin{array}{l}\text { increased bone } \\
\text { implant contact } \\
\text { after } 12 w\end{array}$ \\
\hline
\end{tabular}

Several groups have explored the use of oral or intravenous bisphosphonates in conjunction with implant surgery (Millett et al. 2002;Jeppsson et al. 2003;Zou et al. 2003; Skoglund et al. 2004; Wise et al. 2005;Bobyn et al. 2005;Altundal and Gursoy 2005). This approach has been effective, but it does not represent a novel drug delivery system and is therefore outside of the scope of this review.

\subsubsection{Topical or Subcutaneous Bisphosphonates with Implant Devices}

The immediate goal after inserting a surgical implant is to achieve osseointegration, or the direct attachment of bone tissue to the surface the implant, without intervening connective tissue (Meraw et al. 1999). Bisphosphonates can be applied topically at the site of an implant device to aid in bone regrowth.

Immediately following insertion, implants are surrounded by traumatized bone and blood vessels. Osteoclasts will begin the bone remodelling process; but fluid pressure, mechanical instability and wear particles can cause excessive bone resorption around the implant which can lead to aseptic prosthetic loosening. To demonstrate that bisphosphonates could reduce peri-prosthetic bone resorption Åstrand et al. applied 
alendronate topically ( $20 \mu \mathrm{l}$ of $1 \mathrm{mg} / \mathrm{ml}$ for 1 minute, then rinsed 3 times with saline solution) to the site of a titanium bone screw in a rat tibia model (Astrand and Aspenberg 2004). After 5 days to allow fibrous tissue to form between the implant and the bone, 20 cycles of pressure $(0.6 \mathrm{MPa}, 0.17 \mathrm{~Hz})$ was applied twice a day for 5 days to stimulate bone resorption. Rats given topical alendronate had half the soft tissue damage at the interface, compared to saline treated controls.

To demonstrate that bisphosphonates can enhance early screw fixation, Skoglund compared local $(0.1 \mathrm{mg})$ and systemic $(0.6 \mathrm{ml}$ of $3 \mu \mathrm{g}$ subcutaneous injections, daily) administration of ibandronate in rats with stainless steel screws implanted in their tibiae (Skoglund et al. 2004). After 14 days, the tibiae were harvested and the biomechanical pull-out force and stiffness were evaluated. Pull-out force increased by $15 \%$ over control for local ibandronate and $30 \%$ for systemic ibandronate. Stiffness was $28 \%$ greater than control with local treatment; no difference was observed for systemic administration.

Topical administration demonstrated a rapid effect on implant fixation and osseointegration, which may be important in the prevention of aseptic loosening. The effects were evaluated after only 2 weeks of healing. However, a sustained dose of bisphosphonate may be important in applications where the bone surface is larger and healing is slower.

A recent study (Eberhardt et al. 2005) attempted to address the important issue of optimal dose for local delivery. Rats received uncoated or hydroxyapatite-coated titanium implants in the femur, and were randomly assigned to daily subcutaneous administration of low or high concentrations of ibandronate $(1 \mu \mathrm{g} / \mathrm{kg}$, osteoporosis dose or $25 \mu \mathrm{g} / \mathrm{kg}$, hypercalcaemia of malignancy dose) or saline control. Histomorphometric evaluation after 28 days showed significant enhancement in osseointegrated implant surfaces in the high dose group compared to the low dose or control. No significant differences were observed between the 2 types of implant.

\subsubsection{Bone Regeneration in Orthopaedic Procedures}

Hip implant prostheses are composed of a long stem that is inserted in the femur and an acetabular cup which is inserted in the cup-shaped socket of the hip. Topical application of a bisphosphonate solution at the site of the implant would not be convenient over such a large surface area and it would be difficult to ensure that the drug concentration would be consistent. This suggests that an implant coating might be a more efficient drug delivery system. Dr. R. Wang in the UBC Department of Materials Engineering has 
developed a method to coat porous tantalum hip prostheses with calcium phosphate, collagen and bisphosphonate (Duan et al. 2005; Fan et al. 2005).

Incorporating a bisphosphonate drug around an implant is intended to enhance bone integration and inhibit aseptic loosening. Aseptic loosening can occur when particles of wear debris from the prosthetic cup enter the joint space around the implant and trigger an inflammatory immune response. This can activate the osteoclasts leading to increased bone resorption at the implant interface (Al Saffar and Revell 1999).

Several groups have observed enhanced peri-implant bone growth when bisphosphonates are immobilized on the implant surface. Locally applied alendronate significantly increased the amount of bone peripheral to both hydroxyapatite and titanium implants in a dog dental model (Meraw and Reeve 1999). After 28 days, the rate of bone formation was faster and the amount of bone-to-implant contact increased for both types of implants in the presence of alendronate (Meraw et al. 1999).

Tengvall et al. coated stainless steel screws with cross-linked fibrinogen, then immobilized pamidronate on the fibrinogen and finally adsorbed ibandronate on the surface. These screws were inserted in the tibiae of male rats. After 2 weeks, the bisphosphonate-coated screws required $28 \%$ greater force to pull out, supporting the idea that bone fixation is increased in the presence of bisphosphonates (Tengvall et al. 2004).

A similar effect was observed using pamidronate immobilized on titanium implants that had calcium ions embedded using an ion beam dynamic mixing apparatus (Kajiwara et al. 2005). The implants were soaked in $3 \mathrm{mg} / \mathrm{ml}$ pamidronate solution for 24 hours at $37^{\circ} \mathrm{C}$. After 4 weeks, significantly more new bone had formed around the pamidronatecoated implant than controls.

Peter et al. have developed a calcium phosphate/bisphosphonate delivery system (Peter $e t$ al. 2005a). Titanium alloy cylinders were plasma coated with hydroxyapatite then soaked in zoledronate solution of various concentrations in ultrapure water. The amount of adsorbed zoledronate was quantified by determining the remaining drug in the supernatant. Implants coated with $0,0.2,2.1,8.5$ and $16 \mu$ g zoledronate were obtained. The drug-coated cylinders were implanted in rat femurs. After 3 weeks, mechanical fixation increased with increasing drug concentration, except at the 2 highest concentrations. The same group repeated the experiment on osteoporotic rats (Peter et al. 2006). In this study, concentrations up to $8.5 \mu \mathrm{g} / \mathrm{implant}$ had positive effects on mechanical fixation. 


\subsubsection{Bone Regeneration in Periodontal Surgery}

Inflammation due to periodontitis can infiltrate the periodontal ligament and the marrow spaces of the jawbone. This can lead to osteoclastic bone resorption around the tooth and a loss of tooth attachment (Kinane and Lindhe 2000). Treatment usually consists of tooth scaling, root planing and removal of the inflamed tissue. However, tissue regeneration following surgery can be erratic; rapid proliferation of the epithelial cells into the wound space can discourage bone growth (Laurell et al. 1998).

In a technique called guided tissue regeneration, a barrier membrane is placed under the gum and over the remaining bone (Trombelli et al. 2002). The purpose of the procedure is to preserve the ridge and allow for the regeneration of new bone where it has been lost. It is sometimes done in combination with bone void fillers. Some of the barrier membranes are biodegradable and others (i.e., polytetrafluoroethylene, Gore- $\mathrm{Tex}^{\circledR}$ ) require a second surgery to be removed (Hammerle and Jung 2003).

Including a bisphosphonate in the barrier membrane could have a potentially important role in promoting bone regrowth in periodontal applications (Tenenbaum et al. 2002).

In addition, dental surgeons have observed that a burst of bone resorption follows periodontal surgery. Administration of topical alendronate inhibits active bone resorption without interfering with bone formation. In an initial experiment, alendronate solution was applied locally in a rat dental model but no reduction in bone resorption was observed (Yaffe et al. 1995). However, when the investigators applied an alendronatesoaked surgical pellet to the exposed bone surface during mucoperiosteal flap surgery in rats, a significant reduction in bone resorption was observed (Yaffe et al. 1997). They also found that an alendronate-soaked gelatin sponge reduced bone loss both at the site of dental surgery and also had a systemic effect (Binderman et al. 2000).

The effect of immobilizing pamidronate in calcium phosphate coated onto titanium dental implants was observed in a dog model. After 12 weeks, greater bone contact was observed compared to calcium phosphate coated and pure titanium implants (Yoshinari et al. 2001)

\subsubsection{Bone Void Fillers}

Another potential application for local delivery of bisphosphonates is in conjunction with bone void fillers. Where there has been extensive local bone loss, bone void fillers are placed into the cavity to guide bone regeneration. Autogenous bone grafts are the most effective bone graft material. They contain osteoclastic precursors but there is limited 
availability, significant morbidity due to blood loss and the procedure can lead to chronic pain at the harvest site (usually the iliac crest) for up to 3 months. Allografts are demineralized, freeze-dried human cadaver bone. Allografts contain the osteoinductive properties of autografts, but can be expensive and can carry the potential for infection (hepatitis, HIV, etc.) (Moore et al. 2001). Other frequently used materials include bovine bone, hydroxyapatite, and bioglass (Nasr et al. 1999). It has been difficult to find a synthetic material that is osteoconductive and consistently stays in place for the duration of healing (Cornell 1999). The addition of a bisphosphonate, either as a coating or in controlled release microspheres, to synthetic bone void filler might improve bone ingrowth and speed healing.

The effective dose for local administration of bisphosphonates around implants is unclear. Early studies indicated that if; the local concentrations were too high, (alendronate $3.0 \mathrm{mg} / \mathrm{kg}$ ) bone growth would be inhibited (Tenenbaum et al. 2002). Although the methods for coating the implants are described, only one group (Peter et al. 2005a; Peter et al. 2006) determined the final drug content on the implant. In addition, it is evident that a controlled release delivery system for bisphosphonates would be beneficial in situations where the area is large or the healing period is long. Characterizing the loading and release profiles is a critical component of the development of local controlled release drug delivery system for bisphosphonates.

\subsection{Polymeric Drug Delivery Systems}

\subsubsection{Biodegradable Polymers as Biomaterials}

There are four major classes of biomaterials: polymers, metals, ceramics, and plant- or animal-derived natural materials (Hoffman 2004). Polymers represent the largest class of biomaterials, ranging from natural materials such as cellulose, sodium alginate, natural rubber, collagen, heparin, hyaluronic acid and deoxyribonucleic acid to synthetic materials such as silicone rubber, polyethylene, poly propylene, poly(ethylene terephthalate, poly tetrafluoroethylene, and poly(methyl methacrylate). Another large class of synthetic polymers are the more polar compounds such as poly(vinyl chloride), the nylons, poly(ethylene glycol) and poly(lactic-co-glycolic acid). Some of these compounds are hydrolytically unstable in the presence of water and degrade in the body (Cooper et al. 2004). Biodegradable polymers have been widely used in such varied applications as: wound closures, orthopaedic pins, drug delivery systems, vascular grafts, vascular stents, to augment bone defects, and as ligament/tendon prosthesis (Chu 2000). 
Biodegradable polymers have been used extensively in the development of controlled release drug delivery systems for a broad range of drugs and in many different applications, including anticancer agents, hormones, growth factors, vaccines, local anaesthetics, antibiotics, anti-inflammatory agents, anti-psychotics (for reviews, see (Bala et al. 2004; Jones 2004; Park et al. 2005)).

The goals of controlled release drug delivery include: maintaining the drug at the desired therapeutic range (for days to years) with a single dose, localizing delivery of the drug to the site of action, reducing need for follow up care, increasing patient comfort and improving compliance (Langer 1990). A biomaterial should have suitable biomechanical properties (depending on the proposed application), biocompatibility, ease of purification and sterilization and suitable surface properties (Piskin 1995).

\subsubsection{Polymer Structure and Morphology}

The structure and morphology of a biodegradable polymer will impact its biomaterial characteristics.

Polymers are composed of a linked series of monomers, often dozens or hundreds of units long. Normally, a polymer sample will be composed of molecules with a distribution of different chain lengths. There are two statistically useful definitions of average molecular weight: the number-average molar mass $(\mathrm{Mn})$ or the weight-average molar mass (Mw).

Mn is defined as:

$$
\mathrm{Mn}=\mathrm{W} / \mathrm{N}=\sum N i M i / \sum N i
$$

Equation 1

Where $\mathrm{W}$ is the total weight of a polymer sample, $\mathrm{N}$ is the number of moles of polymer. $N i$ is the number of moles species $i$, and $M i$ is the molecular weight of species $i$.

In contrast, the weight-average molar mass $(\mathrm{Mw})$ is calculated by replacing the number of polymers of molecular weight $i(\mathrm{Ni})$ in the above equation, with the molecular weight of the polymer of particular weight $i(\mathrm{NiMi})$. This gives:

$\mathrm{Mw}=\sum N i M i^{2} \Sigma N i M i$

Equation 2 
$\mathrm{Mn}$ is sensitive to the number of molecules of lower molecular weight, and $\mathrm{Mw}$ is sensitive to the contribution of longer polymer chains. $\mathrm{Mw}$ is always larger than $\mathrm{Mn}$. The ratio of the number average $(\mathrm{Mn})$ to the weight average $(\mathrm{Mw})$ is called the polydispersity index. A polymer with a narrow distribution of chain lengths would have a polydispersity index closer to 1 . The molecular weights and polydispersity index can be determined by gel permeation chromatography, which separates polymer chains by molecular weight.

Polymer morphology describes the extent to which a polymer sample can be described as amorphous or crystalline. The term "crystallinity" in polymers refers to small areas within a disordered amorphous polymer which are able to form areas of parallel alignment. Either segments from different polymer chains align and become crystalline (fringed micelle model), or a single polymer chain can fold upon itself to form lamellar crystallites (chain folded model) (Rosen S.L. 1993). Polymer morphology can impact mechanical properties, thermal behaviour, permeability, and degradation rates.

\subsubsection{Drug Release Mechanisms}

A drug delivery device in which the drug is evenly distributed throughout the polymer is called a monolithic device. The rate of drug release from a monolithic device can be controlled either by the rate of diffusion of the drug out of the polymer, or by the rate of degradation of the polymer itself.

\subsubsection{Diffusion Controlled Release}

In diffusion controlled release, the polymer matrix is assumed to be inert, and the rate of diffusion depends on the solubility of the drug in the polymer.

The Higuchi model is often used to describe diffusion-controlled drug release from a monolithic dispersion (Higuchi 1961). Assuming that the drug is dispersed evenly throughout the polymer, the drug on the surface layer will diffuse out of the polymer first. When the surface layer is depleted, the next layer will then diffuse through the drugdepleted layer to the surface based on the permeability of the polymer and the diffusivity of the drug. This can lead to a burst effect at the beginning of drug release.

The equations describing the theoretical drug release profiles for polymer matrix systems in a variety of geometries are derived in detail by Baker (Baker 1987). He showed that the release rate from a simple monolithic dispersion in slab geometry is:

$$
\frac{d \mathrm{M}_{\mathrm{t}}}{d t} \approx \frac{\mathrm{A}}{2}\left(\frac{2 D C_{s(m)} C_{o}}{t}\right)^{1 / 2} \quad \text { for } C_{o} \gg C_{s(m)} \quad \text { Equation } 3
$$


Where:

$d \mathrm{M}_{\mathrm{t}} / d t$ is the steady state drug release rate at time $t$

A is the total area of the slab (both sides)

$\mathrm{D}$ is the diffusion coefficient of the drug in the polymer matrix

$C_{s(m)}$ is the solubility of the drug in the polymer matrix

$C_{o}$ is the total concentration of drug initially present

$t$ is time

This equation predicts that drug release will be directly proportional to surface area of the slab, and inversely proportional to the square root of time.

\subsubsection{Degradation Controlled Release}

The second drug release mechanism is degradation controlled release. This mechanism is significant for polymers that are susceptible to hydrolysis, such as polyesters and polyanhydrides. For example, in the degradation of poly(lactic-co-glycolic acid), the ester linkages are hydrolyzed in water to produce lower molecular weight oligomers and monomers of lactic and glycolic acids (Anderson and Shive 1997; Freiberg and Zhu 2004). Lactic and glycolic acid resulting from the degradation of PLGA polymers can decrease the local $\mathrm{pH}$ values which can then accelerate polymer degradation due to autocatalysis (Shenderova et al. 1999). There is a rapid loss of mass in the polymer as the lower molecular weight oligomers and monomers become soluble and disperse (Jain 2000).

The influence of diffusion and degradation controlled drug release mechanisms varies as a function of different time points in the drug release profile. It is common for both diffusion and degradation mechanisms to be occurring simultaneously.

\subsubsection{Factors Influencing Drug Release}

Numerous factors can impact the rate of degradation and drug release from biodegradable polymers, such as polymer composition and structure (morphology, molecular weight, glass transition temperature), nature of the drug, extent of drug loading and the presence of a second polymer or plasticizer (Alexis 2005). Of these, the extent of drug loading, the composition and molecular weight of the polymer and the type of polymer blend were of particular interest in this work. 
In a biodegradable monolithic system, the drug is evenly distributed in the polymer and is released by a combination of diffusion 'and polymer erosion (Langer 1998). At low drug loading levels $(0-5 \%)$ the release of the compound involves diffusion of water into the polymer followed by diffusion of the drug to the surface. At higher loading levels (5$10 \%$ ), diffusion of drug near the surface leaves cavities in the polymer matrix that provide preferred pathways for drug diffusion. These pathways may not be continuous, but they will increase the apparent permeability of the device. When the drug loading exceeds $20 \%$ by volume, cavities left by drug diffusing out the polymer will leave a continuous channel to the surface of the matrix (Baker 1987).

The composition of the polymer is an important factor influencing the degradation rate. An increase in hydrophobicity will decrease the rate of water penetration and subsequent polymer hydrolysis and degradation. An increase in crystallinity will also impact the rate of water penetration, as will an increase in molecular weight. As the molecular weight increases, the rate of degradation and drug release decreases (Alexis 2005).

The addition of another polymer or plasticizer to the matrix can also alter the rate of drug release and polymer degradation. If the polymer or plasticizer is more water-soluble than the pure polymer, it may leach out of the matrix, leaving pores and channels for greater water penetration. This could lead to increased hydrolysis and degradation (Alexis 2005).

\subsubsection{Polymers Used in Film Manufacture}

Three polymers were used to manufacture films for this project: PLGA, and blends of PLGA and poly(ethylene glycol), or PLGA and diblock copolymer. Each of these polymers is described in the following sections.

\subsubsection{Poly(DL-lactic-co-glycolic acid) (PLGA)}

PLGA is a copolymer of lactic acid and glycolic acid. The general structure is shown in Figure 3.

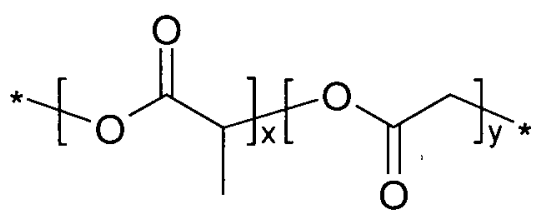

Figure 3 Structure of poly(lactic-co-glycolic acid) 
There are many different types of PLGA depending on the ratio of lactic to glycolic acid repeat units, the length of the polymer chains, and whether the monomer units are distributed randomly or in an ordered fashion. Poly (glycolic acid) is more crystalline than poly(lactic acid) because it lacks the methyl side group. Lactic acid is also more hydrophobic than glycolic acid, so PLGA copolymers that contain a greater proportion of lactic acid are more hydrophobic, absorb less water and subsequently degrade more slowly. Upon degradation, both monomers are readily metabolized through the Krebs cycle as carbon dioxide and water (Jain 2000).

PLGA is the most widely investigated and most commonly used synthetic, biodegradable polymer. PLGA devices are commercially available and approved in the form of sutures, grafts, bone pins, implants and prosthetic devices (Kohn et al. 2004). PLGA can also be used to manufacture microspheres, strands and injectable implants capable of controlled drug release over 1 to 4 months (Jiang et al. 2005). Commercially available drug delivery systems based on PLGA copolymers include: goserelin (Zoladex ${ }^{\circledR}$ ), leuprolide acetate $\left(\right.$ Eligard $^{\boxplus}$, Lupron $\left.{ }^{\circledR}\right)$, and recombinant human growth hormone $\left(\right.$ Nutropin $\left.{ }^{\circledR}\right)$.

The PLGA selected for use in this study was an amorphous, random copolymer of lactide and glycolide units in the weight ratio of $85: 15$, respectively. The glass transition temperature has been previously reported to be $47^{\circ} \mathrm{C}$ (Jackson et al. 2004), $51^{\circ} \mathrm{C}$ (Wang and Wang 2003), or in the range of $50-55^{\circ} \mathrm{C}$ (Park and Jonnalagadda 2006).

Dr. Burt's lab has extensive experience using polyesters such as PLGA and poly(L-lactic acid) in combination with release-modifying agents to formulate drug-loaded micelles (Zhang et al. 1996), microspheres (Liggins and Burt 2001;Liggins and Burt 2004;Liggins and Burt 2004) and films (Jackson et al. 2002;Jackson et al. 2004;Owen et al. 2005).

\subsubsection{Polyethylene glycol (PEG)}

In this work, two different polymers were blended with PLGA for forming films. Bisphosphonates are ionic salts, so the addition of a hydrophilic polymer was intended to improve drug encapsulation efficiency and modify the drug release characteristics. Polyethylene glycol (PEG) is a hydrophilic polyether available in a variety of chain lengths, ranging from viscous liquids at low molecular weights to waxy, crystalline solids at higher molecular weights (Fruijtier-Polloth 2005). The general structure is shown in Figure 4 . 


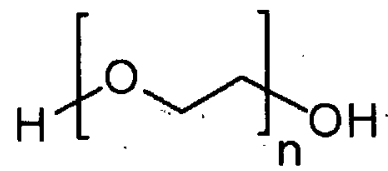

Figure 4 Structure of polyethylene glycol (PEG). PEG 600 is also known as PEG 12.

PEGs are used extensively as biomaterials, and also in cosmetic and drug delivery applications due to their broad chemical compatibility, water solubility, and biocompatibility (Sedlak 2005). PEG 300 and 400 are commercially available as solubilising excipients in methocarbamil and lorazepam intramuscular injections, and as a cosolvent in numerous soft gelatin capsule oral formulations such as nifedipine, etoposide and digoxin (Strickley 2004). The end groups can be conjugated to other polymers, proteins or drugs to make PEG-conjugates that have increased circulation times and are resistant to recognition by the immune system (Bhadra et al. 2002; Veronese and Pasut 2005).

\subsubsection{Amphiphilic Diblock Copolymer}

The second polymer blended with PLGA was an amphiphilic diblock copolymer (referred to in this work as "diblock"). The structure of poly(DL-lactic acid)-blockmethoxy poly(ethylene glycol) is shown in Figure 5.<smiles>[CH]OC(=O)C(=O)COCCOC</smiles>

Figure 5 Structure of poly(DL-lactic acid)-block-methoxy poly(ethylene glycol), or "diblock"

The diblock polymer was composed of a block of poly(DL-lactic acid) approximately 30 repeat units long, coupled to a block of methoxy poly(ethylene glycol), approximately 28 repeat units long. It was synthesized from D,L-lactide and MePEG by a ring opening bulk polymerization in the presence of stannous octoate (Burt et al. 1999). The ratio of the two polymer components was $40 \%$ PLLA to $60 \%$ MePEG by weight, using MePEG with a molecular weight of 2000 . The theoretical molecular weight is therefore $3333 \mathrm{~g} / \mathrm{mol}$, but 
the observed molecular weight was reported to be $\mathrm{M}_{\mathrm{GPC}}=5240 \mathrm{~g} / \mathrm{mol}$ (Zhang et al. 1996).

PDLLA-MePEG polymer chains will self-assemble into micelles in aqueous solution, if they are above the critical micelle concentration. The hydrophobic block of the polymer will congregate in the centre of the micelle, while the hydrophilic block forms a corona on the outer aqueous side. These micelles have been used to solubilise paclitaxel within their hydrophobic core (Zhang et al. 1996; Liggins and Burt 2002). Similar micelles made of amphiphilic diblock copolymers have been used to encapsulate adriamycin (Piskin $e t$ al. 1995), indomethacin (Kim et al. 1998) and testosterone (Allen et al. 2000).

\subsubsection{Controlled Release of Bisphosphonates from Polymers}

The use of biodegradable polymers as a local delivery system for bisphosphonates has been previously reported for clodronate and pamidronate.

Perugini et al. encapsulated clodronate into microspheres intended for parenteral administration for bone diseases (Perugini et al. 2001). Several batches of microspheres were prepared by the water-in-oil-in-water double emulsion method from PLGA copolymers of various molecular weights and molar compositions and one PDLLA homopolymer. Clodronate is a low molecular weight, hydrophilic compound, and it was released from the PLGA copolymer microspheres within 48 hours. The drug release rate was prolonged to 20 and 45 days respectively when the additives carboxymethylcellulose or sorbitan monolaurate 20 (Span 20) were added. The authors attributed this prolonged release behaviour to better drug dispersion in the polymer matrix and a more rigid barrier against water penetration and drug diffusion. The PDLLA homopolymer also had a 20day release profile. PDLLA is more hydrophobic than the copolymers.

Khang et al. prepared implantable biodegradable wafers of PLGA loaded with 10-40\% pamidronate by direct compression. The 10 and $20 \%$ loaded wafers released the drug within 30-50 days. Reduced osteoclast and increased osteoblast activity was observed after implanting the wafers on the mastoid (behind the ear) of Mongolian gerbils with experimental aural cholesteatoma (Khang et al. 2003).

Another group prepared pamidronate-loaded microspheres using a star-branched polymer poly(DL-lactide-co-glycolide-D-glucose) (Weidenauer et al. 2003). They found that if they increased the drug loading beyond $15 \%$, there was an unfavourable initial burst of drug release ( $>99 \%$ within 24 hours). An investigation of the internal structure of the microspheres showed many vacuoles, pores and channels which allowed the drug to 
dissolve out quickly. The same group also prepared a lyophilized pamidronate/chitosan complex which was embedded in the same star-branched polymer (Weidenauer et al. 2004). This system offered controlled release of pamidronate over 36 days. They also found that micronizing the drug particles allowed for better dispersion throughout the polymer matrix and a more continuous release profile over 48 days with drug loadings up to $30 \%$.

Enhancing bone regeneration by embedding a drug in a biodegradable polymer membrane has also been explored (Park et al. 2000). In this paper they used tetracycline rather than a bisphosphonate, because it has both antibacterial properties as well as tissue regenerating activity. The barrier membranes were composed of porous poly(L-lactic acid) cast on poly(glycolic acid) mesh. Controlled release of tetracycline over a 4 week period was observed.

\subsection{Thesis Goals and Objectives}

The overall objective of this work was to develop and characterize a controlled-release alendronate-loaded drug polymeric film that might be suitable to promote bone growth in a periodontal application. Desirable characteristics for a controlled-release bisphosphonate delivery system include: a biocompatible and biodegradable polymer matrix, controlled release of the bisphosphonate over 2-4 weeks, good encapsulation efficiency, and suitable physical properties (i.e., will adhere to the desired surface, has convenient shape and flexibility).

The specific aims of the project were to:

- Develop and validate a sensitive HPLC method for the determination of alendronate in drug release studies.

- Prepare and characterize various formulations of controlled-release alendronateloaded polymeric films.

- Determine the effect of alendronate-loaded polymeric films on osteoblast proliferation. 


\section{EXPERIMENTAL}

\subsection{Materials}

\subsubsection{Sodium Alendronate}

Sodium alendronate trihydrate (M.W. 325.12) was provided by Dr. Rizhi Wang, from the Department of Metals and Materials Engineering at the University of British Columbia. Standard sodium alendronate trihydrate (lot 105K4707) was obtained from SigmaAldrich (St. Louis, MO).

\subsubsection{Polymers}

Polymer films were manufactured from 85:15 poly (DL-lactic-co-glycolic acid) (PLGA) with an intrinsic viscosity of $0.61 \mathrm{dl} / \mathrm{g}$ in chloroform at $30^{\circ} \mathrm{C}$ (lots $\mathrm{d} 96051$ and $\mathrm{d} 96056$, Birmingham Polymers Inc.). Carbowax Sentry ${ }^{\circledR}$ polyethylene glycol (PEG) (NF, FCC grade) with a molecular weight of 600 was purchased from Union Carbide (Danbury, CT). Diblock copolymer consisting of poly(DL-lactic acid)-block-methoxy poly(ethylene glycol) (PDLLA-MePEG) was generously provided by Angiotech Pharmaceuticals. The PDLLA/MePEG weight ratio is 40:60, using MePEG with a molecular weight of 2000 .

\subsubsection{Chemicals and Solvents}

HPLC-grade acetonitrile, dichloromethane and methanol, and ACS-grade sodium dihydrogen orthophosphate, sodium phosphate, sodium chloride, sodium hydroxide, cupric nitrate, nitric acid and (ethylenedinitrilo)-tetraacetic acid disodium salt (EDTA) were obtained from Fisher Scientific (Fairlawn, NJ). Ceric ammonium nitrate and fluorescamine were obtained from Sigma (St. Louis, MO).

\subsubsection{General Equipment}

General equipment and supplies used during the course of these experiments are listed in Table 3 . 


\section{Table 3 General Equipment and Supplies}

Equipment and Supplies

Mettler model AE 163 or AJ100

balance

Accumet ${ }^{(\mathbb{B}}$ Model $230 \mathrm{pH}$ meter

Model 370 magnetic stirrer/heater

Branson ultrasonic cleaner

Vanlab vortex mixer

$15 \times 45 \mathrm{~mm}$ glass vials with rubber closures

Eppendorf 5415D centrifuge

Beckman GS-6 centrifuge

Eppendorf series 2100 adjustable volume pipettes

Pipetman, variable volume pipettes
Supplier

Mettler Instruments (Zurich, Switzerland)

Fisher Scientific (Fairlawn, NJ)

VWR Scientific (Mississauga, ON)

Branson Ultrasonics Corp. (Danbury, CT)

VWR Scientific (Mississauga, ON)

Ampolletas, S.A. (Mexico City, Mexico)

Brinkmann (Mississauga, ON)

Beckman Coulter (Mississauga, ON)

Brinkmann (Mississauga, ON)

Gilson Company (Middleton, WI)

\subsubsection{Stock Solutions for Drug Release Studies}

Drug release experiments were performed in phosphate buffered saline (PBS). One litre of PBS contains $2.3 \mathrm{~g}$ sodium phosphate dibasic, $0.3 \mathrm{~g}$ sodium dihydrogen orthophosphate and $8.22 \mathrm{~g}$ sodium chloride in deionised water adjusted to $\mathrm{pH} 7.35$.

The fluorescence HPLC mobile phase was prepared as a $1 \mathrm{mM}$ solution of EDTA (e.g., $0.372 \mathrm{~g}$ in 1 litre deionised water) adjusted to $\mathrm{pH}=6.5$ with saturated sodium hydroxide solution. The solution was filtered through a $0.20-\mu \mathrm{m}$ white nylon Millipore filter (Fisher GNWP, $47 \mathrm{~mm}$ ), and then $3 \%$ was replaced with methanol.

Fluorescamine solution was prepared by dissolving $2 \mathrm{mg} / \mathrm{ml}$ in acetonitrile. 
The 0.13 M EDTA buffer solution was prepared by dissolving $4.84 \mathrm{~g}$ EDTA in $\sim 80 \mathrm{ml}$ deionised water, adjusting the $\mathrm{pH}$ to 10 with saturated sodium hydroxide solution, and quantitatively diluting to $100 \mathrm{ml}$ with deionised water.

\subsubsection{Cell Culture}

Osteogenic cells from newborn Sprague-Dawley rat calvaria were isolated by Dr. Brunette's laboratory. Primary cultures were subcultured by trypsinization $(0.25 \%$ trypsin (Sigma, St. Louis, MO), 0.1\% glucose (Sigma), citrate/saline buffer pH 7.8 (BDH Chemical Ltd., Poole, England)) and maintained in minimal essential medium ( $\alpha$-MEM, Stem Cell Technologies Inc., Vancouver, BC) containing 15\% fetal calf serum (Cansera International Inc., Rexdale, $\mathrm{ON}$ ) and antibiotics, $100 \mu \mathrm{g} / \mathrm{mL}$ penicillin $\mathrm{G}$ (Sigma); $50 \mu \mathrm{g} / \mathrm{mL}$ gentamicin (Sigma); $3 \mu \mathrm{g} / \mathrm{mL}$ amphotericin B (Fungizone ${ }^{\circledR}$, Gibco, Grand Island, NY) in a humidified atmosphere with $5 \% \mathrm{CO}_{2}$ at $37^{\circ} \mathrm{C}$ (Forma Scientific Waterjacketed incubator, Caltec Scientific, Richmond BC).

Cultures were maintained in $\mathrm{BD}$ Falcon ${ }^{\mathrm{TM}}$ tissue-culture-treated flasks, with $75 \mathrm{~cm}^{2}$ growth area and $0.2 \mu \mathrm{m}$ vented blue caps (BD Bioscience, Mississauga, ON). Osteoblast experiments were performed in 12- or 24-well Falcon ${ }^{\mathrm{TM}}$ tissue-culture-treated plates (BD Bioscience). Thermanox ${ }^{\text {TM }}$ (Nunc) sterile coverslips were used as positive controls in cell culture experiments. Coverslips were $0.2 \mathrm{~mm}$ thick and $13 . \mathrm{mm}$ in diameter. They were made of a flexible transparent proprietary polymer (of the polyolefin family) that has been culture treated on one side for enhanced cell attachment and growth.

For MTS cell proliferation assays, the osteoblast media was exchanged with PC-3 media and samples were transferred into Corning ${ }^{\circledR}$ Inc. 96-well tissue-culture-treated plates (Corning, NY). One litre of PC-3 media contains 1 packet of F-12 nutrient media, $111 \mathrm{ml}$ fetal bovine serum, $11 \mathrm{ml}$ penicillin/streptomycin (all from Invitrogen, Carlsbad, CA) and $1.176 \mathrm{~g}$ sodium bicarbonate (Sigma, St. Loius, MO) diluted to volume in distilled, deionised water, and sterile filtered through a Nalgene ${ }^{\circledR} 0.2 \mu \mathrm{m}$ bottle-top filter (VWR, Mississauga, ON).

\subsection{Equipment}

\subsubsection{UV-Vis Spectrophotometer}

Spectroscopic analysis of alendronate was performed on an HP8452A diode array spectrophotometer equipped with $1 \mathrm{~cm}^{2}$ quartz cuvettes and Agilent UV-Visible Chem Station software. 


\subsubsection{HPLC}

Ion chromatography was performed on a Waters Alliance system consisting of a 1525 binary HPLC pump, 717+ autosampler, 2410 refractive index detector and 2487 dual wavelength absorbance detector, with Waters Breeze software (Waters Corporation, Mississauga ON). Separation was effected with an IC-Pak ${ }^{\mathrm{TM}}$ Anion-HR column (4.6 x 15 $\mathrm{mm})$.

Analysis of alendronate by fluorescence chromatography was performed on a Waters HPLC (Milford, MA) system, consisting of a model 717+ autosampler, 600 Controller Pump, and a 470 Scanning Fluorescence detector with a bus SAT/IN module interface and Waters Millenium v4.0 software. The column was a Nova-pak ${ }^{\circledR} \mathrm{C} 184 \mu \mathrm{m}, 3.9 \mathrm{x}$ $150 \mathrm{~mm}$ cartridge. Halfway through the project, the detector was replaced with a Waters 474 Scanning Fluorescence detector and the column was replaced with an Altech Nucleosil 100 (C18) $10 \mu \mathrm{m}, 4.6$ × $250 \mathrm{~mm}$ column.

\subsubsection{Liquid Chromatography/Mass Spectrometry}

LC/MS experiments were performed on a Waters Alliance HT 2795 Separations Module with an IC-Pak ${ }^{\mathrm{TM}}$ Anion-HR column $(4.6 \times 15 \mathrm{~mm})$ and a Waters Micromass Quattro micro $^{\mathrm{TM}}{ }^{\mathrm{ESC}} \mathrm{i}^{\mathrm{TM}}$ multimode ionization mass spectrometer with MassLynx 4.0 software.

\subsubsection{Scanning Electron Microscope}

Surface morphology studies were performed with a Hitachi S-3000N scanning electron microscope (Tokyo, Japan). Samples were coated with a $\sim 10 \mathrm{~nm}$ thick layer of 60:40 alloy of gold:palladium using a Denton Vacuum Desk II sputtercoater (Moorestown, NJ) at 50 millitorr.

\subsubsection{X-Ray Powder Diffractometer}

The crystal structures of sodium alendronate samples were determined using a Bruker D8 Advance (Madison, WI) X-ray powder diffractometer.

\subsubsection{Thermal Analysis}

Thermal analysis was performed at Angiotech Pharmaceuticals using a Mettler Toledo MX5 microbalance and either a TA Instruments DSC Q1000 with a refrigerated cooling system for differential scanning calorimetry, or a TA Instruments TGA Q500 for thermogravimetric analysis. 


\subsubsection{Gel Permeation Chromatography}

The gel permeation chromatography system consisted of a Waters 515 HPLC pump, 717plus autosampler, and a 2410 refractive index detector at $40^{\circ} \mathrm{C}$ with Waters Millenium v4.0 software. Styragel ${ }^{\circledR} 7.8$ x $300 \mathrm{~mm}$ HR3 and HR1 (THF) columns (Waters, Mississauga ON) were connected in series. The mobile phase was chloroform at a flow rate of $1 \mathrm{ml} /$ minute.

\subsubsection{Cell Culture}

After trypsinization, osteoblast density was determined on a $\mathrm{ZI}^{\mathrm{TM}}$ Coulter Counter $^{\circledR}$ cell and particle counter. A $0.5 \mathrm{ml}$ aliquot of cells was diluted to $10.0 \mathrm{ml}$ with Isoton $\mathbb{B}$ II diluent (Beckman Coulter Inc., Fullerton, CA) in a $35 \mathrm{ml}$ Accuvette ${ }^{\circledR}$ II vial (Beckman Coulter). The number of cells greater than $5 \mu \mathrm{m}$ was determined in triplicate and averaged.

Polymer films were sterilized with a Harrick PDC-32G Plasma Cleaner/Sterilizer connected to a SPX Robinair CoolTech high performance vacuum pump (SPX Corp, Owatonna $\mathrm{MN}$ ).

Fluorescent microscope images were obtained on a Zeiss Axioplan-2 imaging microscope (Carl Zeiss, Toronto, ON) using the DAPI and Rhod filters. Images were recorded using Northern Eclipse (Empix, Mississauga ON) imaging software.

Cell proliferation was measured using CellTiter $96^{\circledR} \mathrm{AQ}_{\text {ueous }}$ One Solution Cell Proliferation Assay (Promega, Madison WI). The change in absorbance at $492 \mathrm{~nm}$ (minus the blank reading at $600 \mathrm{~nm}$ ) was recorded on a Labsystems Multiskan Ascent photometric plate reader using Ascent Software version 2.4.2 (Labsystems, Helsinki, Finland).

\subsection{Preparation of Polymer Films}

Teflon squares measuring $1 \mathrm{~cm}$ by $1 \mathrm{~cm}$ were applied to glass slides as film templates. They were cleaned with 70\% isopropyl alcohol and dried prior to film manufacture.

Film casting solutions were prepared by dissolving PLGA containing PEG 600 or diblock copolymer (and ground alendronate if applicable) in a small quantity of dichloromethane (DCM). The mixtures were vigorously mixed by vortexing and ultra-sonication until the polymers had dissolved and the alendronate was evenly suspended. The mixtures were cooled in an ice bath to increase viscosity and slow evaporation after casting. A $50 \mu \mathrm{l}$ aliquot was cast over the template using an Eppendorf pipettor fitted with a disposable tip 
with $2 \mathrm{~mm}$ of the end snipped off. The glass slides were placed in a loosely closed plastic container and placed in the refrigerator for 3-5 days to let the solvent evaporate slowly.

The proportions used to manufacture the lead formulation at various concentrations of alendronate are shown in Table 4.

Table 4 Theoretical loadings of $0,0.1,0.25,0.5 \%$ alendronate into $10 \%$ diblock in PLGA films

\begin{tabular}{lccc}
\hline $\begin{array}{l}\text { Theoretical } \\
\text { Alendronate } \\
\text { Concentration (\%) }\end{array}$ & $\begin{array}{c}\text { Weight of Diblock } \\
(\mathbf{m g})\end{array}$ & $\begin{array}{c}\text { Weight of } \\
\text { Alendronate (mg) }\end{array}$ & $\begin{array}{c}\text { Weight of PLGA } \\
(\mathbf{m g})\end{array}$ \\
\hline & & - & 270 \\
0 & 30 & - & 270 \\
0.1 & 30 & 0.3 & 270 \\
0.5 & 30 & 0.8 & 270 \\
\hline
\end{tabular}

\subsection{Physicochemical Characterization}

\subsubsection{Solubility of Alendronate}

Samples $(0.5 \mathrm{~g})$ of alendronate were placed in $10 \mathrm{~mL}$ volumetric flasks and dispersed in either distilled, deionised water ( $\mathrm{pH} 5.74)$ or $\mathrm{PBS}(\mathrm{pH} 7.47)$ previously warmed to $37^{\circ} \mathrm{C}$. The flasks were placed in a $37^{\circ} \mathrm{C}$ oven with circular shaking at a rate of $50 \mathrm{rpm}$ and $0.5 \mathrm{ml}$ samples were taken at $1,2,5,24,48$ and 72 hours. The samples were filtered through a Millex ${ }^{\circledR}$ HV syringe-driven filter unit and diluted by half in either water or PBS. Samples were further diluted $0.4 \mathrm{ml}$ into $10.0 \mathrm{ml}$ prior to analysis by fluorescence HPLC. The reported solubilities are the mean of the concentrations determined at 24, 48 and 72 hours for the samples dissolved in water, and the mean of the concentrations determined at 48 and 72 hours for the samples dissolved in PBS.

\subsubsection{Alendronate Analysis by Spectrophotometry}

A $1.2 \mathrm{mg} / \mathrm{ml}$ stock solution of alendronate in water was prepared. Aliquots were transferred to a series of $10 \mathrm{ml}$ volumetric flasks to give final alendronate concentrations of $0,2.4,4.8,9.6,14.4,24.0$, and $36.0 \mu \mathrm{g} / \mathrm{ml}$. A $1.5 \mathrm{ml}$ aliquot of $0.1 \%$ ceric nitrate solution $\left(0.025 \mathrm{~g}\right.$ ceric ammonium nitrate in $\left.25.0 \mathrm{ml} 0.5 \mathrm{M} \mathrm{H}_{2} \mathrm{SO}_{4}\right)$ was added and the solutions were allowed to stand at room temperature for 1 hour. The samples were quantitatively diluted to $10.0 \mathrm{ml}$ with $0.5 \mathrm{M}$ sulphuric acid. The absorbance at $\sim 320 \mathrm{~nm}$ was recorded and subtracted from the blank. Typical spectra are shown in Figure 6. 


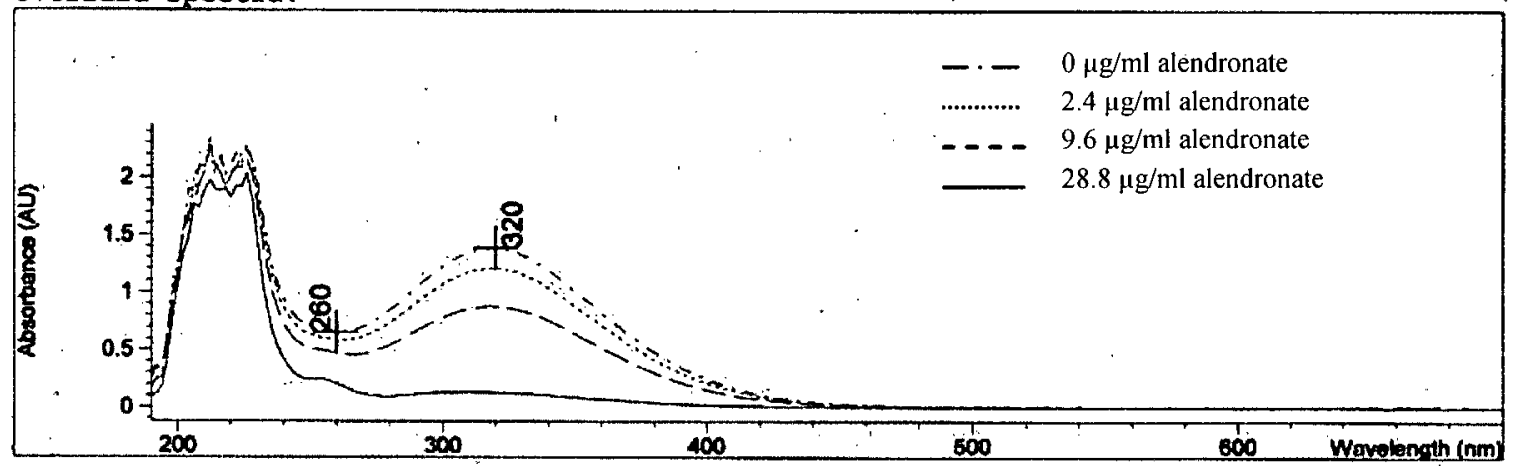

Figure 6 UV-Vis spectra of alendronate standards in ceric nitrate solution containing $0,2.4,9.6$ and $28.8 \mu \mathrm{g} / \mathrm{ml}$ alendronate. Loss of signal at $320 \mathrm{~nm}$ is proportional to alendronate concentration.

\subsubsection{Alendronate Analysis by Ion Chromatography}

Anion exchange chromatography was used for samples dissolved in buffers containing amine groups (e.g., HEPES) that would interfere with the fluorescence assay. Samples did not require pre-treatment. The mobile phase was composed of $0.5 \mathrm{mM}$ cupric nitrate in $1.0 \mathrm{mM}$ nitric acid (e.g., $116.3 \mathrm{mg} \mathrm{Cu}\left(\mathrm{NO}_{3}\right)_{2} \cdot 5 \mathrm{H}_{2} \mathrm{O}$ and $0.063 \mathrm{H}_{2} \mathrm{NO}_{3}$ in 11 deionised water, $\mathrm{pH} \sim 2.9$ ) at a flow rate of $1.0 \mathrm{ml} /$ minute. An IC-PAK ${ }^{\mathrm{TM}}$ anion exchange column (Waters, Mississauga $\mathrm{ON}$ ) was used for separation. Alendronate can be detected indirectly by UV-Vis spectroscopy at $245 \mathrm{~nm}$. Alendronate elutes at 1.5 minutes, well separated from the injection front. Copper elutes as a negative peak at approximately 5 minutes. A representative chromatogram is shown in Figure 7. 


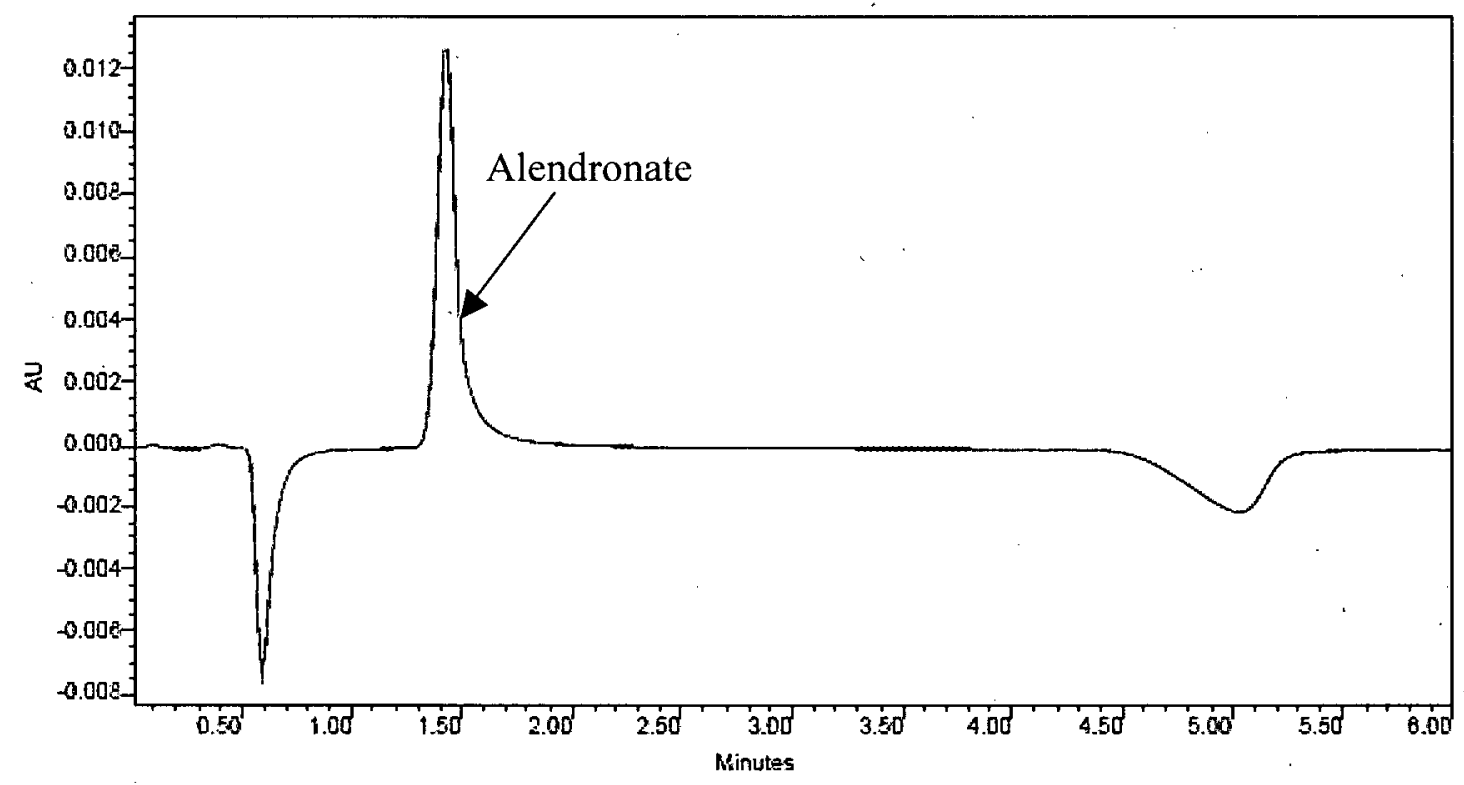

Figure 7 Representative chromatogram of $25 \mu \mathrm{g} / \mathrm{ml}$ alendronate standard by ion chromatography. Mobile phase: $0.5 \mathrm{mM}$ cupric nitrate, $1.0 \mathrm{mM}$ nitric acid, $1 \mathrm{ml} / \mathrm{min}$. UV-Visible detection at $245 \mathrm{~nm}$.

\subsubsection{Alendronate Analysis by Fluorescence HPLC}

Samples were prepared for HPLC analysis by mixing $100 \mu \mathrm{l}$ of sample with $900 \mu \mathrm{l}$ of $0.13 \mathrm{M}$ EDTA buffer (pH 10) and $500 \mu \mathrm{l}$ of $2 \mathrm{mg} / \mathrm{ml}$ fluorescamine in acetonitrile in a $4 \mathrm{ml}$ glass vial. Samples were gently agitated until the solution was clear and a yellow colour developed, approximately 10 seconds. One $\mathrm{ml}$ of dichloromethane was added to extract the acetonitrile, and the vials were capped and shaken vigorously. The layers were allowed to separate and the yellow upper layer was withdrawn for HPLC analysis. The sample-processing scheme is shown in Figure 8. 


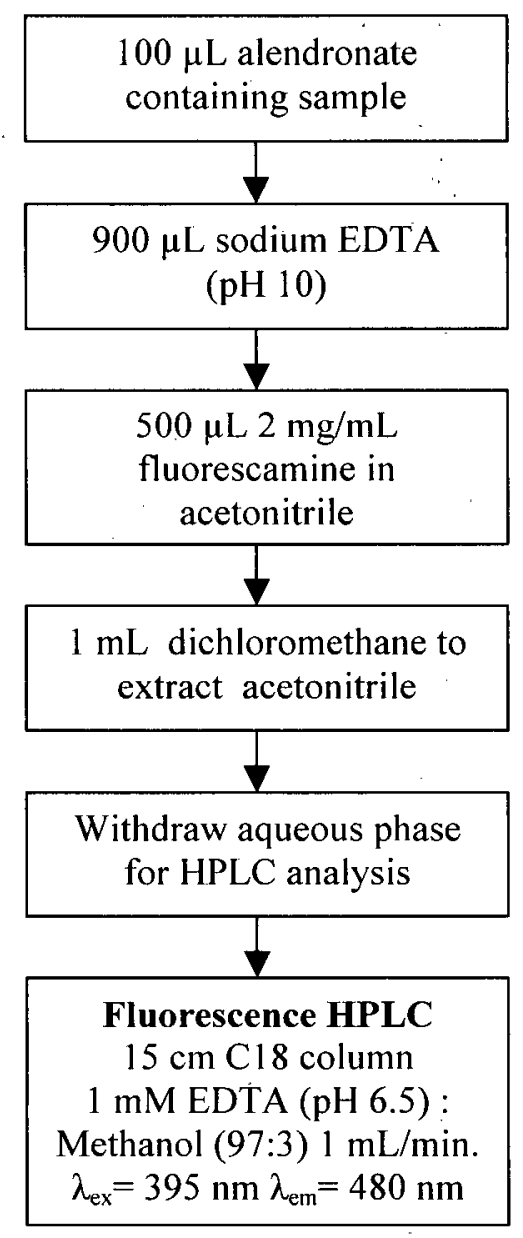

Figure 8 Sample preparation flow chart for the determination of alendronate by fluorescence HPLC

Separation of the fluorescamine-derivatized alendronate peak was achieved by reversephase HPLC. The mobile phase was composed of a 97:3 solution of $1 \mathrm{mM}$ EDTA:methanol at a flow rate of $1 \mathrm{ml} /$ minute through a $15-$ or $25-\mathrm{cm} \mathrm{C18} \mathrm{column,} \mathrm{with}$ fluorescence detection $\left(\lambda_{\mathrm{ex}}=395 \mathrm{~nm}, \lambda_{\mathrm{em}}=480 \mathrm{~nm}\right)$.

The derivatized alendronate peak eluted at approximately 3.5 minutes. Unreacted fluorescamine was well separated from the peak of interest, as shown in Figure 9. 


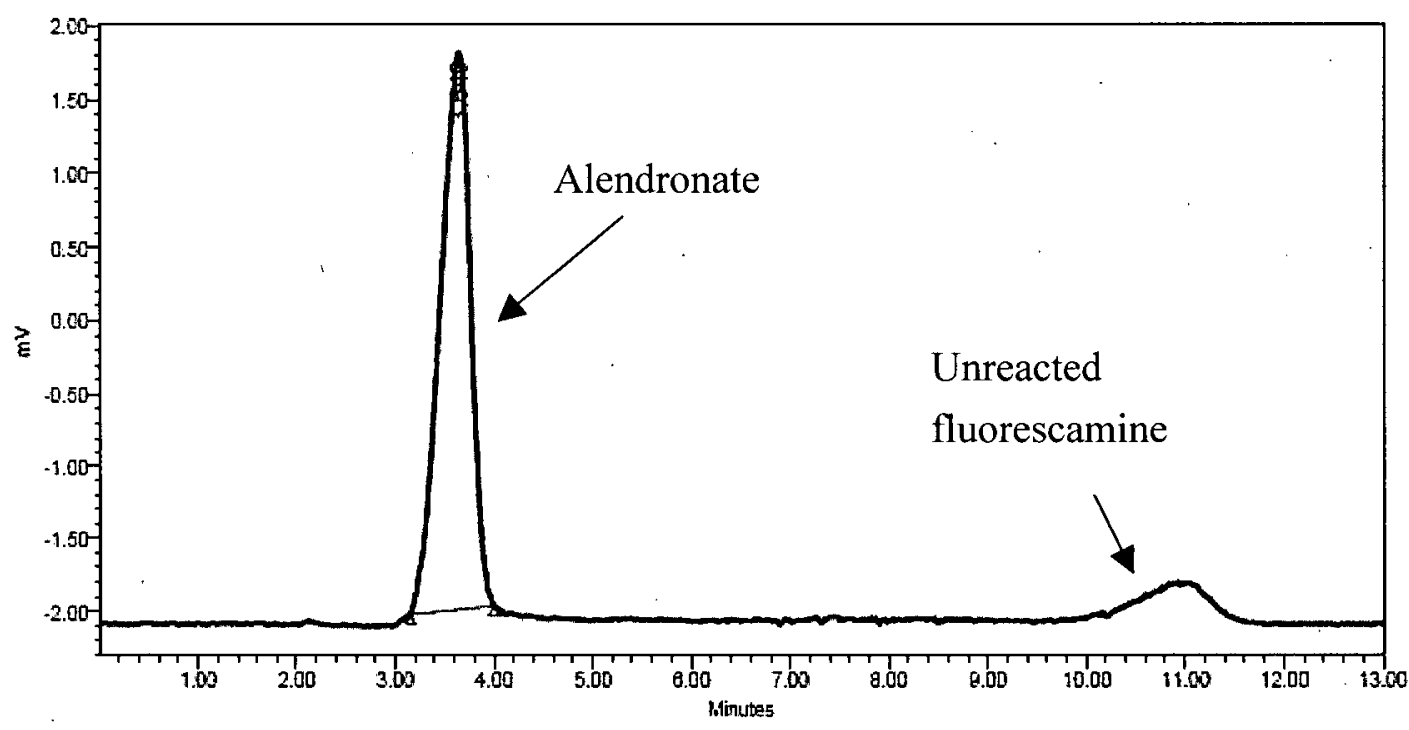

Figure 9 Fluorescence HPLC chromatogram of alendronate standard, concentration $0.01 \mathrm{mg} / \mathrm{ml}$. Mobile phase: 97:3 (1 mM EDTA (pH 6.5):methanol), $1 \mathrm{ml} / \mathrm{min}$. Excitation wavelength, $395 \mathrm{~nm}$, emission wavelength $480 \mathrm{~nm}$.

\subsubsection{Processing of Alendronate}

A portion of the original alendronate powder, termed "ground", was ground to a fine powder with a mortar and pestle for 10 minutes. Another sample, termed "lyophilized", was dissolved in water and lyophilized at $-40^{\circ} \mathrm{C}$ under vacuum for 3 days using a FreeZone 4.5-liter Benchtop Freeze Dry System (Labconco Corporation, Kansas City, $\mathrm{MO})$.

\subsubsection{In vitro Release Studies}

Drug release from various polymer film formulations was determined by weighing individual films into $4 \mathrm{ml}$ glass vials. One $\mathrm{ml}$ of PBS was added and the films were capped and incubated at $37^{\circ} \mathrm{C}$ with agitation. At defined intervals, the PBS was withdrawn for analysis and replaced with fresh PBS and returned to the chamber. Since alendronate is very soluble in water, sink conditions were maintained at all times. Details of specific studies are provided below.

To determine the amount of residual alendronate left in the films at the end of the in vitro release study, the films were dried under vacuum $(27 \mathrm{~mm} \mathrm{Hg}$ ) for 90 minutes then dissolved in $1 \mathrm{ml}$ dichloromethane. One $\mathrm{ml}$ water was then added and the alendronate was extracted into the aqueous layer with vigorous shaking. The concentration of alendronate in the aqueous layer was determined by fluorescence HPLC. 
Loading efficiency was determined by weighing individual films into $4 \mathrm{ml}$ glass vials. One $\mathrm{ml}$ dichloromethane was added to each film to dissolve the polymer. One $\mathrm{ml}$ water was then added and the alendronate was extracted into the aqueous layer with vigorous shaking. The concentration of alendronate in the aqueous layer was determined by fluorescence HPLC.

Release studies to determine the effects of alendronate processing on drug release from 85:15 PLGA were conducted as follows: individual films ( $\mathrm{n}=5, \sim 10 \mathrm{mg} / \mathrm{film}$ ) composed of $10 \%(\mathrm{w} / \mathrm{w})$ lyophilized, as received or ground alendronate in PLGA were weighed into $4 \mathrm{ml}$ glass vials, and $1 \mathrm{ml}$ of phosphate buffered saline (PBS, pH 7.5) was added. The vials were capped and incubated at $37^{\circ} \mathrm{C}$ with gentle agitation. At 1 hour, and 6 hours, and then daily for 10 days, and every second day until day 18 , the entire volume of buffer was removed and replaced with fresh PBS buffer. The concentration of alendronate in the withdrawn buffer was determined by the fluorescence HPLC method. Buffer samples that could not be tested immediately were sealed and stored at $2-8^{\circ} \mathrm{C}$.

Release studies to determine the effects of alendronate processing on drug release from $20 \%$ PEG 600 in 85:15 PLGA were conducted in the same manner, except that the films were composed of $10 \%(\mathrm{w} / \mathrm{w})$ lyophilized, as received or ground alendronate in $20 \%$ PEG 600 in 85:15 PLGA, and the study ended after 9 days because full release of the drug from the films had been achieved.

Release studies to determine the effects of increasing concentrations of diblock copolymer were performed in the same manner using films $(n=5)$ composed of $0 \%, 10 \%$, $20 \%$ and $30 \%$ diblock copolymer $(\mathrm{w} / \mathrm{w})$ in PLGA containing $5 \%$ alendronate by weight. Samples were taken 1 hour, 6 hours, daily for 8 days, every 3-4 days until day 29 and weekly thereafter. Studies on samples containing $20 \%$ and $30 \%$ diblock were ended after 18 and 7 days respectively, when full drug release from the films had been achieved.

Release studies to determine the effect of low drug concentration films were performed using 3 different batches of films loaded with $0.10 \%, 0.25 \%$ and $0.50 \%(\mathrm{w} / \mathrm{w})$ alendronate in 10\% diblock in PLGA films. The PBS buffer was replaced on days 1, 2, 4 and 7 and weekly thereafter until day 28. Three films from each batch at each concentration were tested, and the plotted values are the mean of the 3 batches ( $n=9$ for each data point).

Release studies to determine the effect of glow discharging on drug release were performed in the same manner as the low drug concentration films. Films from the same 
3 manufacturing batches were glow discharged for 4 minutes as described in 3.5.1 and run in parallel with the low drug concentration studies.

\subsubsection{Surface Morphology}

Surface morphology was determined using a scanning electron microscope (SEM). Powder samples of alendronate were dusted on the adhesive surface of the sample holder. A $\sim 10 \mathrm{~nm}$ thick layer of 60:40 alloy of gold:palladium was sputtered on to the samples under vacuum. After coating, samples were placed in the SEM and observed at $20 \mathrm{kV}$.

The mean particle size was estimated by measuring the longest diameter of each particle clearly visible in the micrograph.

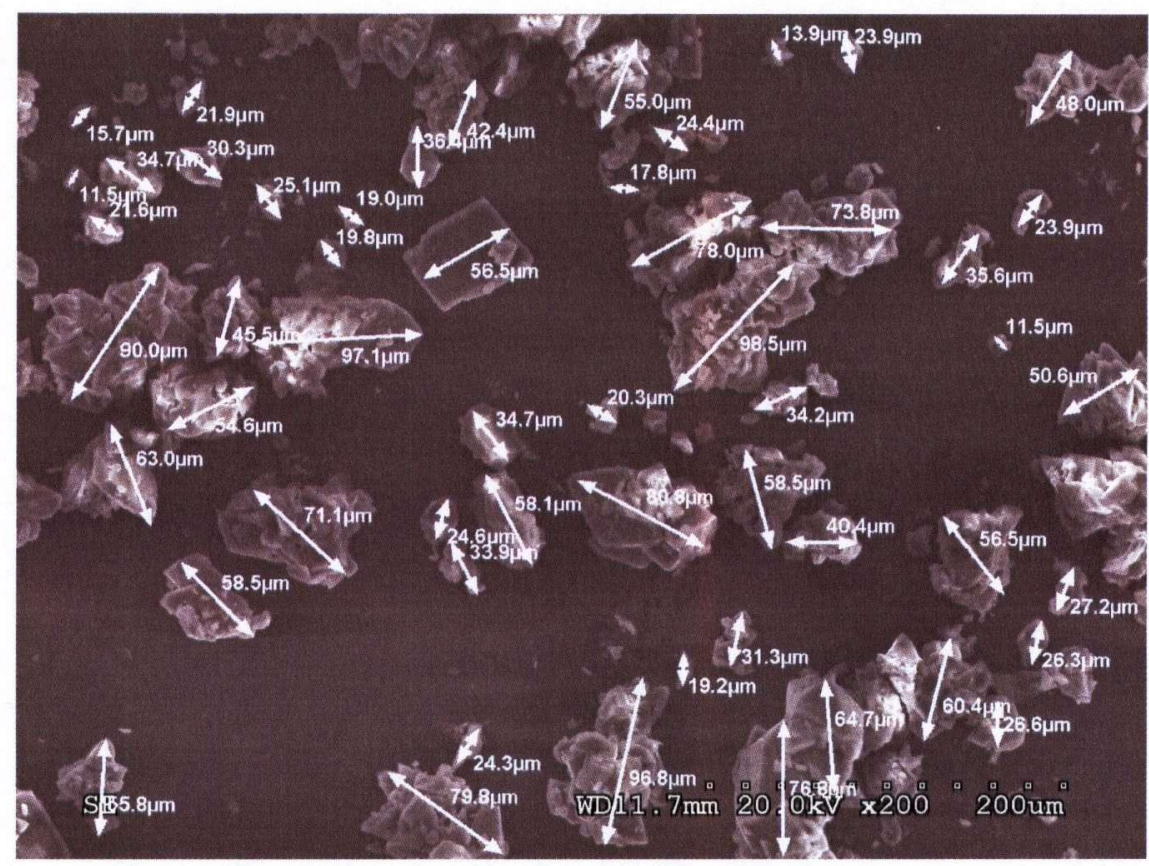

Figure 10 Scanning electron micrograph of sodium alendronate trihydrate as received from Dr. Wang. Mean particle size $~ 30 \mu \mathrm{m}$ (range 9-97 $\mu \mathrm{m}$ ).

\subsubsection{X-Ray Powder Diffraction}

$\mathrm{X}$-ray powder diffraction patterns of alendronate and alendronate in polymer films were obtained using a Bruker D8 Advance diffractometer in Bragg-Brentano configuration with a $\mathrm{Cu}$ source at $25^{\circ} \mathrm{C}$. Samples were scanned from $5.000-45.000^{\circ} 2 \theta$, using a step size of $0.020^{\circ}$, and a step time of 1 second per step. Samples of approximately $300 \mathrm{mg}$ 
were packed into standard Bruker sample holders. The polymer films were adhered to a glass slide and the slides were mounted, with plasticine, flush to the diffracting plane (top) of the sample holders. To improve particle statistics, all samples were rotated during data collection.

The theoretical powder diffraction data were created by converting the fractional atomic coordinates of the published structure from the Cambridge Structural Database, from the .cif to the .res format using Mercury Crystal Structure Visualization software (CSD, Cambridge, UK). Then Powdercell 2.4 (Federal Institute for Materials Research and Testing, Berlin, Germany) was used to open the res file and calculate the theoretical diffraction pattern.

\subsubsection{Thermal Analysis}

Polymer samples weighing $2-5 \mathrm{mg}$ were accurately weighed on a microbalance into aluminum pans and an aluminum lid was crimped in place. Samples were heated to $200^{\circ} \mathrm{C}$ at a rate of $10^{\circ} \mathrm{C} / \mathrm{min}$. The initial heat was followed by a cooling scan from $200^{\circ} \mathrm{C}$ to $-50^{\circ} \mathrm{C}$ and a second heating scan from $-50^{\circ} \mathrm{C}$ to $200^{\circ} \mathrm{C}$ under the same conditions. Diblock samples followed the same protocol, except they were cooled to $-100^{\circ} \mathrm{C}$. The glass transition temperatures were taken as the midpoint of the heat capacity change in the second heating.

Thermogravimetric analysis was performed by weighing $\sim 50 \mathrm{mg}$ alendronate samples directly onto the pan. The temperature was increased from $20-500^{\circ} \mathrm{C}$ at a rate of $20.0^{\circ} \mathrm{C} /$ minute, or isothermal if the change in percent weight was greater than $1.00 \%$.

\subsubsection{In vitro Degradation Studies}

The short-term degradation of diblock from the diblock in PLGA films was monitored by gel permeation chromatography. Duplicate samples $(\sim 10 \mathrm{mg})$ from three batches of $10 \%$ diblock in PLGA films with and without glow discharging were placed in glass tubes with $1 \mathrm{ml}$ PBS in a $37^{\circ} \mathrm{C}$ chamber with agitation. After 3 or 7 days, the PBS was removed and the films were dried under vacuum at room temperature.

Gel permeation chromatography was used to determine any change in the polymer ratios or diblock molecular weight (Jackson et al. 2004). HPLC grade chloroform (Fisher) was used as the mobile phase at a flow rate of $1 \mathrm{ml} / \mathrm{min}$. Samples were prepared at a concentration of approximately $1.0 \%(\mathrm{w} / \mathrm{v})$ i.e. a $10 \mathrm{mg}$ piece of film dissolved in $1 \mathrm{ml}$ of chloroform. The injection volume was $20 \mu \mathrm{l}$. 
The experiments were performed on films that did not contain alendronate. Alendronate is not soluble in chloroform and the particles could create an obstruction in the chromatography system.

A typical gel permeation chromatogram is shown in Figure 11. PLGA elutes at 10 minutes; the diblock peak appears as a shoulder at 12 minutes.

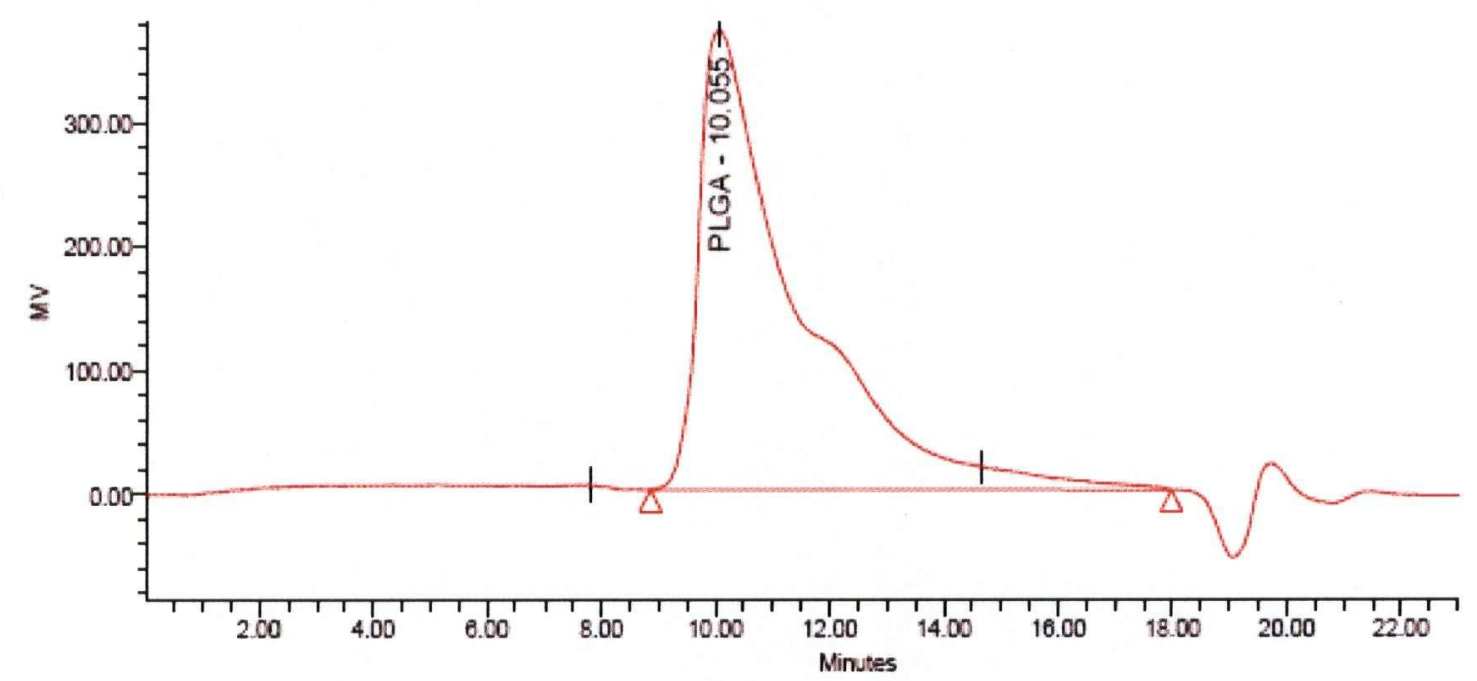

Figure 11 GPC elution profile of a 10\% diblock in 85:15 PLGA film (not glow discharged) after 3 days in $\mathrm{PBS}$ at $37^{\circ} \mathrm{C}$. Solvent: chloroform, $1 \mathrm{ml} /$ minute; injection volume $20 \mu \mathrm{l}$.

Polystyrene standards were used to construct a calibration curve to detect any changes in the diblock molecular weight. A calibration graph of log molecular weight versus retention time (Figure 12) was established for the column using polystyrene standards with molecular weights of $300,1000,4000,9000,20,000$, and 30,000 g/mol (PolySciences Inc., Warrington PA). A linear relationship between $\log$ molecular weight and retention time was observed $\left(\mathrm{R}^{2}=0.993\right)$. 


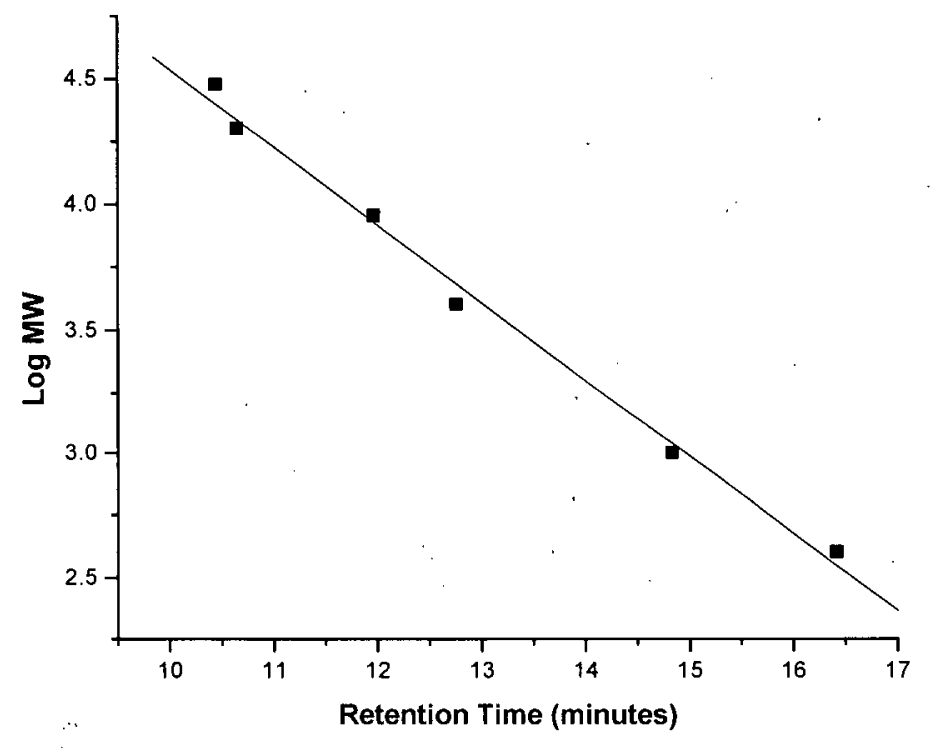

Figure 12 GPC standard curve for polystyrene standards with molecular weights from 300 to $30,000 \mathrm{~g} / \mathrm{mol}$. (Mobile phase: chloroform at $1.0 \mathrm{ml} / \mathrm{min}$. through two Styragel ${ }^{\circledR}$ columns (HR3 and HR1) connected in series with refractive index detection at $40^{\circ} \mathrm{C}$, injection volume: $\left.20 \mu \mathrm{l}\right)$. Equation: $y=-0.3103 x+7.6411, R^{2}=0.993$.

A universal calibration curve for gel permeation chromatography can be used to calculate molecular weight from retention time. The product of the intrinsic viscosity $[\eta]$ and molecular weight is related to hydrodynamic volume, and once established for a given column, temperature and solvent, it can be used to determine the molecular weight of any random coil polymer (Grubisic et al. 1967). A plot of log [ๆ]M.W. versus retention time will yield a linear curve for a wide range of polymers. Unfortunately, the intrinsic viscosity for the diblock was not determined, so the reported values for molecular weight are not absolute, but do show relative changes.

The retention time of the PLGA peak was not in the calibration range, so the molecular weight of PLGA was not determined. However, the ratio of the diblock to PLGA peak heights was determined in an attempt to determine a significant loss of diblock from the films over time. 


\subsubsection{Film Thickness}

The thickness of the polymer films was determined by taking measurements in at least 3 places on each film with callipers capable of reading $0.001 \mathrm{~mm}$ (Mitutoyo, Kawasaki, Japan). Samples of various drug concentrations (0 to $0.5 \%$ ) were taken from 4 batches of alendronate-loaded polymer films.

\subsection{Osteoblast Culture Studies}

\subsubsection{Glow Discharge}

PLGA films were treated with argon plasma glow discharge to provide sterility and a negatively charged surface to which the cells could adhere. The films, still on their Teflon ${ }^{\circledR}$ templates, were placed in the glow discharge chamber. The chamber was evacuated for 4 minutes, then flushed with argon and re-evacuated 3 times. An RF field was used to generate an argon plasma for 4 minutes.

\subsubsection{Cell Proliferation by Staining}

Polymer films composed of $10 \%$ diblock in PLGA and containing $0,0.1,0.25$ or $0.5 \%$ ground alendronate were sterilized by glow discharge and placed in individual wells in a 12-well plate. Thermanox ${ }^{\mathrm{TM}}$ tissue-culture treated cover slips were used as a control.

Two milliliters of osteoblast media and 50,000 osteoblast cells were added. Media was exchanged on day $1,2,3,4$ and 7 . On days $1,2,4$, and 7, films of each concentration were removed to a separate 12 well plate and fixed by replacing the cell culture medium with $4 \%$ formaldehyde solution (EM Grade, Canemco Int. St. Laurent) in PIPES buffer (Sigma, St. Louis, MO) for 10 minutes at room temperature. The sample films were then rinsed 3 times with $2 \mathrm{ml}$ PBS buffer.

Osteoblasts on sample films were stained with sulforhodamine B acid chloride (Fluka Biochemika, Oakville, ON) for 30 minutes, and then rinsed with PBS until the solution ran clear. The cell nuclei were stained with Hoescht Stain Solution (Sigma, St. Louis, $\mathrm{MO}$ ) for 1 minute then the films were rinsed 3 times with $2 \mathrm{ml}$ PBS buffer.

Films were mounted between 2 glass slides and 8 representative images per film were recorded at 10X magnification using the DAPI filter to visualize entire osteoblasts or the Rhod filter for nuclei only. The numbers of cells per image were counted manually.

\subsubsection{Cell Proliferation by MTS}

The effect of alendronate in solution on osteoblast cells was determined by seeding 24well plates with $1 \mathrm{ml}$ of osteoblast media containing 20,000 cells $/ \mathrm{ml}$. A $100-\mu l$ aliquot 
containing $0,0.01,0.1,1,10$, or $100 \mu \mathrm{g} / \mathrm{ml}$ alendronate in water was added and the plates were incubated for 2 days in an incubator at $37^{\circ} \mathrm{C}$ in a humidified atmosphere and $5 \%$ $\mathrm{CO}_{2}$. Then the osteoblast media was replaced with $1 \mathrm{ml}$ of PC-3 media and $0.1 \mathrm{ml}$ of MTS solution was added (osteoblast media interferes with the MTS assay). The plates were incubated 2 hours, and $100 \mu \mathrm{l}$ samples from each well were transferred to a 96-well plate for analysis. The absorbances at 492 and $620 \mathrm{~nm}$ were recorded. The difference between the absorbance at $492 \mathrm{~nm}$ and the blank absorbance at $620 \mathrm{~nm}$ was reported. Data were normalized with respect to the absorbance of the control wells (no alendronate). The experiment was repeated three times with different batches of films and different passages of osteoblasts, with $\mathrm{N}=4$ replicates at each alendronate concentration.

The proliferation of osteoblast cells on polymer films was determined as follows. Polymer films containing $0,0.1,0.25$ and $0.5 \%$ alendronate were sterilized by glow discharge and placed treated side up in individual wells in a 12-well plate. Two millilitres of osteoblast media containing 20,000 cells/ml was added to each well and the osteoblasts were allowed to proliferate over the films and along the sides of the well as shown in Figure 13. Control wells contained the same amounts of cells and osteoblast media, but no films or drug.

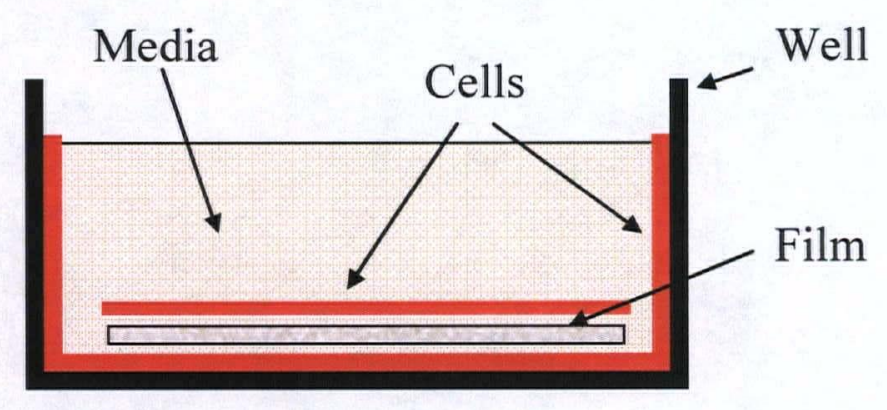

Figure 13 Schematic diagram of osteoblast cells proliferating over drug-loaded films and along walls of 12 -well plate

In order to distinguish proliferation on the films from total osteoblast proliferation, at days 1,2, 4 and 6 or 7, the films were removed to a second 12-well plate and incubated in $1 \mathrm{ml} \mathrm{PC}-3$ media and $0.1 \mathrm{ml}$ MTS solution for 2 hours. In the control wells and the now empty treatment wells, the osteoblast media was replaced with $1 \mathrm{ml} \mathrm{PC}-3$ media and $0.1 \mathrm{ml}$ MTS solution. After 2 hours incubation at $37^{\circ} \mathrm{C}$, a $0.1 \mathrm{ml}$ aliquot from each well was transferred to a 96-well plate and read at 492 and $620 \mathrm{~nm}$. The absorbance at $620 \mathrm{~nm}$ was subtracted from the value at $492 \mathrm{~nm}$ as a blank, and the results were normalized with 
respect to the absorbance in the control wells, which contained no films and no drug. Osteoblast proliferation on the alendronate-loaded films alone, as well as total osteoblast proliferation in the sum of the films and the wells were recorded. The experiment was repeated 3 times with different batches of films and different passages of osteoblasts, with $\mathrm{N}=3$ replicates at each alendronate concentration. However, one set of experiments had to be discarded because the osteoblasts had reached confluence prior to the start of the experiment and failed to continue to proliferate.

\subsection{Statistical Analysis}

Data collected from multiple independent samples from the same experiment are presented as mean \pm standard deviation, where the $\mathrm{N}$ number represents the number of samples. If the experimental design provided for multiple sample sets each composed of several replicates, the data are reported as mean \pm standard error of the mean, with the $\mathrm{N}$ number representing the number of samples sets used in the analysis. Statistical analysis was performed using OriginPro version 7.5 (OriginLab Corporation, Northampton MA) with a significance level of $\mathrm{p}<0.05$. The two-tailed Student's $t$-test were used for comparisons between groups with a significance level of $\alpha<0.05$ considered to be statistically significant and marked with an asterisk $\left({ }^{*}\right)$.

An analysis of similarity and difference $(\mathrm{f} 1, \mathrm{f} 2)$ of the drug release curves was performed in accordance with the FDA Guidance for Industry: Dissolution Testing of Immediate Release Solid Oral Dosage Forms (Center for Drug Evaluation and Research 1997). The following description of the approach is quoted from this guidance document:

"This model-independent approach uses a difference factor (f1) and a similarity factor (f2) to compare dissolution profiles (Moore and Flanner 1996). The difference factor (f1) calculates the percent (\%) difference between the two curves at each time point and is a measurement of the relative error between the two curves:

$$
f_{1}=\left\{\left[\sum_{t=1}^{n}\left|R_{t}-T_{t}\right|\right] /\left[\sum_{t=1}^{n} R_{t}\right]\right\} \cdot 100
$$

Equation 4

where $\mathrm{n}$ is the number of time points; $\mathrm{R}_{t}$ is the dissolution value of the reference (prechange) batch at time $t$, and $T_{t}$ is the dissolution value of the test (postchange) batch at time $\mathrm{t}$. 
The similarity factor (f2) is a logarithmic reciprocal square root transformation of the sum of squared error and is a measurement of the similarity in the percent (\%) dissolution between the two curves.

$$
f_{2}=50 \cdot \log \left[\left[1+(1 / 1) \sum_{t=1}{ }^{n}\left(R_{t}-T_{t}\right)^{2}\right]^{-0.5} \cdot 100\right\}
$$

For curves to be considered similar, $\mathrm{f} 1$ values should be close to 0 , and $\mathrm{f} 2$ values should be close to 100 . Generally, f1 values up to $15(0-15)$ and $\mathrm{f} 2$ values greater than 50 (50100) ensure sameness or equivalence of the two curves and, thus, of the performance of the test (postchange) and reference (prechange) products.

This model independent method is most suitable for dissolution profile comparison when three to four or more dissolution time points are available. As further suggestions for the general approach, the following recommendations should also be considered:

- The dissolution measurements of the test and reference batches should be made under exactly the same conditions. The dissolution time points for both the profiles should be the same (e.g., 15, 30, 45, 60 minutes). The reference batch used should be the most recently manufactured prechange product.

- Only one measurement should be considered after $85 \%$ dissolution of both the products.

- To allow use of mean data, the percent coefficient of variation at the earlier time points (e.g., 15 minutes) should not be more than $20 \%$, and at other time points should not be more than $10 \%$." 


\section{RESULTS AND DISCUSSION}

\subsection{Assay Development}

\subsubsection{Sodium Alendronate Trihydrate}

Sodium alendronate trihydrate has a molecular formula of $\mathrm{C}_{4} \mathrm{H}_{12} \mathrm{NaNO}_{7} \mathrm{P}_{2} \cdot 3 \mathrm{H}_{2} \mathrm{O}$ and a molecular weight of 325.12. The chemical structure is shown in Figure 14 in two representations.
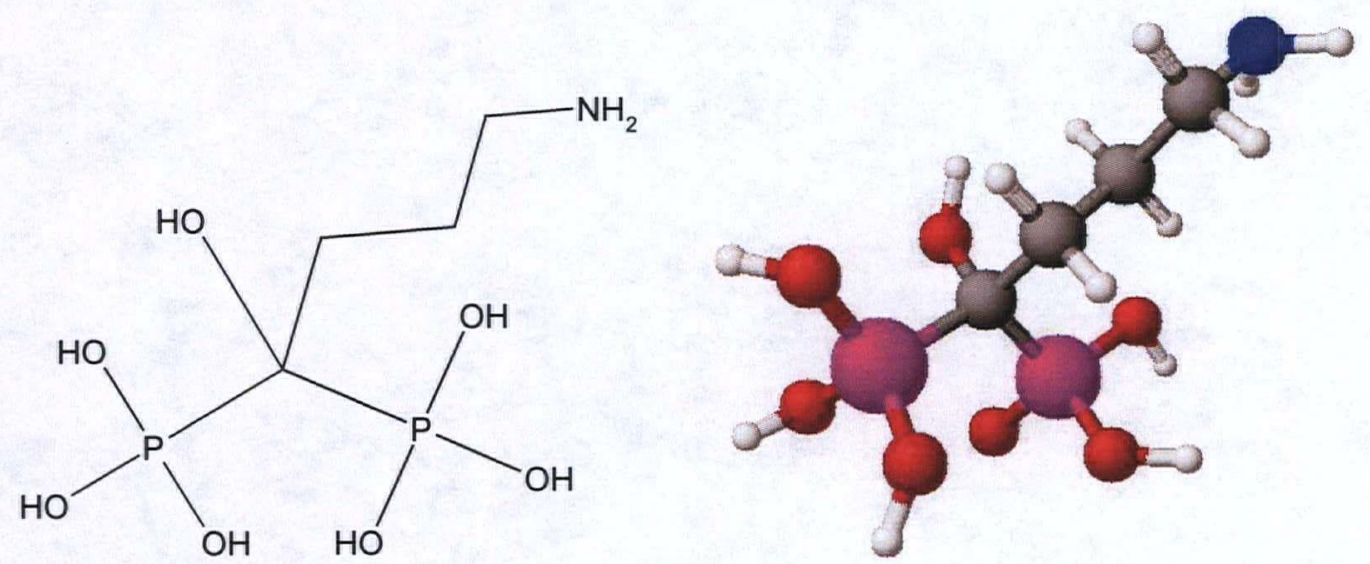

Figure 14 Chemical structure and ball-and-stick model of alendronate. Carbon atoms are shown in grey, phosphorus in pink, oxygen in red, nitrogen in blue and hydrogen in white.

Alendronate has $5 \mathrm{pKa}$ values: $0.8,2.2,6.3,10.9$ and 12.2. At physiological pH, alendronate is a zwitterion with an overall charge of -2 ( 3 negative charges on the phosphate groups and a protonated amine group). Alendronate is freely soluble in water (10 $\mathrm{mg} / \mathrm{ml}$ ), but insoluble in most other common solvents. The trihydrate has a monoclinic crystal structure (Vega et al. 1996) and there are no reported polymorphs.

The solubility of sodium alendronate trihydrate in deionized water and phosphate buffered saline $(\mathrm{pH}=7.5)$ at $37^{\circ} \mathrm{C}$ was determined in order to establish that solution saturation would not be a limitation in the planned drug release studies (Figure 15). 


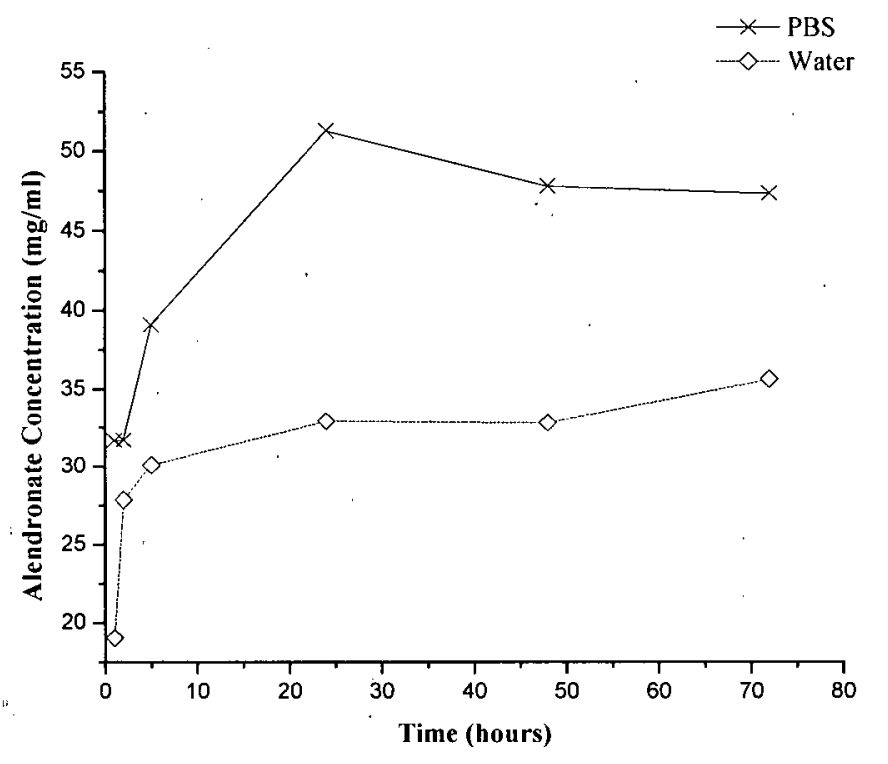

Figure 15 Solubility of sodium alendronate trihydrate at $37^{\circ} \mathrm{C}$ in $(x)$ phosphate buffered saline $(\mathrm{pH} 7.5)$ and $(\diamond)$ distilled water $(\mathrm{pH}$ 5.7).

The solubility of alendronate in $37^{\circ} \mathrm{C}$ deionized water was determined to be $34 \mathrm{mg} / \mathrm{ml}$. In PBS, the solution showed a small degree of supersaturation at 24 hours, which then reequilibrated and the solubility was determined to be $47 \mathrm{mg} / \mathrm{ml}$. The difference in solubility was attributed to the difference in $\mathrm{pH}$ between water (5.7) and PBS (7.5). Alendronate has a $\mathrm{pKa}$ value at 6.3 , so at $\mathrm{pH} 7.5$ the concentration of ionized species would be higher, thus increasing the solubility.

\subsubsection{Analytical Method Literature Review}

The first goal of the project was to develop, optimize and validate a suitably sensitive analytical method for the determination of alendronate in the drug release assays. The published analytical methods for bisphosphonates similar to alendronate (i.e., alendronate, etidronate and pamidronate) were reviewed. These compounds do not possess a chromophore, so detection must be performed indirectly or by derivatization. The literature on bisphosphonate analysis can be roughly divided into 4 approaches of increasing complexity, as shown in Table 5. 


\section{Table 5 Literature Review: Bisphosphonate Analytical Methods}

\begin{tabular}{|c|c|c|}
\hline Analytical Method & Observations & References \\
\hline UV Spectroscopy & $\begin{array}{l}\text { - Suitable for samples of known } \\
\text { composition and concentration (e.g., } \\
\text { pharmaceutical preparations) } \\
\text { - Fast } \\
\text { - Cannot distinguish impurities or matrix } \\
\text { effects } \\
\text { - Limited linear range }\end{array}$ & $\begin{array}{l}\text { (Ostovic et al. } \\
\text { 1993; Kuljanin et al. } \\
\text { 2002; Taha and Youssef } \\
\text { 2003; Al Deeb et al. } \\
\text { 2004; Tzanavaras et al. } \\
\text { 2005) }\end{array}$ \\
\hline Ion Chromatography & $\begin{array}{l}\text { - Suitable for samples of known } \\
\text { composition (e.g., pharmaceutical } \\
\text { preparations) } \\
\text { - Detection by refractive index, indirect } \\
\text { UV or conductivity measurement } \\
\text { - Unsuitable for samples with a high } \\
\text { concentrations of ions in the matrix }\end{array}$ & $\begin{array}{l}\text { (Tsai et al. } \\
\text { 1992; denHartigh et al. } \\
\text { 1993; Quitasol and Krastins } \\
\text { 1994; Tsai } \text { et al. } \\
\text { 1994;Sparidans } \text { et al. } \\
\text { 1995) }\end{array}$ \\
\hline $\begin{array}{l}\text { HPLC with On-line } \\
\text { Derivatization }\end{array}$ & $\begin{array}{l}\text { - Suitable for samples of unknown } \\
\text { composition } \\
\text { - Significant sample preparation required } \\
\text { - On-line reactors required for some } \\
\text { methods } \\
\text { - Wide linear range } \\
\text { - Low limit of quantitation } \\
\text { - Good reproducibility }\end{array}$ & $\begin{array}{l}\text { (Daley-Yates et al. } \\
\text { 1989;DeMarco J.D. et al. } \\
\text { 1989;Flesch and Hauffe } \\
\text { 1989; Kline } \text { et al. } \\
\text { 1990; Flesch } \text { et al. } \\
\text { 1991;Kline and } \\
\text { Matuszewski 1992) }\end{array}$ \\
\hline $\begin{array}{l}\text { Co-precipitation, } \\
\text { extraction and } \\
\text { derivatization } \\
\text { followed by } \\
\text { fluorescence HPLC }\end{array}$ & $\begin{array}{l}\text { - Suitable for biological samples } \\
\text { - Extensive sample preparation required } \\
\text { - Low limit of quantitation } \\
\text { - Internal standard required for } \\
\text { reproducibility in co- } \\
\text { precipitation/extraction steps }\end{array}$ & $\begin{array}{l}\text { (King and Vieth } \\
\text { 1996;Sparidans } \text { et al. } \\
\text { 1997; Sparidans } \text { et al. } \\
\text { 1997;Sparidans } \text { et al. } \\
\text { 1998;Sparidans and den } \\
\text { Hartigh 1999;Ptacek et al. } \\
\text { 2002; Wong et al. } \\
\text { 2004; Yun and Kwon 2006) }\end{array}$ \\
\hline
\end{tabular}

The suitability and feasibility of each of these analytical approaches was evaluated, as shown in the following sections. Methods for the determination of alendronate in biological fluids such as urine and plasma were not considered, because under the original scope of this project, biological samples were not expected. These methods generally involve an extensive sample preparation scheme including protein precipitation, calcium precipitation, solid phase extraction and derivatization to determine alendronate. A similar bisphosphonate such as pamidronate can be added as an internal standard to improve reproducibility. 


\subsubsection{Alendronate Analysis by UV-Vis}

Spectrophotometric methods for the analysis of alendronate have been recommended as a rapid, inexpensive assay method for the analysis of pharmaceutical samples with predictable concentrations (Kuljanin et al. 2002; Taha and Youssef 2003;Taha and Youssef 2003; $\mathrm{Al}$ Deeb et al. 2004;Tzanavaras et al. 2005). Using the method reported by Taha (Taha and Youssef 2003) that measures the reduction in cerium ammonium nitrate signal intensity at $320 \mathrm{~nm}$ in the presence of alendronate, a linear response in the range 2 $-24 \mu \mathrm{g} / \mathrm{mL}$ was obtained. The published method suggests a 1 hour incubation period after the addition of the ceric ammonium nitrate solutions; however, it was found that the length of the incubation period could be reduced to as little as 10 minutes without loss of linearity. In addition, standard solutions were found to remain stable for at least 2 hours after the incubation period.

The linear range $(2-24 \mu \mathrm{g} / \mathrm{mL})$ was in agreement with the published value. However, this narrow linear range was not suitable for drug release studies, where low concentration samples were expected. An analytical method with broader range and lower limit of quantitation was required.

\subsubsection{Alendronate Analysis by Ion Chromatography}

The ion chromatography HPLC methods developed by Tsai (Tsai et al. 1992;Tsai et al. 1994) and by Han (Han and Qin 1996) were investigated. All bisphosphonates are strongly ionic at neutral $\mathrm{pH}$, making ion chromatography a logical choice. The stationary phase of an anion exchange column contains positively charged resin particles, such as a quaternary ammonium group covalently bound to a polymeric resin. Negatively charged molecules in the test solution, such as alendronate, would replace the counter ion and bind to the positively charged group on the resin. The alendronate was then detected indirectly by loss of refractive index or UV-Vis $(245 \mathrm{~nm})$ signal compared to the mobile phase (nitric acid).

In the first method, the mobile phase was composed of $6 \mathrm{mM}$ nitric acid at a flow rate of $0.5 \mathrm{ml} /$ minute with a refractive index and UV-Visible detector $(235 \mathrm{~nm})$ connected in series, as shown in Figure 16. The linear ranges were determined to be $150-1000 \mu \mathrm{g} / \mathrm{mL}$ by refractive index detection or $50-1000 \mu \mathrm{g} / \mathrm{mL}$ by UV detection. UV detection was selected as the method of choice because of its lower limit of quantitation. The method was found to be rugged to changes in the flow rate from 0.45 to $0.55 \mathrm{ml} /$ minute. 
A)

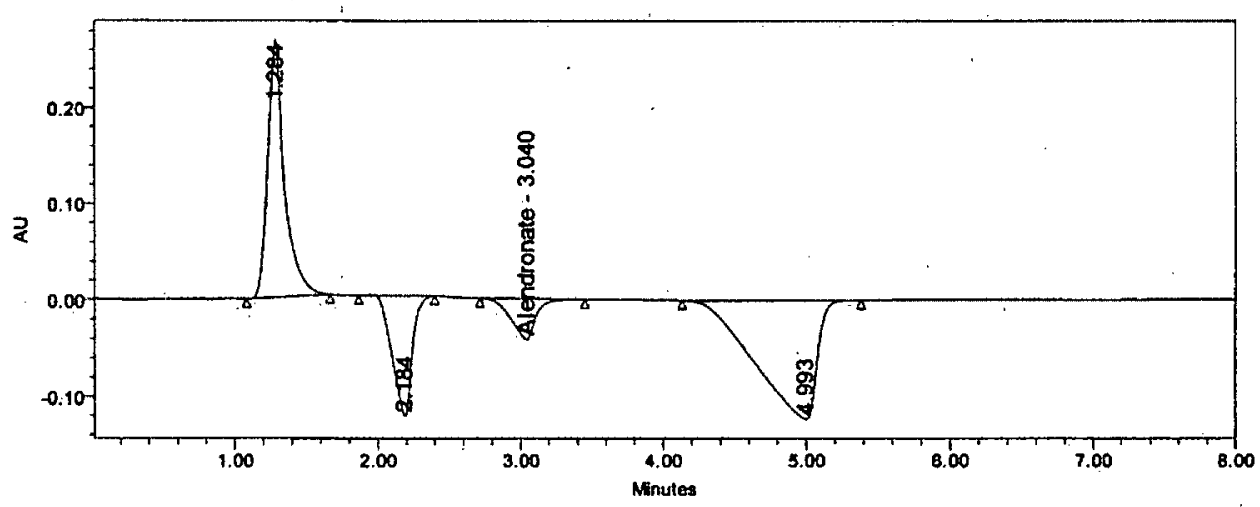

B)

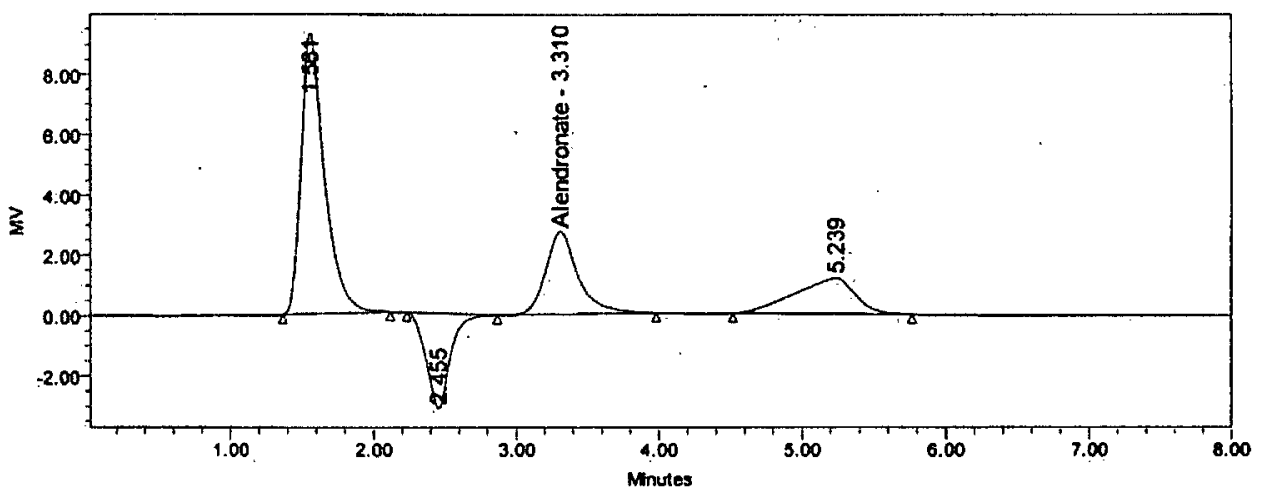

Figure 16 Chromatogram of $0.5 \mathrm{mg} / \mathrm{ml}$ alendronate in phosphate buffer by ion chromatography. Mobile phase: $6 \mathrm{mM}$ nitric acid, flow rate: $0.5 \mathrm{ml} /$ minute, injection volume $20 \mu \mathrm{l}$, detection by A) refractive index or B) UV-Vis at $235 \mathrm{~nm}$.

The specificity of the method with respect to other common ions was determined by injecting samples of various salt solutions and observing the peak positions as shown in Table 6 . The negative peak at $\sim 2.5$ minutes (UV-Vis) was common to all chromatograms including the blank and was associated with the absence of nitrate in the sample. All of the common ion peaks were well separated from the alendronate peak. 
Table 6

Specificity of Alendronate by Ion Chromatography: Retention Times of Common Ions

\begin{tabular}{lcc}
\hline Ion Solution & Concentration & $\begin{array}{c}\text { UV-Vis Retention Time } \\
\text { (minutes) }\end{array}$ \\
\hline Alendronate & $0.15 \mathrm{mg} / \mathrm{ml}$ & Alendronate $=3.331$ \\
Potassium Chloride & $0.2 \mathrm{mg} / \mathrm{ml}$ & $\mathrm{K}^{+}=1.535$ \\
Sodium Chloride & $0.29 \mathrm{mg} / \mathrm{ml}$ & $\mathrm{Na}^{+}=1.540$ \\
Sodium Phosphate & $0.35 \mathrm{mg} / \mathrm{ml}$ & $\mathrm{Na}^{+}=1.529$ \\
& & $\mathrm{PO}_{4}^{-}=4.947$ \\
Calcium Phosphate & $0.15 \mathrm{mg} / \mathrm{ml}$ & $\mathrm{Ca}^{2+}=1.453$ \\
& & $\mathrm{PO}_{4}^{-}=4.783$ \\
\hline
\end{tabular}

In an attempt to lower the limit of quantitation, the method of Sparidans et al. (Sparidans et al. 1995) was investigated. This group adapted the original ion chromatography method by adding copper (II) nitrate to the mobile phase and altering the UV detection wavelength to $245 \mathrm{~nm}$ to obtain the best signal-to-noise ratio. In aqueous solutions, bisphosphonates and copper form soluble UV-absorbing complexes. Sparidans et al. showed that altering the flow rate and the concentrations of nitric acid and copper (II) nitrate could optimize the method for a variety of bisphosphonates similar to alendronate.

This method was adapted by adding $0.5 \mathrm{mM}$ copper (II) nitrate, decreasing the nitric acid concentration to $1 \mathrm{mM}$ and increasing the flow rate to $1.0 \mathrm{ml} /$ minute. This reduced the limit of quantitation to $5 \mu \mathrm{g} / \mathrm{mL}$. A representative chromatogram is shown in Figure 7 . Alendronate eluted at 1.5 minutes, well separated from the injection front ( 0.7 minutes). Copper eluted as a negative peak at 4-5 minutes. The specificity of the copper/ion chromatography method was confirmed by injecting samples containing low concentrations of other common ions. All chromatograms showed peaks for the injection front and copper. No additional peaks were observed for $10 \mathrm{mM}$ sodium chloride or $0.2 \mathrm{mg} / \mathrm{ml}$ potassium chloride solutions. The peak positions and orientations for the following solutions are indicated in brackets: $\mathrm{pH} 6.5$ phosphate buffer (small positive peak at 1.3, large positive peak at 3.5, large negative peak at 7.8 minutes), $5 \mathrm{mM}$ TRIS buffer (positive peak at $3.6 \mathrm{~min}$.), and $\mathrm{Ca}_{5}\left(\mathrm{PO}_{4}\right)_{3} \mathrm{OH}$ (negative peak at $6.7 \mathrm{~min}$.), $2.5 \mathrm{mg} / \mathrm{ml}$ collagen (large negative peak at 13 minutes), $\mathrm{pH} 7.4$ phosphate buffered saline 
(large positive peak at injection front, large positive peak at 4 minutes, very large negative peak at 15-22 minutes). Hence the method was specific for alendronate in the presence of low concentrations of other ions.

However, when this method was used in drug release studies where the concentration of alendronate was low and the concentration of buffer ions, especially saline, was high, the anion exchange column was overwhelmed (Figure 17). The loss of resolution between the alendronate and chlorine peaks increased the limit of detection and decreased the precision to unacceptable levels.

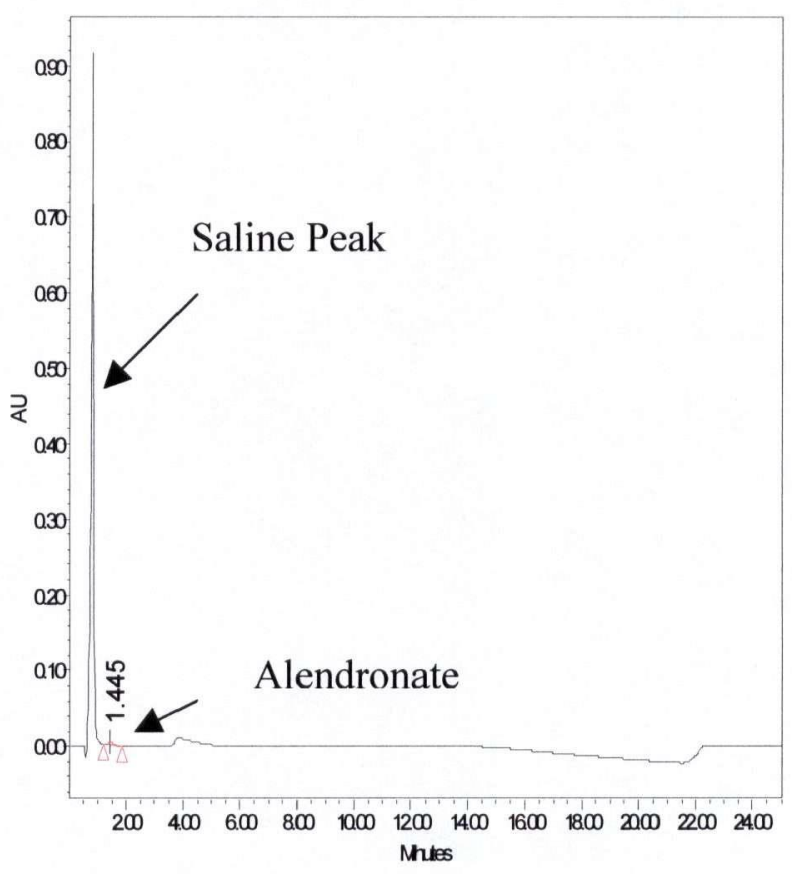

Figure 17 Chromatogram of Alendronate in PBS by Ion Chromatography. Mobile phase: $0.5 \mathrm{mM}$ copper (II) nitrate, $1.0 \mathrm{mM}$ nitric acid, flow rate: $1.0 \mathrm{ml} /$ minute, injection volume $20 \mu \mathrm{l}$, detection by UV-Vis at $245 \mathrm{~nm}$.

The ion chromatography method was useful for samples dissolved in simple matrices, such as the alendronate-coated tantalum samples prepared by Dr. Rizhi Wang's groups at the UBC Department of Metals and Materials Engineering. No sample preparation was required, the materials and equipment were commonly available, and the run time was only 6 minutes. However, the interference by PBS meant that another analytical method was required in order to perform drug release studies. 


\subsubsection{Other methods}

In order to overcome the interference of PBS, the ion chromatography system was coupled to an electrospray mass detector in the negative ionization mode was attempted (Qin et al. 1994). The mobile phase was composed of 5\% acetonitrile, 95\% water, and $0.2 \%$ formic acid at a flow rate of $1.0 \mathrm{ml} / \mathrm{minute}$ with the same column from the previous ion chromatography experiments (IC-Pak ${ }^{\mathrm{TM}}$ Anion-HR column). The parent peak $(\mathrm{m} / \mathrm{z}=$ 248 , formula weight minus 3 waters of hydration, sodium and a proton) was observed at $\sim 4.5$ minutes. Low peak areas were resolved by increasing the injection volume from 10 to $200 \mu \mathrm{l}$. However, a set of alendronate standards diluted in PBS had poor peak shapes indicating that a large fraction of the alendronate was not retained on the column. The mass spectrometry method was not pursued further.

The other published HPLC methods (DeMarco J.D. et al. 1989;Kwong et al. 1990;Kline and Matuszewski 1992;King and Vieth 1996;Sparidans et al. 1997;Sparidans et al. 1998; Ptacek et al. 2002) involved uncommon laboratory equipment such as on-line, precolumn or post-column derivatization apparatus or conductivity detectors. Automation of the derivatization process was essential for accuracy and reproducibility because some of these derivatized bisphosphonate compounds were unstable with respect to time. There were also reports of gas chromatographic methods (Sakiyama et al. 1996;Muntoni et al. 2004) or gas chromatography coupled to a mass spectrometer for detection (Leis et al. 2004; Endele et al. 2005). Finally, there have been 2 publications in which inductively coupled plasma was used to detect phosphorus in the bisphosphonate, either in solutions (Reed et al. 1995), or after separation on an ion exchange column (Kovacevic et al. 2004) A less elaborate method was considered optimal.

\subsubsection{Alendronate Analysis by Fluorescence HPLC}

The next analytical approach involved derivatizing the amino group on the drug with a fluorescent tag molecule which could then be analyzed by reverse-phase HPLC. A previously published method for the analysis of pamidronate in biological samples using fluorescamine as the fluorescent tag was adapted (Flesch and Hauffe 1989;Flesch et al. 1991; Wong et al. 2004; Weidenauer et al. 2004). Both pamidronate and alendronate have an amino group on the $\mathrm{R}_{2}$ side group that can be readily derivatized with fluorescamine. The protein precipitation, calcium precipitation, and solid phase extraction steps common to many of the methods that were originally intended for plasma and urine samples were omitted. Briefly, the alendronate sample was diluted in an EDTA buffer at $\mathrm{pH} 10$. A solution of fluorescamine in acetonitrile was added and reacted with the alendronate amino group within seconds, as shown in Figure 18. 


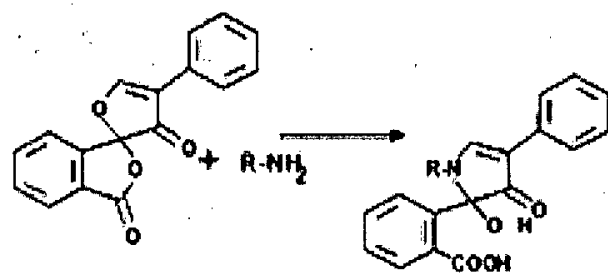

Fluorescamine

Fluorophore

Figure 18 Reaction of fluorescamine with an amino group creating a fluorescent fluorophore

The acetonitrile was extracted with dichloromethane and the aqueous layer was withdrawn for HLPC analysis with fluorescence detection. It was found that changes could be made from the published methods such as: altering the volumes and concentrations of EDTA buffer and fluorescamine, and omitting the centrifugation step separating the organic and aqueous layers, due to the comparative simplicity of the samples.

A summary of the validation results for the fluorescence method are shown in Table 7. The supporting data are discussed in detail in the following sections. The validation parameters have been taken from the ICH Harmonized Tripartite Guideline Q2B: Validation of Analytical Procedures: Methodology (International Conference on Harmonization 1996).

The linear range was very broad $(1-2000 \mu \mathrm{g} / \mathrm{mL})$, and the limit of quantitation was sufficiently low enough for drug release studies. More importantly, the method was specific for alendronate in the presence of PBS. It was therefore deemed suitable for determining alendronate in drug release studies. 
Table 7 Method Validation Data for Fluorescence HPLC Analysis of Alendronate

\begin{tabular}{|c|c|}
\hline Validation Characteristic & Result $^{\mathrm{a}}$ \\
\hline Specificity & $\begin{array}{l}\text { Specific for alendronate in the presence of PBS, PLGA, } \\
\text { diblock } \\
\text { Not specific in the presence of TRIS and chitosan }\end{array}$ \\
\hline Linearity & Typical equation: $y=7 \times 10^{6} \mathrm{x}+2000, \mathrm{R}^{2}=0.999$ \\
\hline Range & $0.5-2000 \mu \mathrm{g} / \mathrm{mL}$ \\
\hline Accuracy & $90-101 \%$ \\
\hline $\begin{array}{l}\text { Precision } \\
\text { Repeatability } \\
\text { Inter-day precision }\end{array}$ & $\begin{array}{l}\mathrm{RSD}=0.9 \%(\mathrm{n}=6,10 \mu \mathrm{g} / \mathrm{mL}) \\
\mathrm{RSD}=5.0 \%(3 \text { days, } 10 \mu \mathrm{g} / \mathrm{mL})\end{array}$ \\
\hline Detection limit & $0.2 \mu \mathrm{g} / \mathrm{mL}$ (based on $3 \mathrm{X}$ signal to noise ratio) \\
\hline Quantitation limit & $0.5 \mu \mathrm{g} / \mathrm{mL}(\mathrm{RSD}<2 \%)$ \\
\hline Robustness & $\begin{array}{l}\text { The following adjustments to the HPLC mobile phase } \\
\text { did not change the size or position of the alendronate } \\
\text { peak: } \\
5 \text { or } 10 \% \text { methanol } \\
3 \% \text { acetonitrile } \\
\text { pH lowered to } 5.3\end{array}$ \\
\hline
\end{tabular}

\subsubsection{Specificity}

The International Conference on Harmonization defines specificity as "the ability to assess unequivocally the analyte in the presence of components which may be expected to be present. Typically these might include impurities, degradants, matrix, etc." Fluorescence HPLC is an inherently specific method. The excitation wavelength of $395 \mathrm{~nm}$ and the emission wavelength of $480 \mathrm{~nm}$ exclude interference from most common solvents and organic impurities, which absorb below $300 \mathrm{~nm}$. In addition, reverse-phase chromatography will separate an impurity that does have the same excitation/emission profile.

Typical chromatograms had only two peaks, as shown in Figure 9, the analyte eluting at $\sim 3.5$ minutes and the unreacted fluorescamine at $\sim 10$ minutes. Common buffers such as 
phosphate buffered saline had no effect on the chromatographic profile. However, substances that contain an amino group (i.e., TRIS buffer, chitosan) that could be derivatized by fluorescamine are potential impurities. In small quantities, they would show up as additional peaks on the chromatogram. In large quantities, they will compete with alendronate to react with the fluorescamine, despite being well resolved from the alendronate peak. Therefore, the method was not specific for alendronate in the presence of TRIS or chitosan.

\subsubsection{Linearity}

A linear relationship between the concentration of standard alendronate and the alendronate peak area was demonstrated over the extended linear range of 0.5 to $2000 \mu \mathrm{g} / \mathrm{ml}$, as shown in Table 8 and Figure 19. Under routine analysis conditions ( 0.5 to $10 \mu \mathrm{g} / \mathrm{ml})$ the coefficient of determination $\left(\mathrm{R}^{2}\right)$ was generally $>0.999$, and a typical equation was $\mathrm{y}=7451565+1449 x$.

Table 8 Linearity of Alendronate Response by Fluorescence HPLC

\begin{tabular}{|c|c|c|c|c|c|}
\hline \multirow{2}{*}{$\begin{array}{l}\text { Standard } \\
\text { Alendronate } \\
(\mu \mathrm{g} / \mathrm{ml})\end{array}$} & \multicolumn{3}{|c|}{ HPLC Response (Absorbance Units) } & \multirow{2}{*}{$\begin{array}{r}\text { Mean } \\
\text { HPLC } \\
\text { Response }\end{array}$} & \multirow{2}{*}{$\begin{array}{c}\text { RSD }^{2} \\
(\%)\end{array}$} \\
\hline & Replicate 1 & Replicate 2 & Replicate 3 & & \\
\hline 0.1 & 3676 & 3466 & 3277 & 3473 & 5.7 \\
\hline 0.2 & 3723 & 3603 & 3815 & 3714 & 2.9 \\
\hline 0.5 & 5709 & 5687 & 5617 & 5671 & 0.8 \\
\hline 1.0 & 9848 & 9866 & 9865 & 9860 & 0.1 \\
\hline 5.0 & 33607 & 33674 & 33843 & 33708 & 0.4 \\
\hline 10 & 66275 & 66627 & 66836 & 66579 & 0.4 \\
\hline 50 & 418270 & 418269 & 419707 & 418749 & 0.2 \\
\hline 100 & 838029 & 840921 & 838687 & 839212 & 0.2 \\
\hline 500 & 4192424 & 4184897 & 4193570 & 4190297 & 0.1 \\
\hline 1000 & 7956390 & 8006906 & 8023749 & 7995682 & 0.4 \\
\hline 1500 & 11310551 & 11136838 & 11162489 & 11203293 & 0.8 \\
\hline 2000 & 13744836 & 13486590 & 13422757 & 13551394 & 1.3 \\
\hline
\end{tabular}


A)

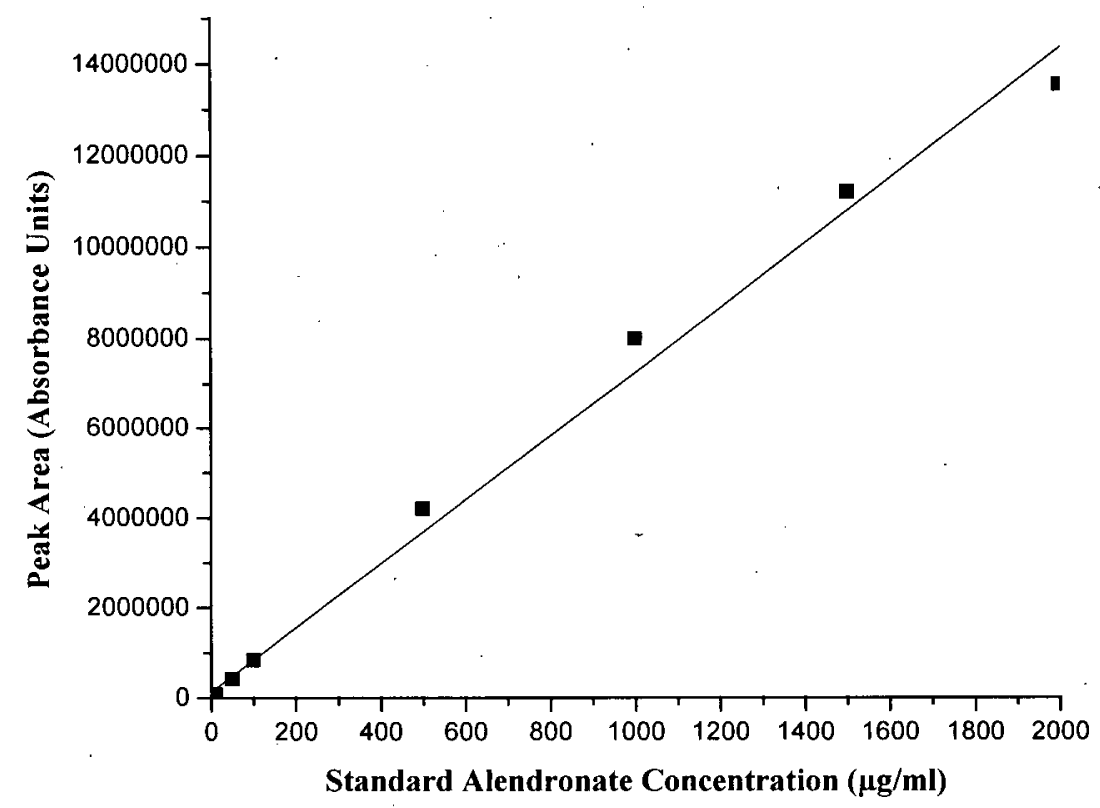

B)

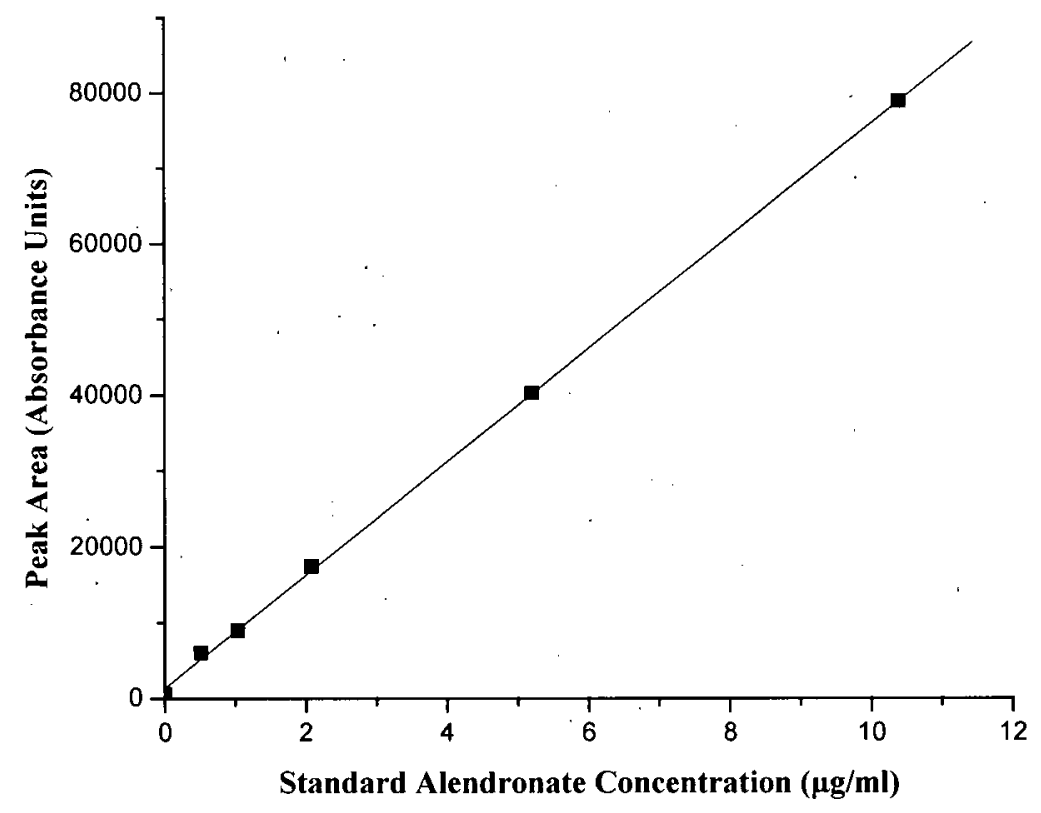

Figure 19 Linearity of fluorescence HPLC standard curve for sodium alendronate standard solutions with concentrations of A) 0.5 to $2000 \mu \mathrm{g} / \mathrm{ml}$ $\left(\mathrm{R}^{2}=0.9936\right)$ or $\left.\mathrm{B}\right) 0$ to $10 \mu \mathrm{g} / \mathrm{ml}\left(\mathrm{R}^{2}=0.9996\right)$. Mobile phase $97: 31 \mathrm{mM}$ EDTA(pH 6.5):Methanol, $1 \mathrm{ml} / \mathrm{min} ., 25 \mathrm{~cm} \mathrm{C18}$ column, $\lambda_{\mathrm{ex}}=395 \mathrm{~nm}$, $\lambda_{\mathrm{em}}=480 \mathrm{~nm}$. 


\subsubsection{Accuracy}

Accuracy is the extent to which the test results represent the true value (International Conference on Harmonization 1996). The ICH recommends "Accuracy should be reported as percent recovery by the assay of known added amount of analyte in the sample or as the difference between the mean and the accepted true value together with the confidence intervals." The accuracy of the fluorescence method was assessed by comparing the result for a series of alendronate standards prepared from pure sodium alendronate trihydrate (Sigma, St. Louis, MO) with the results obtained from the working alendronate standards prepared from material donated by Dr. Wang, shown in Table 9. The concentration of the lower reference standards $(0.5$ to $100 \mu \mathrm{g} / \mathrm{ml})$ was calculated using the working standards in the same (lower) concentration range, because the high standards distorted the intercept. A similar practice of using standards no greater than 10 times more concentrated than the samples was employed during subsequent drug release studies.

Table 9 Accuracy of Fluorescence HPLC Method for Determination of Alendronate

\begin{tabular}{|c|c|c|}
\hline $\begin{array}{l}\text { Expected Alendronate } \\
\text { Concentration }(\mu \mathrm{g} / \mathrm{ml})\end{array}$ & $\begin{array}{c}\text { Observed Alendronate Concentration } \\
\text { Mean }\left(\operatorname{RSD}^{\mathrm{a}}, \mathrm{n}=3\right)(\mu \mathrm{g} / \mathrm{ml})\end{array}$ & \% Recovery \\
\hline 0.5 & $(5.9 \%)$ & $90 \%$ \\
\hline 1.0 & $(1.7 \%)$ & $93 \%$ \\
\hline 10 & $(0.3 \%)$ & $95 \%$ \\
\hline 100 & $(0.3 \%)$ & $99 \%$ \\
\hline 1000 & $(0.3 \%)$ & $101 \%$ \\
\hline 2000 & $(0.1 \%)$ & $99 \%$ \\
\hline
\end{tabular}

The recovery data demonstrated that the method was accurate to within $10 \%$ of the expected value down to a concentration of $0.5 \mu \mathrm{g} / \mathrm{ml}$. As expected, the accuracy decreased as the lower limit of quantitation was approached.

\subsubsection{Precision}

Precision is the measure of the degree of repeatability of an analytical method under normal operation and is normally expressed as the percent relative standard deviation for a statistically significant number of samples. 
Repeatability or, inter-assay precision, should be determined from a minimum of nine determinations covering the specified range of the procedure or from a minimum of six determinations at $100 \%$ of the test or target concentration. At a concentration of $10 \mu \mathrm{g} / \mathrm{ml}$, the RSD of 6 determinations was $0.9 \%$. The repeatability results at other concentrations are reported in Table 8, and range from 0.1 to $5.7 \%$ RSD based on 3 determinations at each concentration. Adequate repeatability $(<2.0 \%)$ was observed at all but the 2 lowest concentrations.

Intermediate precision is the variation in results from within the same laboratory due to random events such as different days, analysts, equipment, etc. The inter-day precision is shown in Table 10. Standard alendronate samples at 5 typical concentrations were analyzed in triplicate on 3 separate days. The relative standard deviations of the daily and overall mean peak area were at or below $5.0 \%$.

Table 10 Inter-Day Precision of Fluorescence HPLC Method for Determination of Alendronate

\begin{tabular}{|c|c|c|c|c|c|c|c|c|}
\hline \multirow{2}{*}{$\begin{array}{l}\text { Alendronate } \\
\text { Conc. } \\
(\mu g / m l)\end{array}$} & \multicolumn{2}{|c|}{ Day 1} & \multicolumn{2}{|c|}{ Day 2} & \multicolumn{2}{|c|}{ Day 3} & \multicolumn{2}{|c|}{ All Days } \\
\hline & $\begin{array}{l}\text { Peak } \\
\text { Area }\end{array}$ & $\begin{array}{c}\text { RSD }^{a} \\
(\%)\end{array}$ & $\begin{array}{l}\text { Peak } \\
\text { Area }\end{array}$ & $\begin{array}{c}\text { RSD }^{\mathrm{a}} \\
(\%)\end{array}$ & $\begin{array}{l}\text { Peak } \\
\text { Area }\end{array}$ & $\begin{array}{c}\text { RSD }^{\mathrm{a}} \\
(\%)\end{array}$ & $\begin{array}{c}\text { Peak } \\
\text { Area }\end{array}$ & $\begin{array}{c}\text { RSD }^{a} \\
(\%)\end{array}$ \\
\hline 5.2 & 44294 & 0.4 & 47158 & 1.2 & 48898 & 0.5 & 46783 & 5.0 \\
\hline 10.4 & 82473 & 0.3 & 89843 & 0.3 & 82494 & 0.3 & 84937 & 5.0 \\
\hline 20.8 & 177046 & 0.1 & 179602 & 0.2 & 164987 & 0.3 & 173878 & 4.5 \\
\hline 52 & 431705 & 0.1 . & 428098 & 0.3 & 418257 & 0.2 & 426020 & 1.6 \\
\hline 104 & 849814 & 0.1 & 858425 & 0.2 & 844557 & 0.2 & 850932 & 0.8 \\
\hline
\end{tabular}

${ }^{a} \mathrm{RSD}=$ Relative standard deviation (standard deviation/mean $\times 100$ )

During the course of the experiments, 3 different $\mathrm{C}_{18}$ columns were used. No difference in the linear range was observed as a result of changing columns.

\subsubsection{Detection Limit and Quantitation Limit}

The limit of detection for alendronate was $0.2 \mu \mathrm{g} / \mathrm{ml}$ based on a signal-to-noise ratio of $3: 1$. The limit of quantitation was $0.5 \mu \mathrm{g} / \mathrm{ml}$ based on acceptable accuracy and linearity.

\subsubsection{Range}

The range of the assay, derived from the precision, accuracy and linearity experiments, was 0.5 to $2000 \mu \mathrm{g} / \mathrm{ml}$. 


\subsubsection{Robustness}

ICH defines robustness as "The reliability of the analysis with respect to deliberate variations in method parameters." The robustness of the method with respect to composition of the mobile phase, the sample vials and sample solution stability was examined.

The HPLC mobile phase normally contains 97\% EDTA buffer ( $\mathrm{pH}$ 6.5) and 3\% methanol. The following adjustments to the composition of the mobile phase did not change the size or position of the alendronate peak: 5 or $10 \%$ methanol, $3 \%$ acetonitrile, $3 \%$ tetrahydrofuran, or $\mathrm{pH}$ lowered to 5.3 . The position of the unreacted fluorescamine shifted \pm 2 minutes.

Samples must be prepared in glass rather than plastic vials. The organic solvents in the sample preparation steps can extract impurities that increase noise of the baseline.

The sample solution stability was determined by observing the peak area of standard alendronate solutions analyzed after 24 hours. The recovery ranged from $99 \%$ to $139 \%$ at the lowest concentration. The concentrations tended to be higher than expected likely due to evaporation of the solvent.

\section{Table 11 Sample Solution Stability of Fluorescence HPLC Method for Determination of Alendronate}

\begin{tabular}{|c|c|c|c|c|c|c|}
\hline \multirow{2}{*}{$\begin{array}{l}\text { Alendronate } \\
\text { Conc. } \\
(\mu \mathrm{g} / \mathrm{ml})\end{array}$} & \multicolumn{2}{|c|}{ Initial } & \multicolumn{2}{|c|}{ After 24 hours } & \multirow{2}{*}{$\begin{array}{l}\text { Observed } \\
\text { Concentration } \\
(\mathrm{mg} / \mathrm{ml})\end{array}$} & \multirow[b]{2}{*}{$\begin{array}{c}\text { Recovery } \\
(\%)\end{array}$} \\
\hline & $\begin{array}{c}\text { Peak } \\
\text { Area }\end{array}$ & $\begin{array}{c}\mathbf{R S D}^{\mathrm{a}} \\
(\%)\end{array}$ & $\begin{array}{l}\text { Peak } \\
\text { Area } \\
\end{array}$ & $\begin{array}{c}\mathbf{R S D}^{\mathrm{a}} \\
(\%)\end{array}$ & & \\
\hline 0.5 & 5279 & $0.7 \%$ & 6374 & $6.4 \%$ & 0.7 & $139 \%$ \\
\hline 1.04 & 9001 & $0.5 \%$ & 10024 & $0.4 \%$ & 1.2 & $111 \%$ \\
\hline 2.08 & 17753 & $0.2 \%$ & 18739 & $1.2 \%$ & 2.6 & $109 \%$ \\
\hline 5.2 & 41474 & $0: 1 \%$ & 41800 & $0.4 \%$ & 5.2 & $99 \%$ \\
\hline 10.4 & 83337. & $0.3 \%$ & 84497 & $0.6 \%$ & 10.6 & $102 \%$ \\
\hline
\end{tabular}

${ }^{\mathrm{a}} \mathrm{RSD}=$ Relative standard deviation (standard deviation/mean $\times 100$ )

The fluorescence HPLC assay for alendronate demonstrated sufficient specificity, linearity, accuracy, and robustness for drug release studies. It was used extensively in the next series of experiments to optimize the drug release rate from various polymer film formulations. 


\subsection{Formulation Development}

Once the analytical method for alendronate was validated, the next objective of the project was to prepare controlled-release formulations of alendronate-loaded polymeric films.

\subsubsection{Preparation and Characterization of Polymer Films}

Three polymers were used in various combinations: PLGA, polyethylene glycol (PEG 600 ) and an amphipathic diblock copolymer of poly(DL-lactic acid-block-methoxy poly(ethylene glycol) (PDLLA-MePEG), referred to in this work as "diblock". The films were cast from polymer solutions made by dissolving the appropriate amount of PLGA, PEG 600 or diblock in a small volume of dichloromethane. The finished films were clear and colorless; at high concentrations $(5 \%$ or $10 \% \mathrm{w} / \mathrm{w}$ alendronate) the drug particles were visible in the films.

\subsubsection{Effect of Processing on Alendronate Powder}

The size of the alendronate particles dispersed in the polymer matrix had an impact on the drug release characteristics. Large particles were more difficult to disperse evenly and could protrude from the film, which would lead to low content uniformity among the films and could cause variability in drug release profiles.

\subsubsection{Surface Morphology}

Sodium alendronate trihydrate solid was obtained from Dr. R. Wang. The mean particle size was $\sim 30 \mu \mathrm{m}$ (range 9-97 $\mu \mathrm{m}$ ). A second sample was ground to a fine powder with a mean particle size of $6 \mu \mathrm{m}$ (range 2-18 $\mu \mathrm{m}$ ). A third sample was lyophilized; it forms a fluffy white cake that was shown to be anhydrous by elemental analysis.

All three samples were examined by scanning electron microscopy (Figure 20). Grinding reduced the particle size and improved particle size uniformity. Lyophilized alendronate resembled fine glassy particles. 
A)

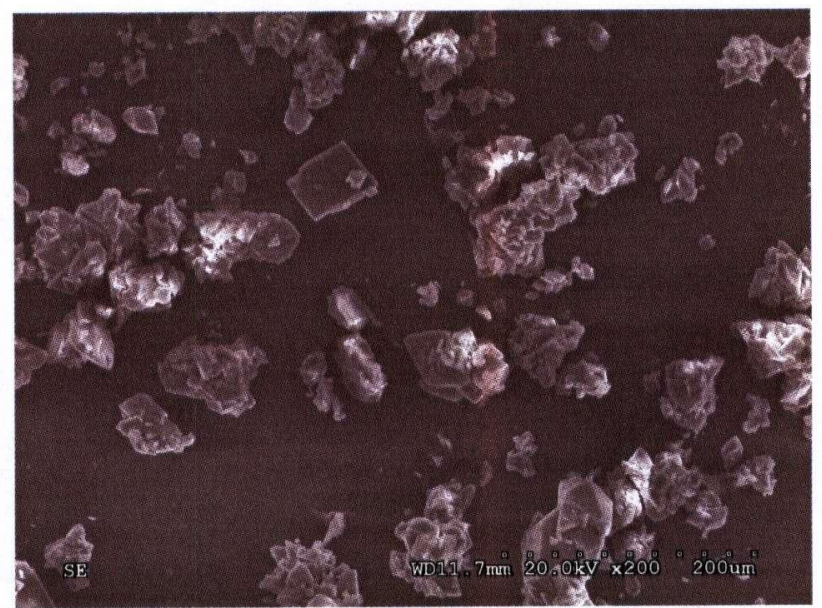

B)

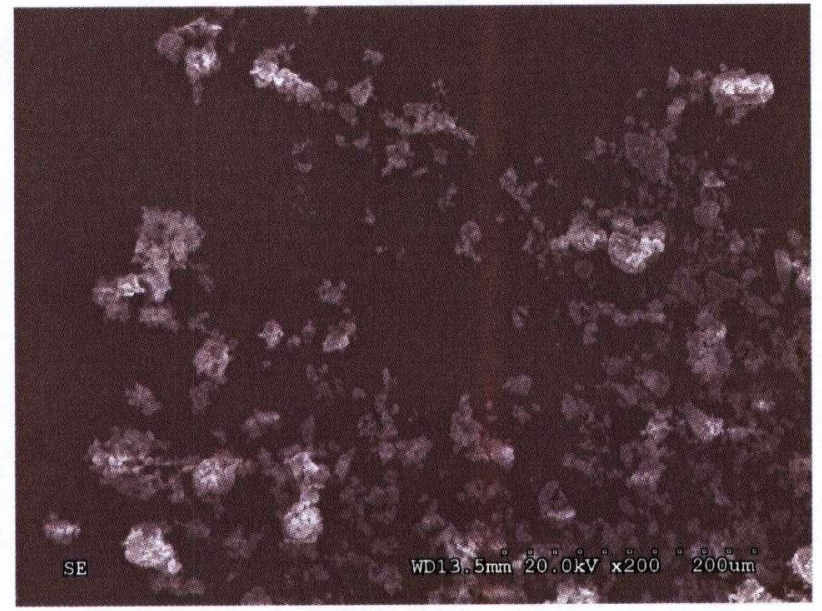

C)

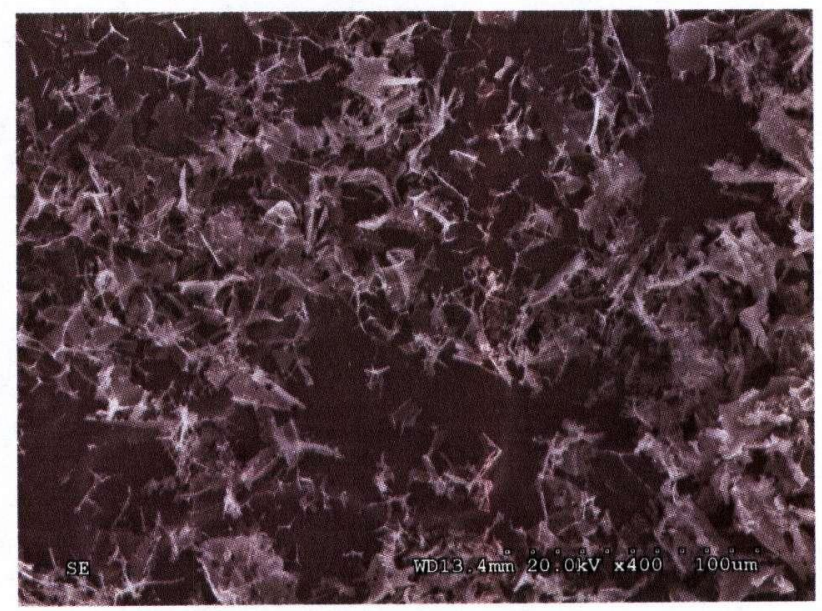

Figure 20 Scanning electron micrographs of sodium alendronate $A$ ) as received (trihydrate), mean particle size $30 \mu \mathrm{m}, \mathrm{B}$ ) ground (trihydrate), mean particle size $6 \mu \mathrm{m}$, C) lyophilized, glassy anhydrous particles. 


\subsubsection{X-Ray Powder Diffraction}

The 3 samples were examined by X-ray powder diffraction (Figure 21) to determine if the sample processing had an effect on the crystal structure. The as received and ground samples possessed similar diffraction patterns with the exception that the $2 \theta$ peak positions of the as received sample were shifted by $\sim 0.1^{\circ}$. This was likely due to the displacement of the powdered sample above or below the diffraction plane of the sample holder. The peak positions and intensities were in good agreement with the published powder diffraction pattern for sodium alendronate trihydrate (Figure 22) (Vickers 2004). The lyophilized sample, however, had lost all evidence of reflecting planes. The featureless diffractogram indicated that lyophilization rendered alendronate amorphous.

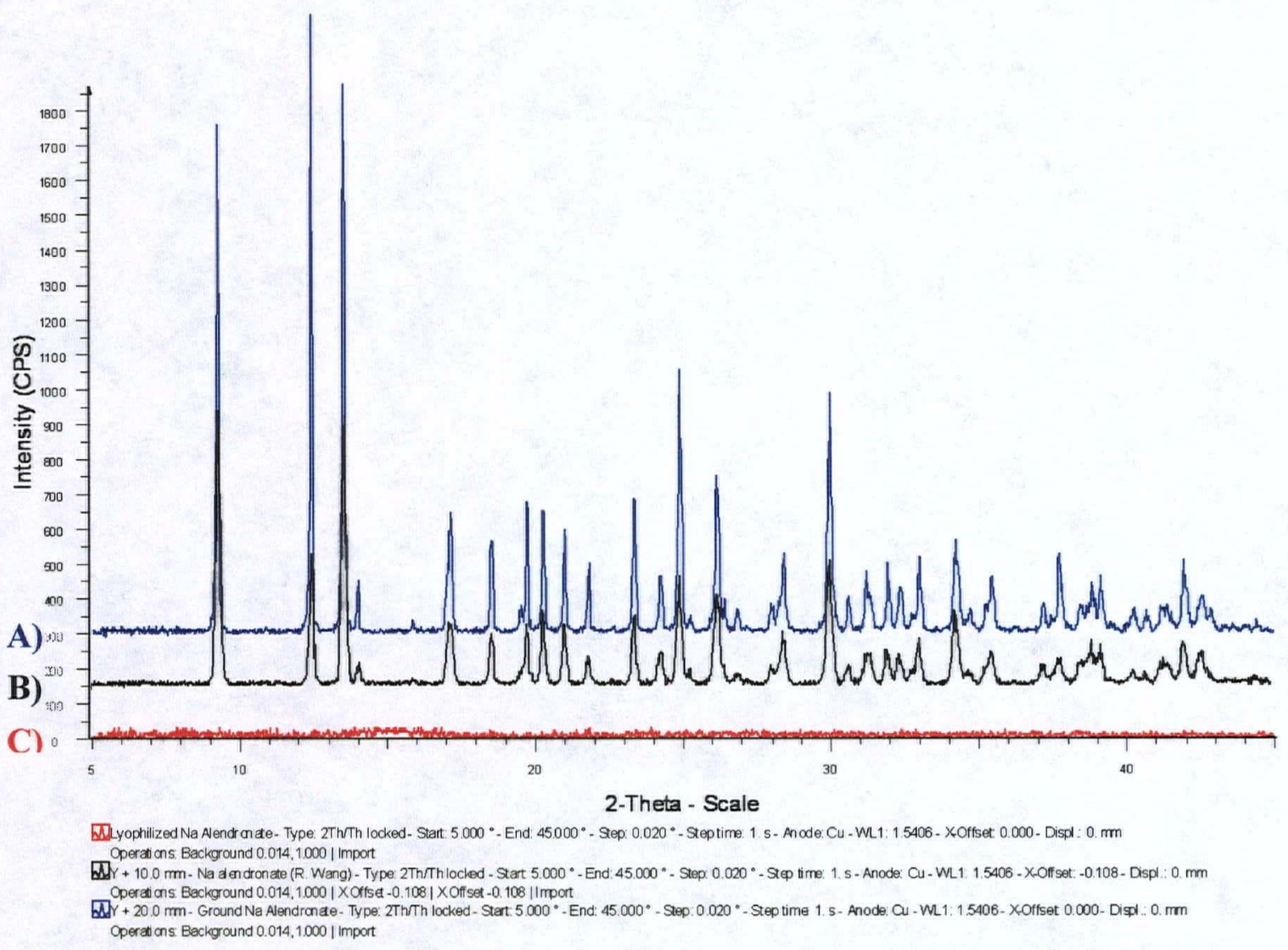

Figure 21 X-Ray Powder Diffraction Patterns of Alendronate A) ground, B) as received and C) lyophilized. 


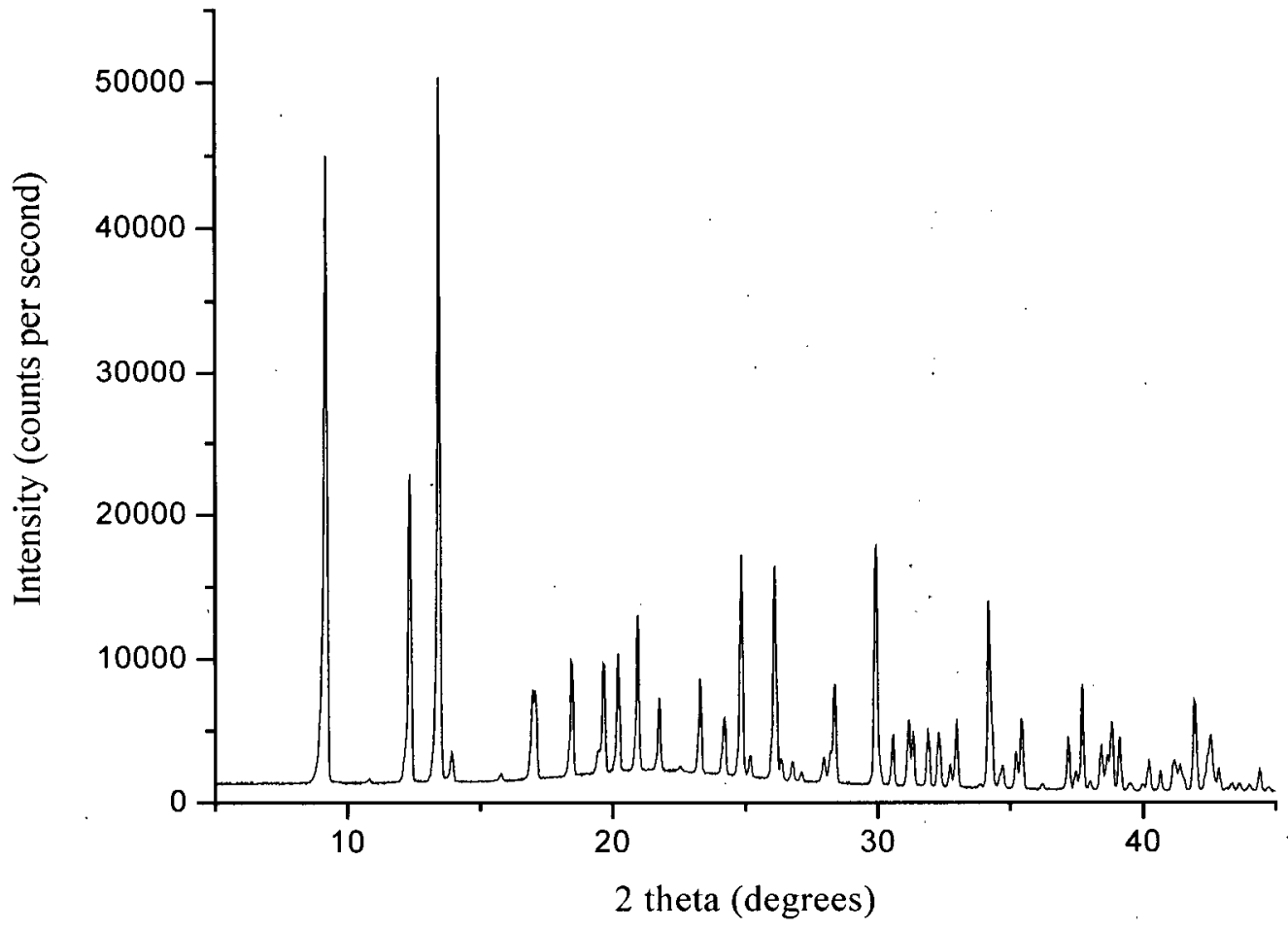

Figure 22 Reference X-Ray Powder Diffraction Pattern of Sodium Alendronate Trihydrate, used with permission (Vickers 2004).

The crystal structure of a single crystal of sodium alendronate trihydrate has also been published (Vega et al. 1996). Using the published fractional atomic coordinates, the peak positions and relative peak intensities of the theoretical powder diffraction pattern were calculated. Table 12 compares the theoretical peak positions and intensities to those of the as received and ground samples. Peaks with relative intensities of less than $5 \%$ have been omitted for clarity.

The table shows excellent agreement between the theoretical peak positions and those of the ground sample. The as received sample also compared favourably, when the $0.1^{\circ} \mathrm{shift}$ due to sample position was taken into account. The differences in the relative peak intensities could be attributed to differences in the preferred particle orientations due to sample packing. 
Table 12 X-Ray Diffraction Peak Positions and Relative Intensities of Theoretical, As Received and Ground Sodium Alendronate Trihydrate

\begin{tabular}{|c|c|c|c|c|c|c|c|}
\hline \multicolumn{2}{|c|}{ Theoretical } & \multicolumn{2}{|c|}{ As Received } & & \multicolumn{3}{|c|}{ Ground } \\
\hline Angle $2 \theta^{\circ}$ & Intensity \% & Angle $2 \theta^{\circ}$ & Intensity \% & & Angle $2 \theta^{\circ}$ & Intensity \% & \\
\hline 9.22 & 100 & 9.35 & 100 & & 9.22 & 82.7 & \\
\hline 12.38 & 41.7 & 12.50 & 47.9 & & 12.38 & 100 & \\
\hline 13.48 & 80.6 & 13.60 & 98.0 & & 13.48 & 88.8 & \\
\hline 13.98 & 6.0 & $14: 10$ & 8.8 & & 13.96 & 9.0 & \\
\hline 17.00 & 7.8 & & & & & & \\
\hline 17.11 & 9.9 & 17.20 & 23.0 & & 17.10 & 19.8 & \\
\hline 17.14 & 6.7 & & & & & & \\
\hline 18.50 & 16.0 & 18.61 & 19.0 & & 18.50 & 15.2 & \\
\hline 19.71 & 16.6 & 19.81 & 22.4 & & 19.72 & 21.4 & \\
\hline 20.25 & 15.8 & 20.34 & 27.5 & & 20.26 & 19.9 & \\
\hline 20.98 & 19.5 & 21.09 & 22.5 & & 20.98 & 17.1 & “ \\
\hline 21.80 & 8.2 & 21.89 & 11.1 & & 21.80 & 11.8 & \\
\hline 23.34 & 20.0 & 23.43 & 24.5 & & 23.34 & 21.9 & \\
\hline 24.26 & 4.2 & 24.35 & $\cdot 12.6$ & & 24.25 & 9.5 & \\
\hline 24.88 & 26.0 & 24.97 & 40.3 & & 24.88 & 42.6 & \\
\hline 24.91 & 7.7 & & & & & & \\
\hline & & 25.35 & 7.0 & & & & \\
\hline 26.14 & 21.8 & 26.25 & 33.2 & & 26.14 & 25.7 & \\
\hline 26.19 & 11.5 & & & & & & \\
\hline 26.41 & 2.5 & & & & 26.41 & 6.5 & \\
\hline 28.00 & 2.9 & 28.10 & 8.2 & & 28.00 & 5.1 & \\
\hline 28.41 & 11.4 & 28.49 & 18.7 & & 28.41 & 13.4 & \\
\hline 29.96 & 35.1 & 30.05 & 46.2 & & 29.96 & 39.1 & \\
\hline 30.61 & 5.6 & 30.70 & 8.6 & & 30.61 & 6.4 & \\
\hline 31.21 & 7.8 & 31.36 & 12.3 & & 31.23 & 8.4 & \\
\hline 31.37 & 6.1 & & & & & & \\
\hline 31.94 & 9.2 & 32.02 & 12.8 & & 31.94 & 11.8 & \\
\hline 32.33 & 4.9 & 32.43 & 11.8 & & 32.34 & 7.7 & \\
\hline 33.01 & 7.6 & 33.09 & 17.5 & & 33.02 & 12.7 & \\
\hline 34.23 & 18.7 & 34.33 & 27.9 & & 34.24 & 15.4 & \\
\hline 34.76 & 2.8 & 34.78 & 6.4 & & 34.71 & 4.3 & \\
\hline 35.46 & 10.3 & 35.55 & 13.2 & & 35.45 & 9.4 & \\
\hline 37.23 & 5.1 & 37.28 & 7.9 & & 37.19 & 5.3 & \\
\hline 37.75 & 8.5 & 37.83 & 9.8 & & 37.75 & 13.1 & \\
\hline 38.48 & 2.3 & 38.56 & 8.9 & & 38.48 & 4.9 & \\
\hline 38.86 & 6.0 & 38.92 & 17.1 & & 38.85 & 8.5 & \\
\hline 39.16 & 9.1 & 39.23 & 15.8 & & 39.14 & 9.8 & \\
\hline 40.27 & 2.9 & 40.33 & 6.5 & & 40.27 & 4.5 & \\
\hline 40.69 & 2.7 & 40.76 & 5.7 & & 40.69 & 4.1 & \\
\hline 41.24 & 1.5 & 41.42 & 9.9 & & 41.22 & 4.2 & \\
\hline & & 41.58 & 7.8 & & & & \\
\hline 41.97 & 11.1 & 42.04 & 17.1 & & 41.97 & 12.3 & \\
\hline 42.61 & 4.8 & 42.64 & 11.9 & & 42.57 & 6.5 & \\
\hline
\end{tabular}




\subsubsection{In Vitro Alendronate Release Profiles}

To determine the comparative drug release profiles of the 3 types of alendronate (as received, ground and lyophilized), they were prepared as $10 \%(\mathrm{w} / \mathrm{w})$ drug-loaded PLGA films. The lyophilized form was fluffy and difficult to weigh accurately. The cumulative release profiles are shown in Figure 23.

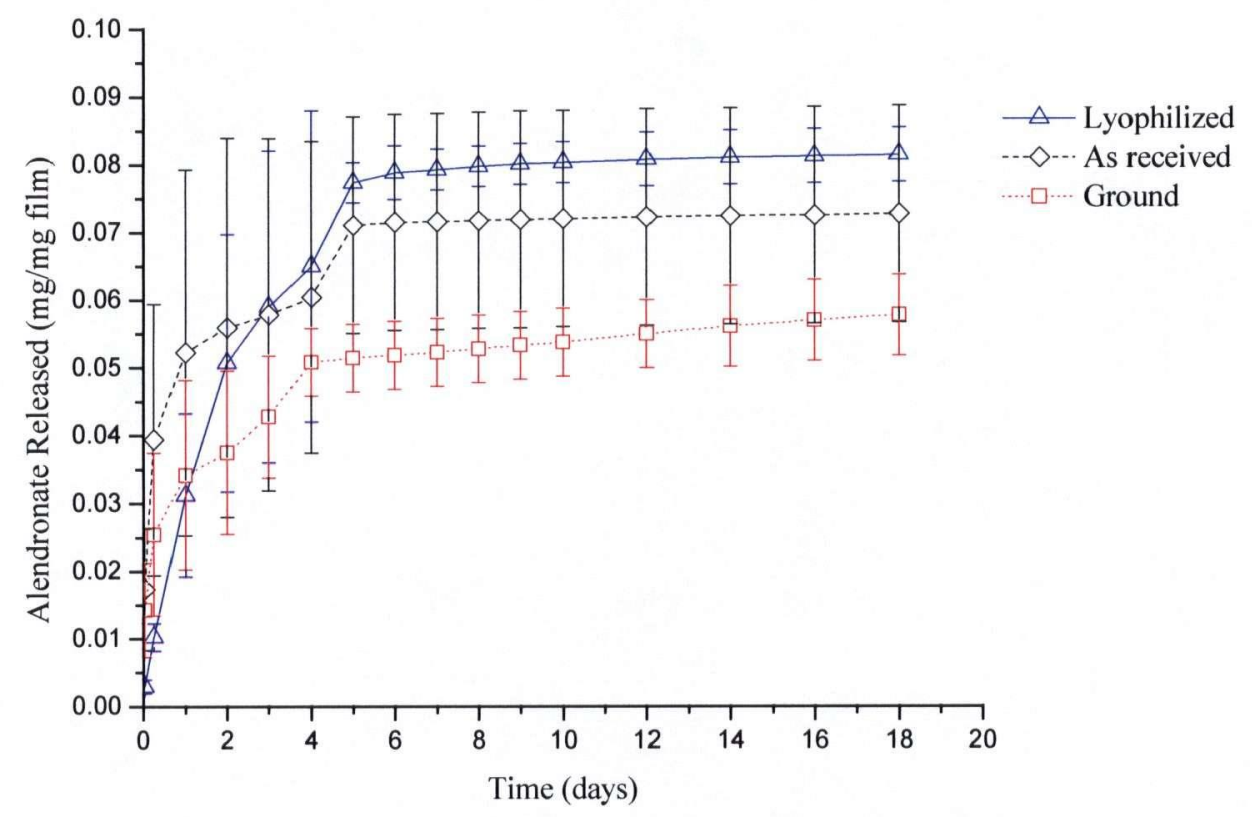

Figure 23 Cumulative Release of Alendronate from 10\% (w/w) drug-loaded 85:15 PLGA films containing: $(\Delta)$ lyophilized, $(\diamond)$ as received and $(\square)$ ground alendronate in PBS at $37^{\circ} \mathrm{C} .0 .1 \mathrm{mg} / \mathrm{mg}$ film represents $100 \%$ theoretical loading. Error bars indicate standard deviation among $n=5$ films of each type.

The films containing lyophilized samples and larger alendronate crystals (as received) showed more rapid rates of drug release than films with ground alendronate. By Day 1, more than $50 \%$ of the theoretical alendronate content had released from the as received sample films; whereas less than $35 \%$ had been released from the ground sample films. Larger particles might be expected to leave larger pores as the drug dissolved then diffused from the films. The large particles may even have protruded from the film surface. The smaller particles were expected to be better dispersed throughout the polymer matrix, and thus released alendronate in a more controlled manner. In previous 
reports of bisphosphonate-loaded polymeric drug delivery systems, reducing particle size led to more controlled drug release characteristics (Perugini et al. 2001; Weidenauer et al. 2004). The lyophilized and as received sample films also showed greater variability among films, as indicated by the size of the error bars (standard deviation).

The loading efficiency of the manufacturing process was determined by measuring the alendronate concentration in films $(n=2$ to 5$)$ prior to in vitro release studies. The loading efficiencies, expressed as percent of the theoretical drug loading $(0.1 \mathrm{mg} / \mathrm{mg}$ film), were: as received $84 \%$, ground $95 \%$ and lyophilized $91 \%$. The different values for total alendronate content in the films was a function of the manufacturing process and the analytical method.

Based on the more consistent nature of the drug release profile and loading efficiency, ground alendronate was selected as the material of choice for future experiments.

\subsubsection{Investigation of Potential Solvate Formation}

The marketed pharmaceutical formulation is sodium alendronate trihydrate; however, both a monohydrate and an anhydrous form have been reported. Since, during the preparation of the polymeric films, alendronate was suspended in dichloromethane, it was possible that solvates might be formed. Hence, a sample of sodium alendronate trihydrate was agitated in dichloromethane for 3 days at $37^{\circ} \mathrm{C}$ and then dried at room temperature for two days. The resulting product was compared to untreated sodium alendronate trihydrate using thermogravimetric analysis and X-ray powder diffraction.

Thermogravimetric analysis (TGA, Figure 24) did not detect any events indicating a loss of solvated dichloromethane. Loss of 3 moles of water was observed at $123^{\circ} \mathrm{C}$ (expected: 16.6\%, observed: $16.4 \%$ ). The onset of decomposition was noted at $256^{\circ} \mathrm{C}$. 
Sample: Sodium Alendronate in DCM

Size: $55.1270 \mathrm{mg}$

TGA

Method: Stepwise isotherma

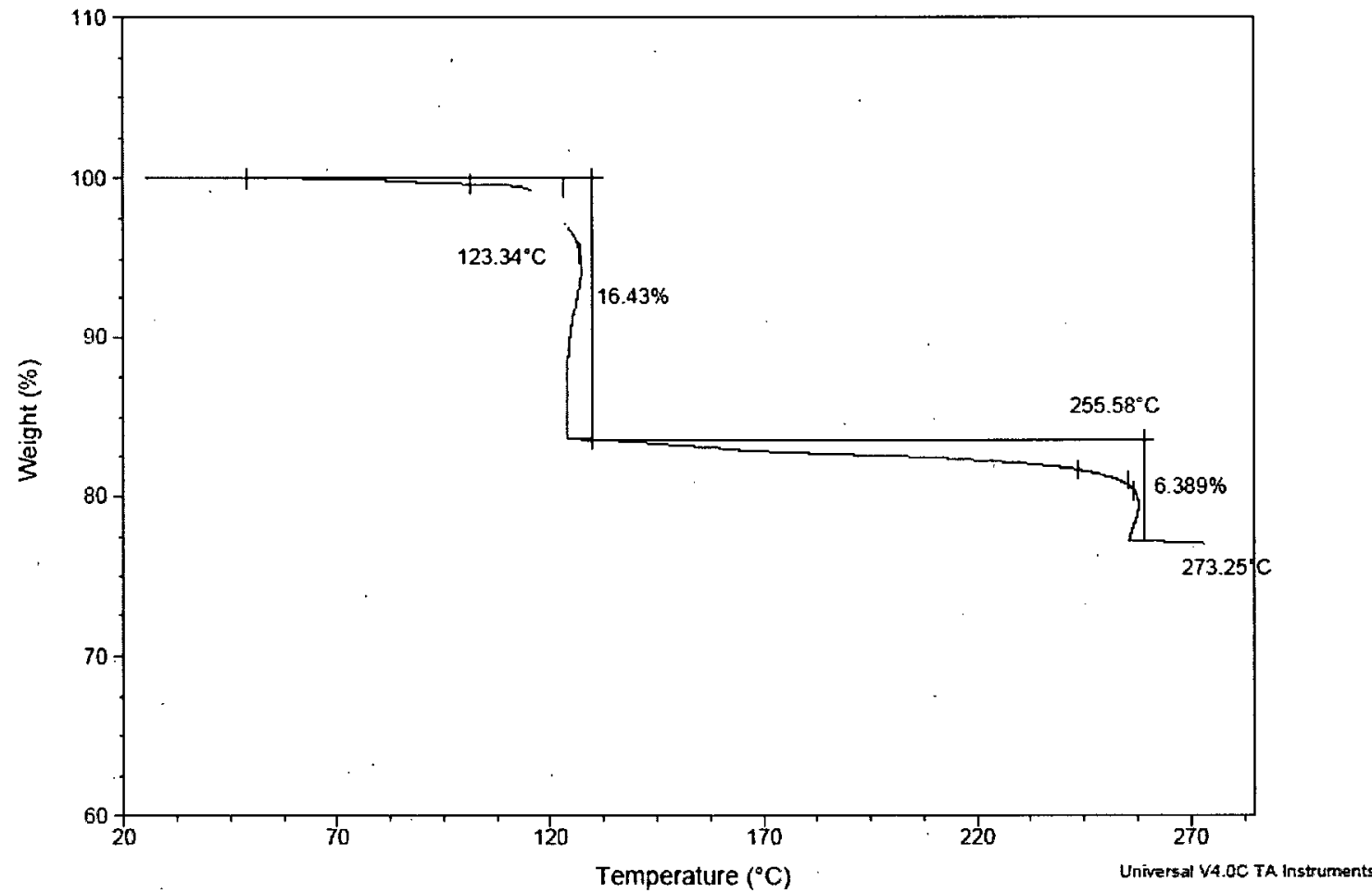

Figure 24 Thermogravimetric analysis of sodium alendronate trihydrate after 3 days in dichloromethane at $37^{\circ} \mathrm{C}$. The temperature ramp rate $=20^{\circ} \mathrm{C} /$ minute, unless a weight change of $>1.00 \% / \mathrm{min}$. was detected, in which case the temperature was held isothermal.

The X-ray powder diffraction (XRD) patterns of as received and dichloromethane-treated alendronate are shown in Figure 25. 


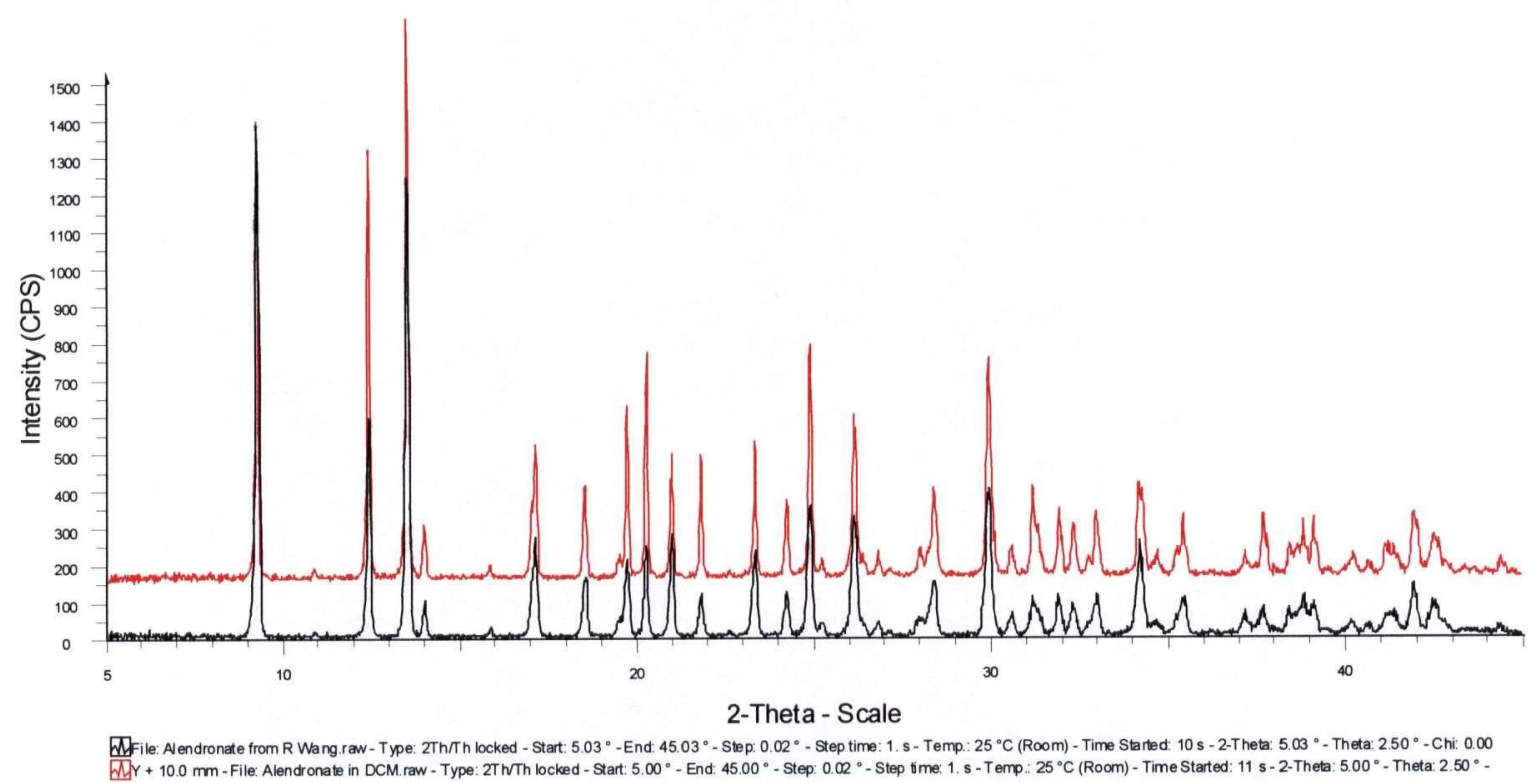

Figure 25 X-ray powder diffraction pattern of sodium alendronate trihydrate as received (black) and after 3 days in dichloromethane at $37^{\circ} \mathrm{C}$ (red).

The peak positions and intensities compared favourably with those observed in the first powder diffraction patterns (Figure 21) and with the published powder diffraction pattern (Figure 22). There were no new peaks or shifts in the diffraction pattern to indicate a difference in crystal structure that might be expected if a new solvate were formed.

The absence of a dichloromethane solvate was almost certainly related to the lack of lipophilic groups on alendronate.

\subsubsection{Effect of Polyethylene Glycol}

The rate of drug release from PLGA films can be modulated by incorporating a second, hydrophilic polymer to form a blend (Jackson et al. 2004;Alexis 2005). Polyethylene glycol (PEG) is a hydrophilic, biocompatible polyether that is widely used in biomedical and cosmetic applications (Fruijtier-Polloth 2005). PEG 600, is a viscous liquid at room temperature, and was selected for incorporation into PLGA.

In preliminary studies, a series of films containing $10 \%$ ground alendronate $(\mathrm{w} / \mathrm{w})$ and a polymer matrix composed of $0 \%, 10 \%, 20 \%$ or $30 \%$ PEG $600(\mathrm{w} / \mathrm{w})$ in PLGA were 
manufactured. Incorporating PEG 600 into PLGA films had a dramatic effect on the drug release profiles. By Day 1, the PLGA only films had released approximately $40 \%$ of their theoretical loaded alendronate content. However, the films containing $10 \%, 20 \%$ and $30 \%$ PEG had released approximately $70 \%, 90 \%$ and $100 \%$ of the loaded alendronate, respectively.

The as received, ground and lyophilized samples of alendronate were manufactured into films composed of $20 \%$ PEG 600 in PLGA, and 10\% alendronate (w/w). The results of the drug release study are shown in Figure 26. The three sample types showed similar trends to those observed in the PLGA-only films (Figure 23), however, there was a marked early burst phase of alendronate release. Almost all of the drug was released within the first 2 days. Ground alendronate showed a slower controlled release profile, probably due to improved dispersion of the alendronate particles throughout the polymer matrix. 


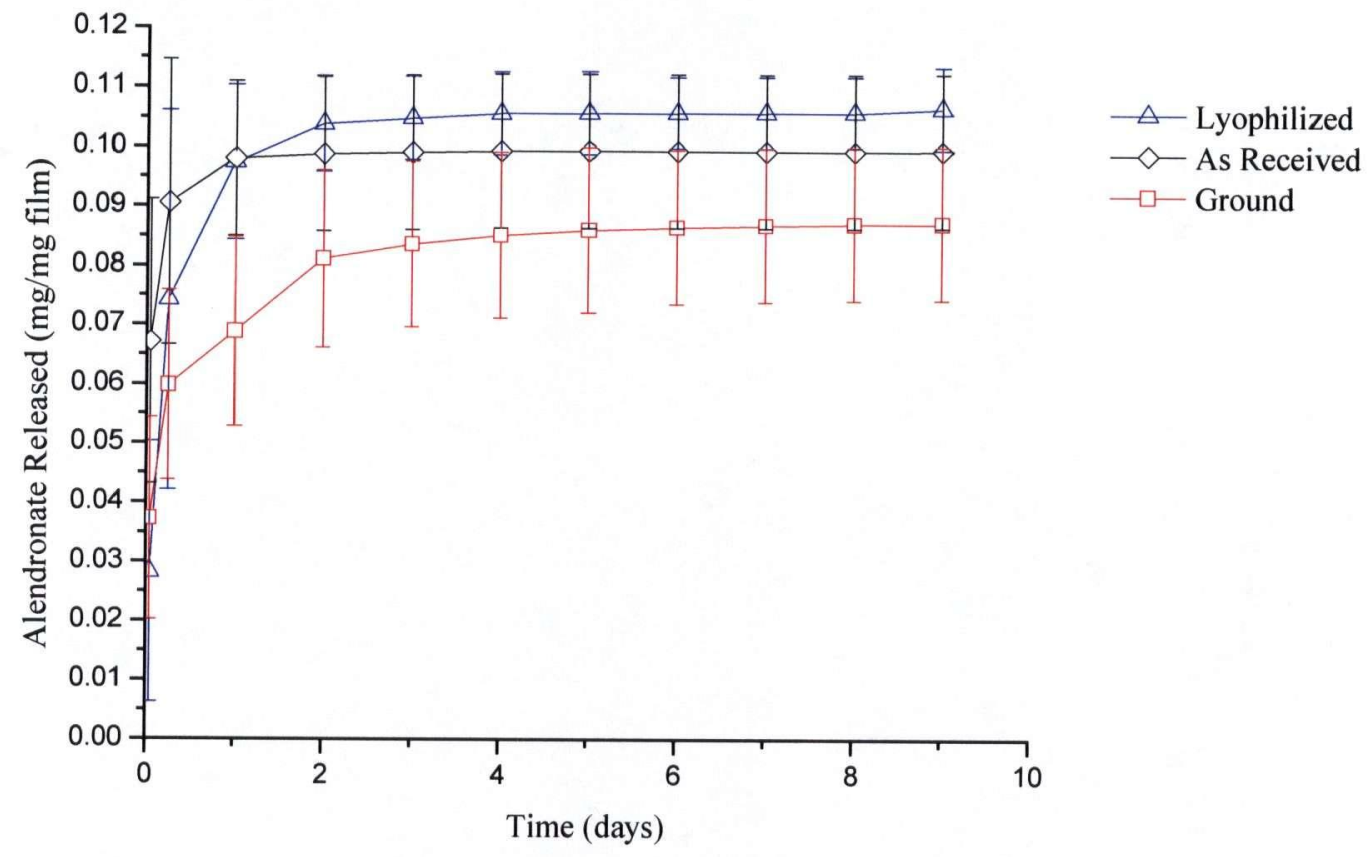

Figure 26 Cumulative release of alendronate from 10\%-drug loaded 20\% PEG 600 in 85:15 PLGA films containing: $(\Delta)$ lyophilized, $(\diamond)$ as received, and () ground alendronate in PBS at $37^{\circ} \mathrm{C} .0 .1 \mathrm{mg} / \mathrm{mg}$ film represents $100 \%$ theoretical loading. Error bars indicate standard deviation among $n=5$ films of each type.

The loading efficiency in the 20\% PEG 600 in PLGA films was determined by measuring the alendronate concentration in films $(n=3$ to 5$)$ prior to the drug release studies. The loading efficiencies, expressed as percent of the theoretical drug loading $(0.1 \mathrm{mg} / \mathrm{mg}$ film), were: as received $76 \%$, ground $83 \%$ and lyophilized $96 \%$. It was likely that the lower loading efficiencies were due to loss of alendronate on the vials during manufacturing.

Incorporating a hydrophilic agent into the PLGA film matrix was intended to increase the solubility of alendronate and provide controlled release over a 2-4 week period. However, the use of PEG 600 led to a very rapid drug release. This was likely due to significant water uptake into the film matrix following rapid release of the water-soluble low molecular weight PEG from the film. This would cause the water-soluble alendronate to dissolve in water-filled pores or channels left by the loss of PEG and be released rapidly 
from the film. Further investigation into other potential release-modulating agents was required.

\subsubsection{Effect of Diblock Copolymer}

Diblock copolymers have been previously used to improve the physical properties and drug-releasing characteristics of PLGA films (Jackson et al. 2004). The cumulative drug release profiles for films containing $5 \%(\mathrm{w} / \mathrm{w})$ alendronate in a polymer matrix composed of $0 \%, 10 \%, 20 \%$ and $30 \%$ diblock copolymer $(w / w)$ in PLGA are shown in Figure 27.

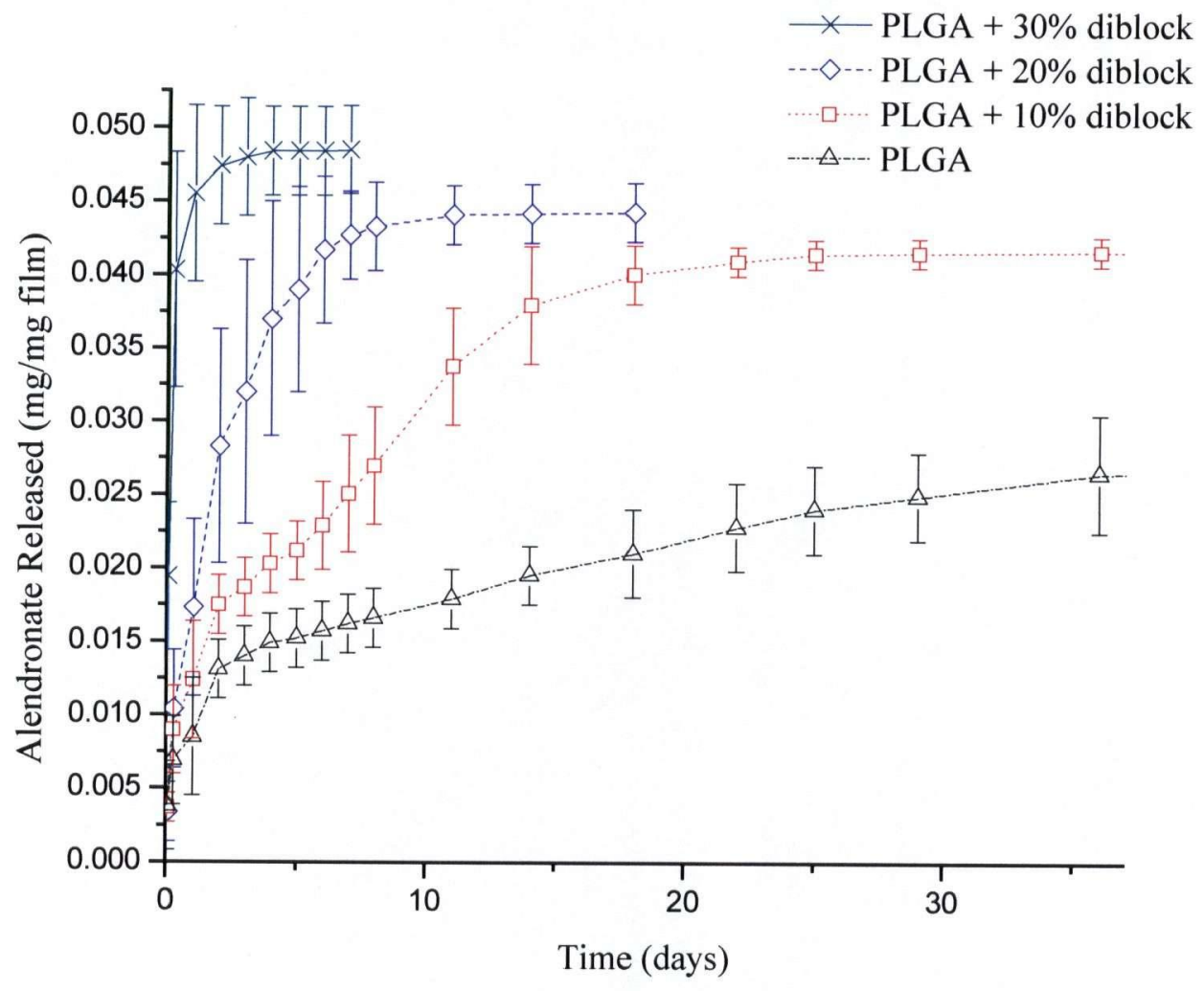

Figure 27 Cumulative release of alendronate from $5 \%(\mathrm{w} / \mathrm{w})$ drug-loaded films composed of 85:15 PLGA and the following amounts of diblock: $(\Delta) 0 \%$, () $10 \%,(\diamond) 20 \%$ or $(\times) 30 \%$ into PBS at $37^{\circ} \mathrm{C} .0 .05 \mathrm{mg} / \mathrm{mg}$ film represents $100 \%$ theoretical loading. Error bars indicate standard deviation among $\mathrm{n}=5$ films of each type.

Increasing the diblock concentration increased the rate of alendronate release. Alendronate release from films composed of $20 \%$ and $30 \%$ diblock in PLGA was 
complete within about 11 and 3 days, respectively. The 10\% diblock in PLGA formulation demonstrated an initial burst of approximately $40 \%$ of the total drug loading in the first 3 days, followed by 2 weeks of controlled drug release. The PLGA-only samples showed a 3-day burst phase followed by slow controlled release.

The sample films were transparent at the beginning of the study, but became swollen and opaque after a day in PBS at $37^{\circ} \mathrm{C}$. The blend of hydrophilic diblock with PLGA likely resulted in greater water penetration into the sample films, causing rapid dissolution of alendronate and subsequent diffusion out of the matrix. Increasing the proportion of diblock in the polymer matrix therefore increased the rate of drug release.

Given the controlled drug release profile and low variability among individual films, $10 \%$ diblock in PLGA was selected as the lead film formulation.

\subsubsection{Mathematical Modeling}

The cumulative drug release data from films composed of various concentrations of blends of diblock in PLGA (Figure 27) were plotted as a function of the square root of time to determine if the drug release kinetics could be described by the Higuchi model, as shown in Equation 3 in Section 2.3.3.1. This mathematical model applies to diffusion controlled drug release. The data are shown in Figure 28. 


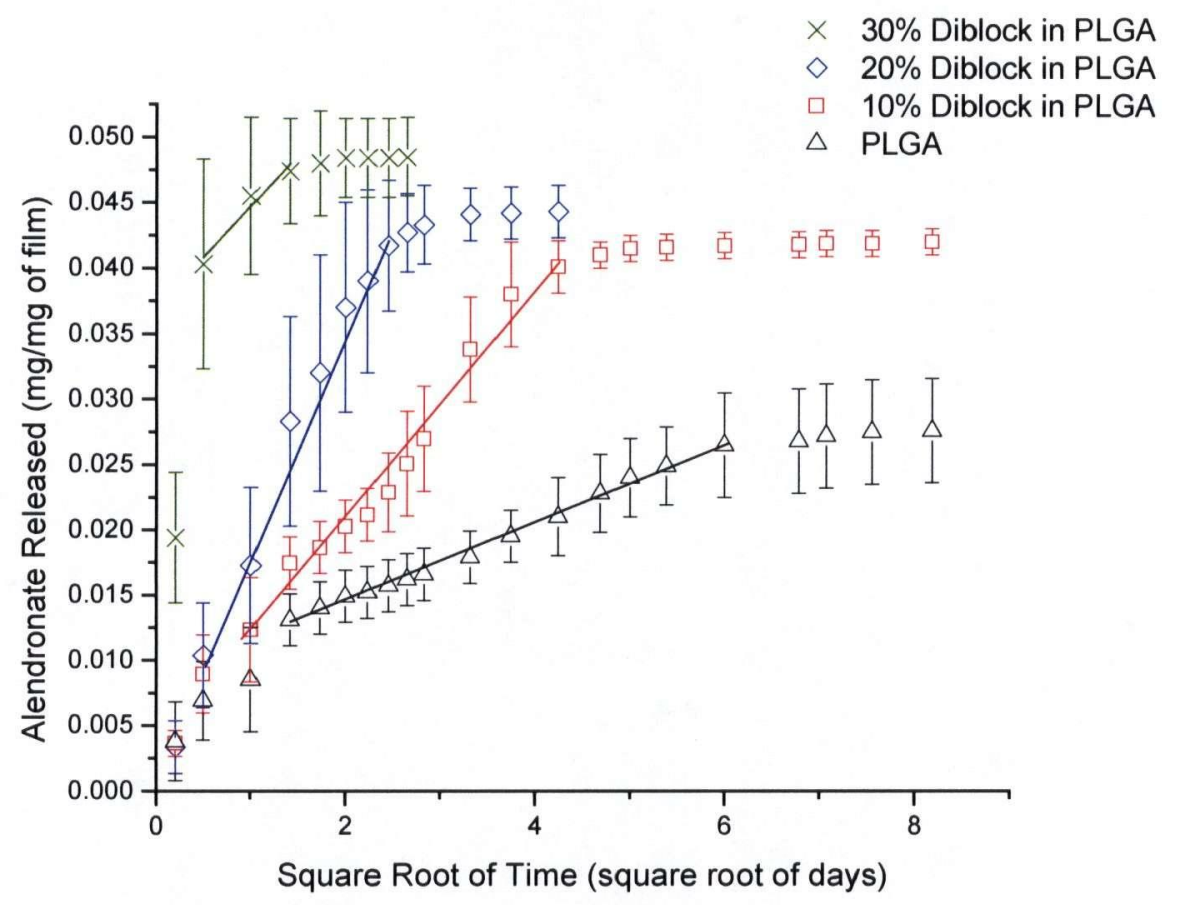

Figure 28 Cumulative release of alendronate as a function of the square root of time from 5\% (w/w) drug-loaded films composed of 85:15 PLGA and the following amounts of diblock: $(\Delta) 0 \%,(\square) 10 \%,(\diamond) 20 \%$ or $(\times) 30 \%$ into PBS at $37^{\circ} \mathrm{C}$. $0.05 \mathrm{mg} / \mathrm{mg}$ film represents $100 \%$ theoretical loading. Error bars indicate standard deviation among $\mathrm{n}=5$ films of each type. Lines shown are linear regressions of the given data points.

For PLGA films with and without diblock, the release of alendronate appeared to follow triphasic release kinetics. The initial burst phase of drug release was likely due to dissolution of the highly hydrophilic alendronate at or near the surface of the films into the medium. This was followed by a phase of drug release that was linear with respect to the square root of time for all films. However, there were differences in the duration of the linear phase for the different compositions. This phase was attributed to diffusioncontrolled release, as predicted by the Higuchi equation. Films composed of PLGA only, showed a linear relationship for a duration of about 34 days $\left(R^{2}=0.995\right)$. For films composed of $30 \%$ diblock, the period of the diffusion-controlled release was very short (less than 1 day, $\mathrm{R}^{2}=0.958$ ). For the $10 \%$ and $20 \%$ diblock in PLGA films, the duration of the diffusion controlled phase of release was about 15 days and 6 days, respectively. 
The third phase of release was much slower and clearly the Higuchi model no longer fits the data $\left(\mathrm{R}^{2}=0.982\right.$ and 0.984 , respectively). The Higuchi model was derived assuming a rate-limiting and nondegradable polymer matrix. For the PLGA-only films, this condition was probably maintained over the first 36 days of release since the PLGA (85:15) polymer has a long degradation lifetime (Alexis 2005). However, for films containing diblock, the GPC data (Figure 11 and Figure 12) showed that both the molecular weight of the diblock copolymer and the ratio of diblock to PLGA were decreasing. This indicated that the diblock was degrading and diffusing out of the matrix. At the diblock loadings of $10 \%, 20 \%$ and $30 \%$ in the films, it is possible that degradation and diffusion of diblock out of the films led to the formation of pores and channels leading to faster release rates of alendronate. Therefore, it is suggested that drug release from the diblock in PLGA blended films was determined by both molecular diffusion through the polymer matrix and diffusion of alendronate through water-filled pores and channels.

\subsubsection{Effect of Alendronate Concentration}

Once the lead formulation was selected, the drug release studies were repeated with 3 batches of films using a lower alendronate concentrations better suited to use with bone cells in culture. Figure 29 shows the drug release profiles from films loaded with $0.1 \%$, $0.25 \%$ and $0.5 \%$ alendronate. 


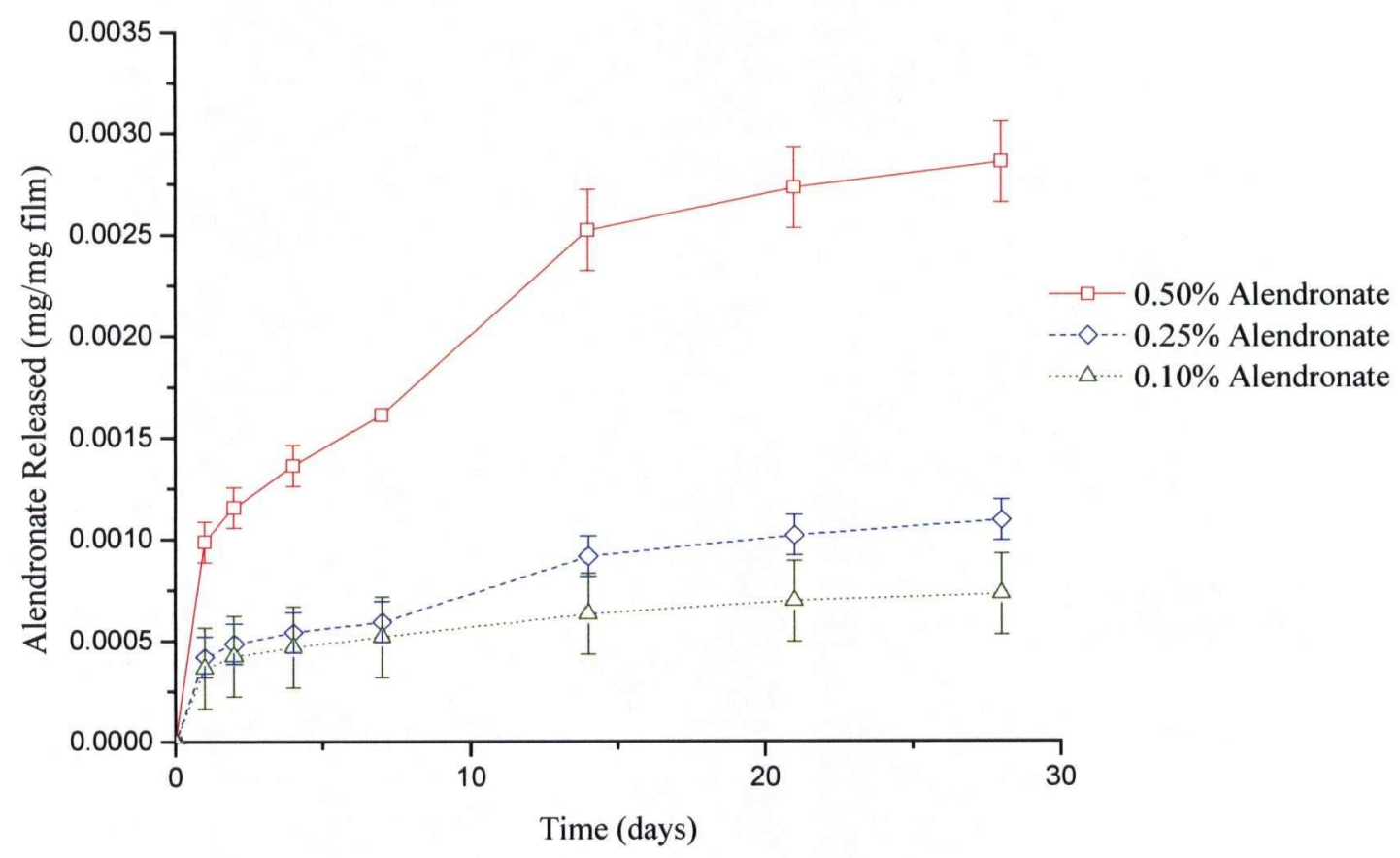

Figure 29 Cumulative release of alendronate from $(\Delta) 0.10 \%,(\diamond) 0.25 \%$ and () $0.50 \%$ drug-loaded $10 \%(\mathrm{w} / \mathrm{w})$ diblock in $85: 15$ PLGA films in PBS at $37^{\circ} \mathrm{C}$. Data expressed as mean \pm SEM $(\mathrm{N}=3)$.

The lower concentration films ( 0.1 to $0.5 \%$ alendronate) produced a burst phase that was shorter ( 1 versus 3 days) that that observed for 5\% loaded films (Figure 27) and the controlled release phase was longer. After 4 weeks, the low concentration films still gave slow controlled drug release, while the $5 \%$ drug-loaded films had reached a plateau by week 3. The slower and more prolonged phase of release for the low loading films was likely due to a combination of the films being less porous (as drug particles dissolve) and possibly due to a difference in the concentration gradient (Baker 1987).

\subsubsection{Effect of Glow Discharge}

Prior to using the polymer films in cell culture work, they were sterilized by exposure to vacuum and argon gas glow discharge. A glow discharge cell contains the samples, 2 electrodes, and argon gas at low pressure. When a potential difference was applied across the electrodes, accelerated electrons formed a plasma of charged species that could collide and react with the samples. It is known that sterilization by $\gamma$-irradiation can cause 
structural changes in polymers, by degradation, scission or cross-linking (Alexis 2005). These changes could in turn affect the rate of drug release from the polymer.

To determine whether the glow discharge process had an effect on drug release from $10 \%$ diblock in PLGA films, drug release studies were performed on three batches of films manufactured at 3 drug concentrations: $0.1 \%, 0.25 \%$ and $0.5 \%$. Glow discharged film samples were compared to control films, as shown in Figure 30.

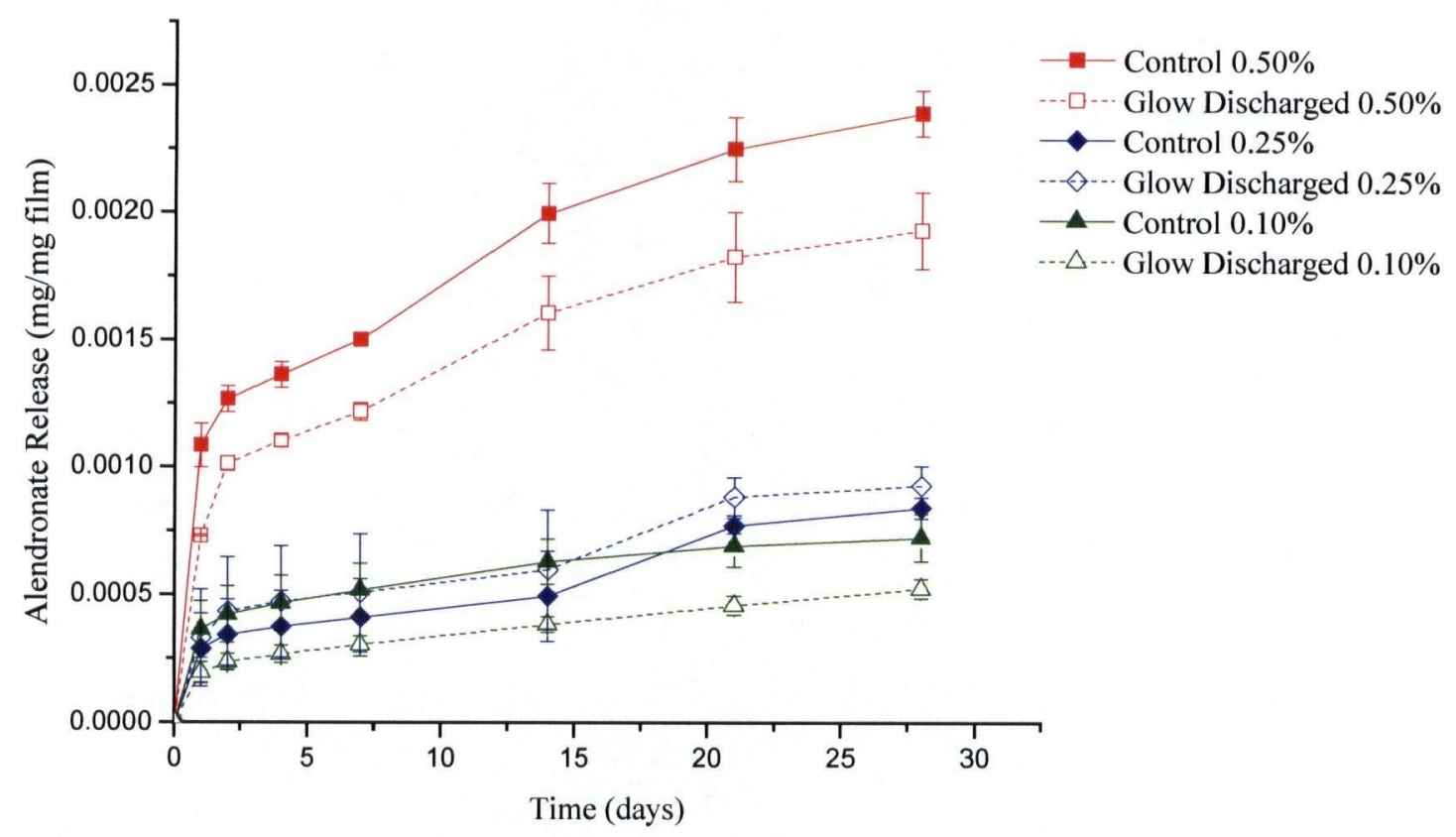

Figure 30 Cumulative release of alendronate from $(\Delta) 0.10 \%,(\diamond) 0.25 \%$ and $(\square)$ $0.50 \%(\mathrm{w} / \mathrm{w})$ drug-loaded $10 \%$ diblock in 85:15 PLGA films in PBS at $37^{\circ} \mathrm{C}$. Glow discharged data are indicated by open symbols and dashed lines. Control data are indicated by filled symbols and solid lines. Data are expressed as mean $\pm \mathrm{SEM}(\mathrm{N}=3)$.

Glow discharging appeared to have a small inhibitory effect on the initial rate of alendronate release in the $0.1 \%$ and $0.5 \%$ alendronate loaded films, but a small increase was observed for the $0.25 \%$ loaded films. After the burst phase (day 2), the slopes of the release curves were similar. 
An analysis of the difference and similarity (f1, f2) of the release curves was performed in accordance with the FDA Guidance for Industry: Dissolution Testing of Immediate Release Solid Oral Dosage Forms (Center for Drug Evaluation and Research 1997). This calculation is normally performed to compare'dissolution profiles, for instance between a generic drug and the innovator product, or to compare batches made before and after a manufacturing change.

The difference factor, $\mathrm{fl}$, is a measure of the relative error between two curves, and the similarity factor, $\mathrm{f} 2$, measures the similarity in the percent dissolution. For curves to be considered similar, f1 values should be close to 0 , and $\mathrm{f} 2$ values should be close to 100 . Generally, f1 values up to $15(0-15)$ and $f 2$ values greater than 50 (50-100) ensure sameness or equivalence of the two curves. The results of the calculation are tabulated in Table 13.

Table 13 Similarity and Difference Factors (f1, f2) for Drug Release Curves of Glow Discharged and Control 10\% Diblock in PLGA Films Containing $0.1,0.25$ and $0.5 \%$ Alendronate

\begin{tabular}{lcc}
\hline Drug Concentration (\% w/w) & $\mathbf{f 1}$ & $\mathbf{f 2}$ \\
\hline Criteria for Sameness & $<15$ & $>50$ \\
& & \\
0.10 & 38 & 98.9 \\
0.25 & 18 & 100 \\
0.50 & 20 & 99.9 \\
\hline
\end{tabular}

While all of the curves met the criteria for sameness (f2) in terms of amount of dissolution, the relative error (f1) did not meet the criteria. This was likely due to the size of the error bars relative to the amount of drug released.

It was possible that the differences in drug release between the films as a result of variability in manufacturing exceeded the variability introduced by the glow discharge process. But, since all films must be sterilized prior to use in in vitro experiments and the effect of glow discharge on drug release appeared to be minimal, it was concluded that glow discharging was an acceptable means to sterilize the films, so long as the process was performed in a repeatable manner with each batch. 


\subsubsection{Characterization of 10\% Diblock in PLGA Blend Formulation}

The physical properties of the $10 \%$ diblock in PLGA formulation were characterized by the following methods. The glass transition temperature was determined by differential scanning calorimetry. The extent of polymer degradation was determined by gel permeation chromatography, and the film thicknesses of various batches were determined with callipers. The results of each of these characterization tests are discussed in the following sections.

\subsubsection{Thermal Analysis}

Thermal analyses were performed at Angiotech Pharmaceuticals to determine the glass transition temperatures (Tg) for PLGA, diblock and their blends. Below the Tg, the amorphous component of a polymer is hard and brittle, above the $\mathrm{Tg}$, it becomes more flexible and elastic. Thermograms of polymer films composed of PLGA, diblock and 10, 20 and $30 \%$ diblock in PLGA were obtained. Samples were heated to $200^{\circ} \mathrm{C}$, cooled to $-50^{\circ} \mathrm{C}\left(-100^{\circ} \mathrm{C}\right.$ for diblock), and then reheated to $200^{\circ} \mathrm{C}$. The glass transition temperatures observed on the second heating cycle are reported in Table 14.

Table 14 Observed Glass Transition Temperatures for PLGA and PLGA/Diblock Blends

\begin{tabular}{lrrrrr}
\hline & \multicolumn{3}{c}{ Glass Transition Temperature $\left({ }^{\circ} \mathbf{C}\right)$} & \\
Sample & Replicate 1 & Replicate 2 & Replicate 3 & Mean & Standard Deviation \\
\hline & 45.69 & 36.86 & 41.11 & $\mathbf{4 1 . 2}$ & 4.4 \\
85:15 PLGA & 25.10 & 23.14 & 21.28 & $\mathbf{2 3 . 2}$ & 1.9 \\
10\% Diblock in PLGA & 16.81 & 15.91 & 16.01 & $\mathbf{1 6 . 2}$ & 0.5 \\
20\% Diblock in PLGA & 7.51 & 6.63 & 8.28 & $\mathbf{7 . 5}$ & 0.8 \\
30\% Diblock in PLGA & -47.48 & -47.54 & -46.95 & $\mathbf{- 4 7 . 3}$ & 0.3 \\
Diblock & & & & & \\
\hline
\end{tabular}

The observed $\mathrm{Tg}$ for PLGA $\left(41^{\circ} \mathrm{C}\right)$ and diblock $\left(-47^{\circ} \mathrm{C}\right)$ were lower than values previously reported $\left(47^{\circ} \mathrm{C}\right.$ and $-35^{\circ} \mathrm{C}$, respectively) (Jackson et al. 2004). However, the data were collected on different batches of polymer, with different instruments and at different heating and cooling rates.

The cooling and second heating curve of a typical film (10\% diblock in PLGA) is shown in Figure 31. The first heating curve has been omitted for clarity. The glass transition temperature of the polymer blend was observed at $21^{\circ} \mathrm{C}$. 


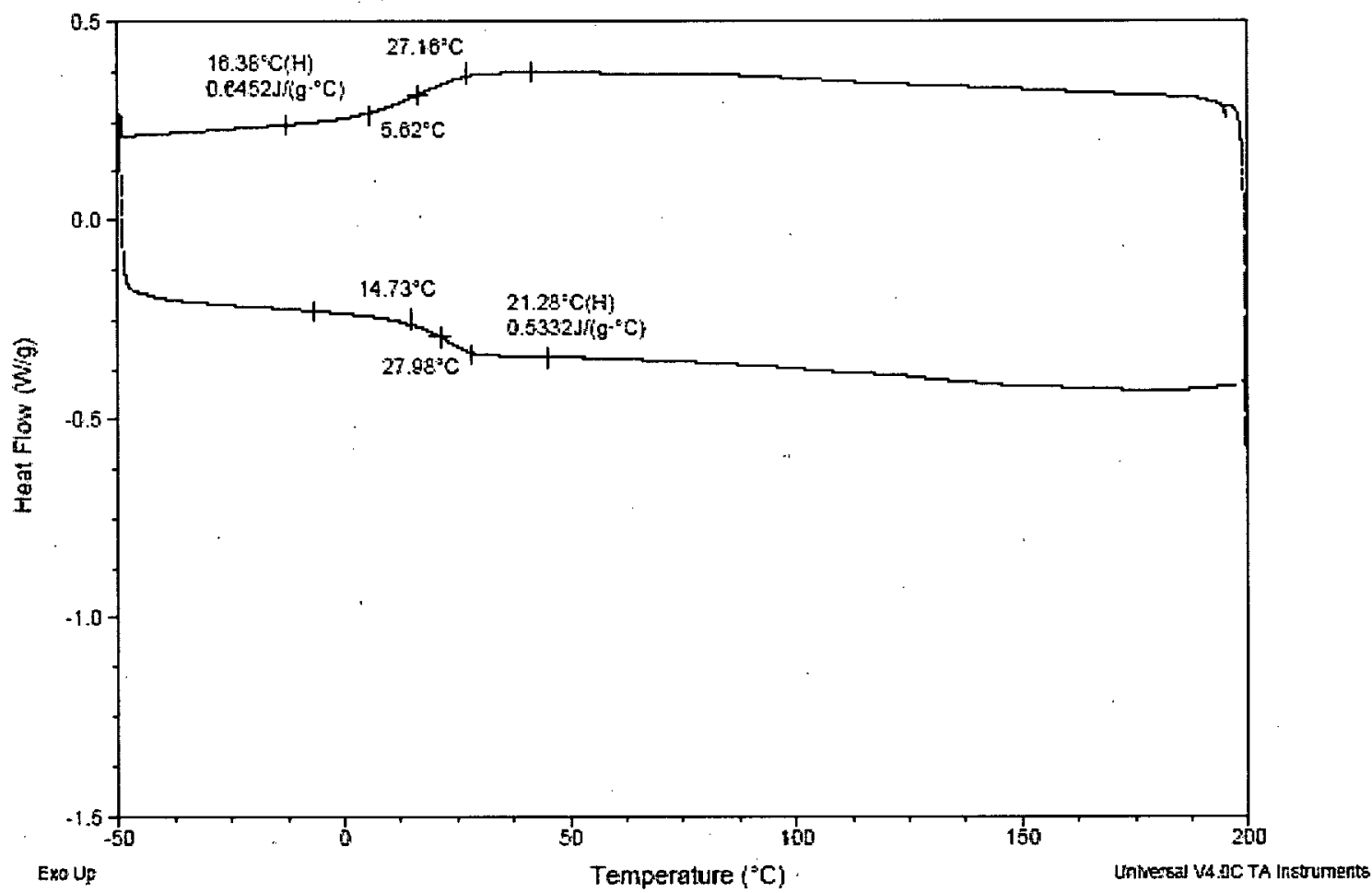

Figure 31 Differential scanning calorimetry cooling/reheating scan of 10\% Diblock in 85:15 PLGA following one heating cycle at a heating rate $10^{\circ} \mathrm{C} /$ minute.

Miscible polymer blends exhibit a single glass transition; whereas immiscible blends will retain the glass transitions for each of the components, although they may become broadened and shift closer to each other. The shift in $\mathrm{Tg}$ in a miscible polymer blend depends on the composition of the blend. Increasing the proportion of diblock to PLGA in the polymer produced a concentration-dependent decrease in the glass transition temperature, Figure 32, as predicted by the Fox equation (Fox 1956):

$\frac{1}{T g \text { (blend) }}=\frac{A}{T g \text { (diblock) }}+\frac{B}{T g \text { (PLGA) }}$

Equation 6 
Where: $\mathrm{A}$ is the weight fraction of diblock, $\mathrm{B}$ is the weight fraction of PLGA, and the glass transition temperature is in Kelvin.

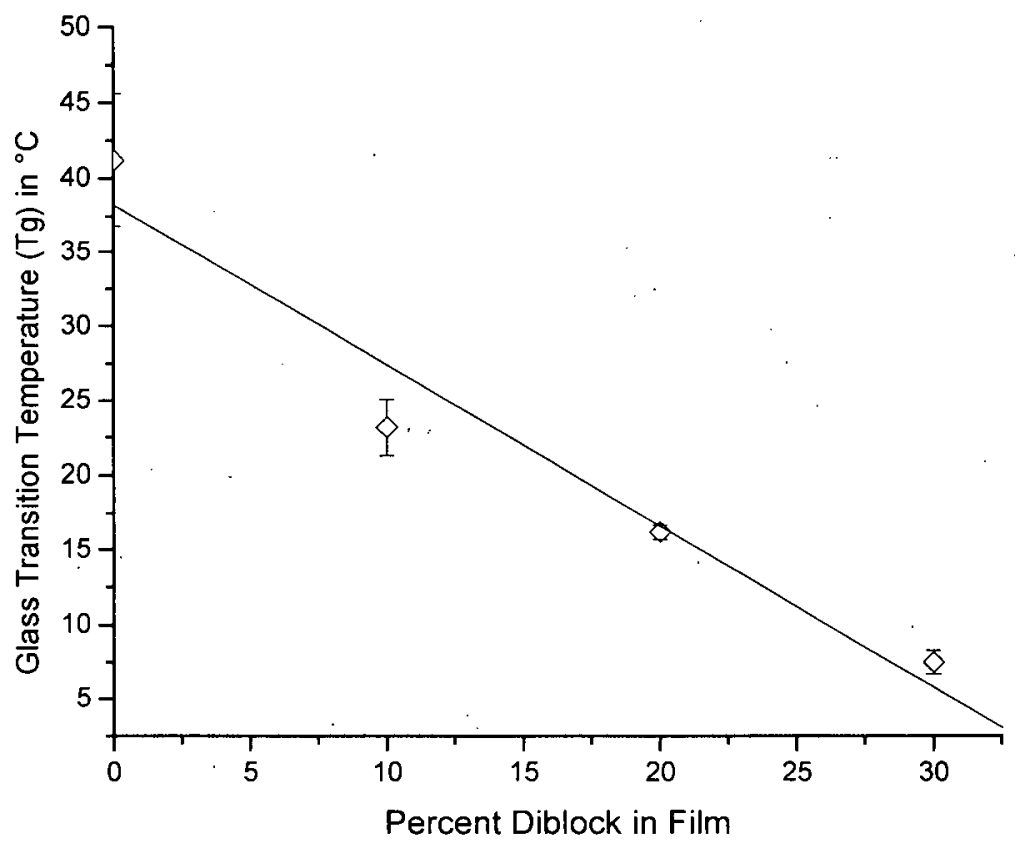

Figure 32 Effect of blending increasing amounts of diblock into 85:15 PLGA films on glass transition temperature ( $\mathrm{Tg})$ of blend. Observed values $(0, \mathrm{n}=3)$ were obtained by differential scanning calorimetry at a heating rate of $10^{\circ} \mathrm{C} /$ minute. Error bars indicate standard deviation. Line shown is the linear regression of the given data points.

The concentration-dependent reduction in Tg upon the addition of diblock to PLGA was in good agreement with the Fox equation. That, and the single intermediate Tg value for the polymer blends, indicated that the polymers formed a miscible blend.

The addition of $10 \%$ diblock to PLGA lowered the $\mathrm{Tg}$ from $41^{\circ} \mathrm{C}$ to $23^{\circ} \mathrm{C}$. This is convenient for a dentistry application, because the films will be stiff enough to trim at room temperature, but become more pliable at body temperature. The diblock functioned as a plasticizer in the polymer blend. 


\subsubsection{Polymer Degradation}

PLGA and diblock are both biodegradable, biocompatible polymers (Anderson and Shive 1997). Gel permeation chromatography was used to determine the extent of polymer degradation during the early stages of drug release. Since the degradation of 85:15 PLGA is generally of the order of weeks to months (Alexis 2005), it was felt to be more critical to measure changes in the molecular weight of the diblock. Hence, the molecular weight of the diblock was monitored for evidence of short-term polymer degradation. In addition, it was necessary to determine if the glow discharge process had an impact on the molecular weight-either increasing the molecular weight by cross-linking or decreasing it by scission. The changes in diblock molecular weights in 3 batches with and without glow discharging are shown in Figure 33.

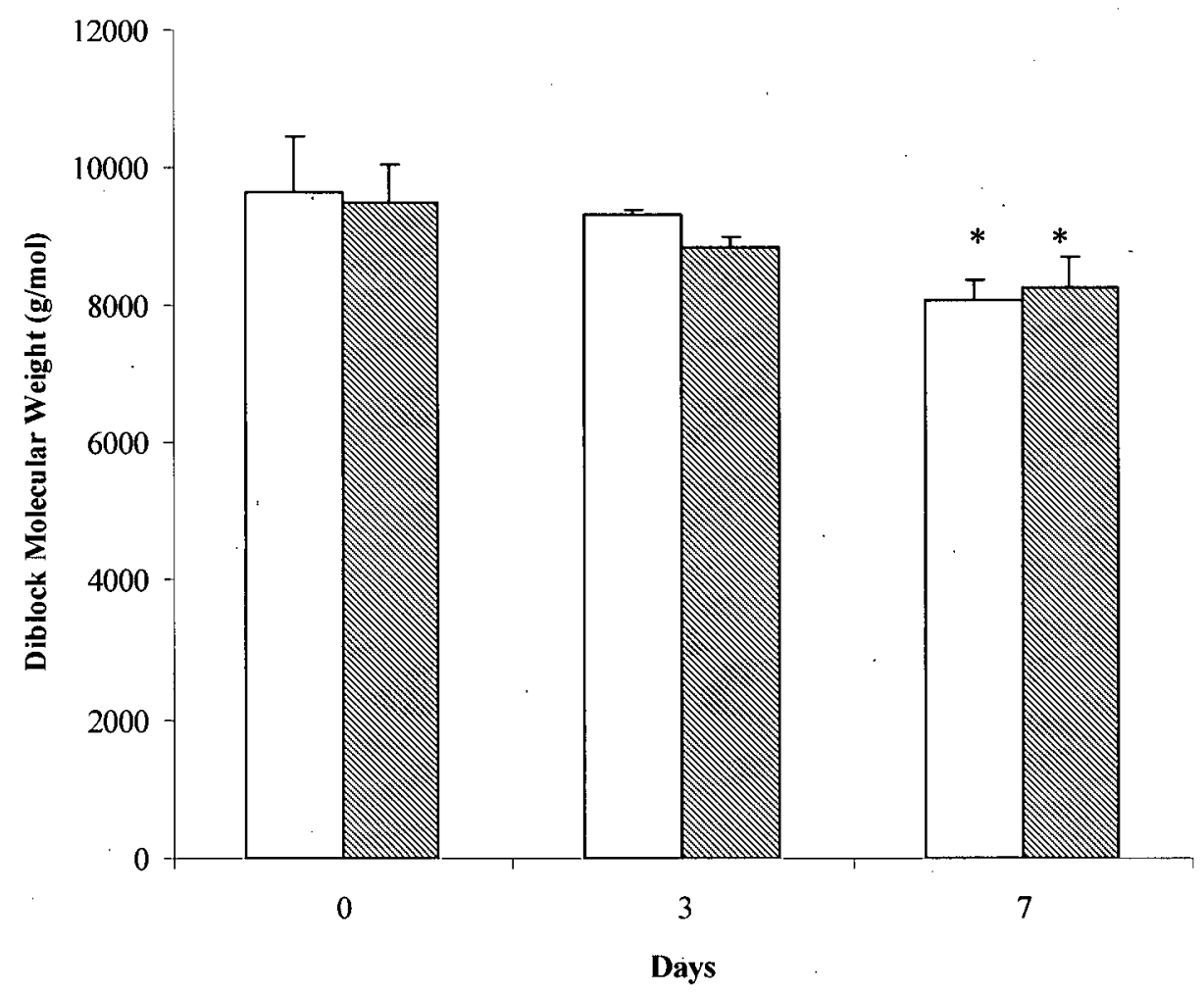

$\square$ Glow Discharged $\mathbb{\$}$ Control

Figure 33 Comparison of diblock molecular weights in glow discharged (solid) and not glow discharged (hatched) 10\% diblock in 85:15 PLGA films agitated in PBS at $37^{\circ} \mathrm{C}$ for 3 or 7 days. Mean and SD for 3 batches determined by GPC, $\left(^{*}\right)$ statistically significant compared to time 0 . 
The GPC elution profiles of films that had or had not been glow discharged were indistinguishable. This indicates that the glow discharge process did not have a measurable effect on the molecular weight of the diblock. The small differences in the drug release profiles of glow discharged versus control films observed in Figure 30 were likely a result of film variation rather than the glow discharge process.

However, there was a change in the retention time of the diblock peak with time. By day 7 , there was a significant reduction in the diblock molecular weight from day 0 in both the glow discharged and control samples, to $84 \%$ and $86 \%$ of original, respectively.

The initial diblock molecular weight determined in this study $\left(\mathrm{M}_{\mathrm{GPC}} \sim 9500 \mathrm{~g} / \mathrm{mol}\right)$ was considerably higher than either the theoretical molecular weight $(3333 \mathrm{~g} / \mathrm{mol})$ or the previously reported molecular weight $(5240 \mathrm{~g} / \mathrm{mol})$ (Zhang et al. 1996). However, the data in this work were collected on a different batch of polymer using polystyrene standards. As noted in the original paper, the Mark-Houwink parameters were not determined for the polymers, so the values were considered relative rather than absolute.

The retention time for PLGA was outside the range of the calibration curve, so the data were not reported. However, there was no apparent trend in the data and no evidence of a reduction in PLGA molecular weight in the 7-day period.

The PLGA and diblock peaks were not well resolved by GPC, so the peak heights rather than peak areas were used to monitor loss of diblock into the medium. Data from 3 batches of diblock in PLGA films incubated in PBS are shown in Figure 34. There was no statistical significance between films that had been glow discharged and control. A decline in peak height ratios was observed indicating a loss of lower molecular weight diblock from the films, but it was not statistically significant after 3 or 7 days. In a similar study using diblock in 50:50 PLGA, only $80 \%$ of the original diblock was left after one week (Jackson et al. 2004). 


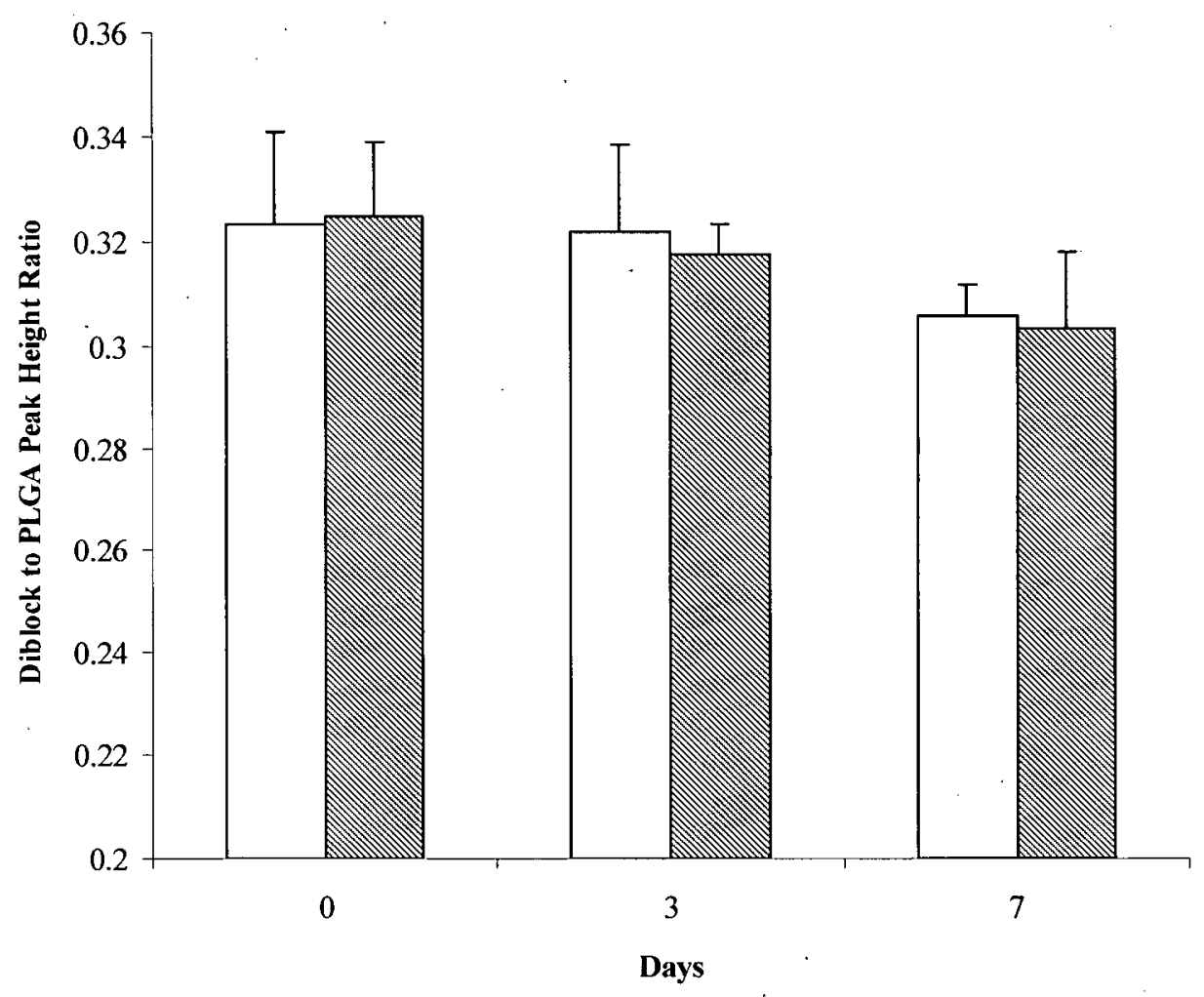

$\square$ Glow Discharged $\$$ Not Glow Discharged

Figure 34 Comparison of diblock to PLGA peak height ratios in glow discharged (solid) and not glow discharged (hatched) 10\% diblock in PLGA films agitated in PBS at $37^{\circ} \mathrm{C}$ for 3 or 7 days. Mean and SD for 3 batches determined by GPC.

\subsubsection{Film Thickness}

The areas of the polymer films were determined by the dimensions of the templates on which they were cast, but there could be some variability in the weight and thickness of the films. Weight and thickness data obtained from 4 batches are shown in Table 15. The mean weight was $\sim 10 \mathrm{mg}$, and the mean thickness was $\sim 0.1 \mathrm{~mm}$. The films tended to be slightly thicker at the edges, but the relative standard deviation among 3 measurements of the same film was generally $5 \%$ or less. In the drug release studies, drug release was normalized to film weight. 
Table 15 Film Thicknesses and Weights of 4 Batches of Alendronate Loaded $10 \%$ Diblock in PLGA Films

\begin{tabular}{lcccc}
\hline Batch & n & $\begin{array}{c}\text { Mean Weight (SD) } \\
\text { mg }\end{array}$ & n & $\begin{array}{c}\text { Mean Thickness (SD) } \\
\mathbf{m m}\end{array}$ \\
\hline & & & & \\
2 & 18 & $9.9(0.7)$ & 54 & $0.106(0.019)$ \\
3 & 18 & $10.8(1.4)$ & 54 & $0.095(0.022)$ \\
5 & 24 & $9.6(0.7)$ & 72 & $0.133(0.033)$ \\
6 & 24 & $9.0(1.4)$ & 72 & $0.104(0.013)$ \\
\hline
\end{tabular}

\subsection{Osteoblasts Cell Culture Data}

With the lead formulation selected and characterized, the effect of alendronate-loaded polymer films on bone cells in vitro was evaluated.

\subsubsection{Effect of Alendronate Concentration}

The concentration of alendronate has been shown to be critical for both osteoclast and osteoblast cell culture (Moreira et al. 2005). At $2 \times 10^{-9} \mathrm{~mol} / \mathrm{L}$, alendronate inhibited $50 \%$ of the resorptive capacity of osteoclasts (Sahni et al. 1993). Concentrations greater than $10^{-3} \mathrm{M}$ have been shown to dramatically reduce cell viability within 48 hours in cultures of human normal osteoblasts (Garcia-Moreno et al. 1998). A similar effect was observed at concentrations $>10^{-4} \mathrm{M}$ in MG-63 human osteoblasts ( $\mathrm{Im}$ et al. 2004). Below the threshold alendronate concentration $\left(10^{-5}\right.$ to $\left.10^{-12} \mathrm{M}\right)$, however, an increase in osteoblast proliferation was observed. Proliferation and osteogenic differentiation of human bone marrow stromal cells was observed at a concentration of $10^{-8} \mathrm{M}$ (Von Knoch et al. 2005).

Dr. Douglas Hamilton, from the laboratory of Dr. Brunette (Department of Oral Biological \& Medical Sciences, UBC Faculty of Dentistry) kindly provided a line of rat osteoblast cells for the proliferation experiments. Unlike the human MG-63 line, these osteoblasts will only continue to proliferate and differentiate for $\sim 10$ passages.

Studies were carried out to determine the threshold alendronate concentration in the rat osteoblast line. The effect of various concentrations of alendronate in solution (i.e., not from polymer films) on the proliferation of rat osteoblasts was determined using an MTS assay. The data are shown in Figure 35. 


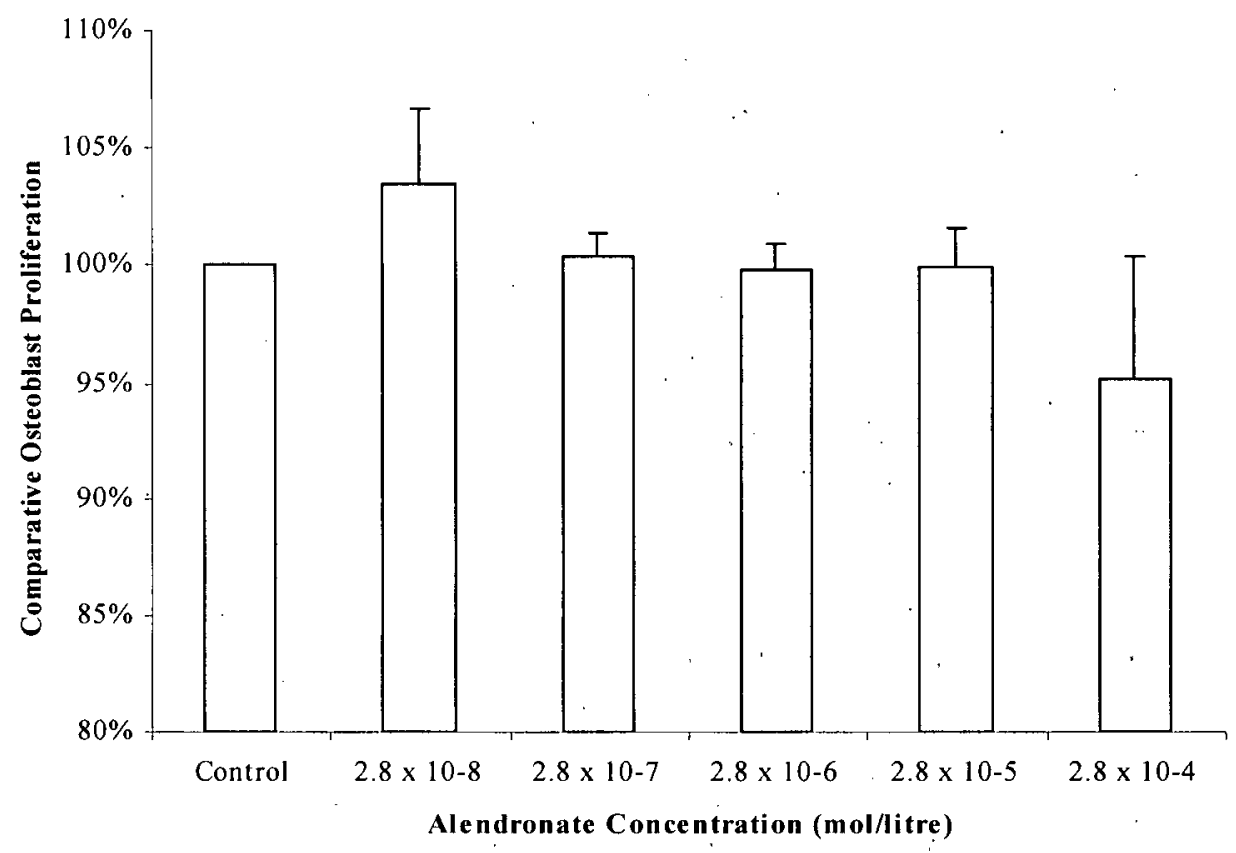

Figure 35 Osteoblast proliferation in the presence of various concentrations of alendronate $\left(2.8 \times 10^{-4}\right.$ to $\left.2.8 \times 10^{-8} \mathrm{M}\right)$. Wells were seeded with $1 \mathrm{ml}$ of media containing 20,000 osteoblasts and an aliquot of alendronate solution. The relative osteoblast proliferation after 2 days at $37^{\circ} \mathrm{C}, 5 \%$ $\mathrm{CO}_{2}$ was measured by the MTS assay. Data expressed as mean $\pm \mathrm{SEM}$ $(\mathrm{N}=3)$.

At $2.8 \times 10^{-8} \mathrm{M}$ alendronate there was an increase in osteoblast proliferation and at $2.8 \times 10^{-4} \mathrm{M}$ there was a decrease; however, these were not statistically significant from the control. The size of the effect was smaller than that reported in the literature (GarciaMoreno et al. 1998; Im et al. 2004), and the correlation with alendronate concentration. was not as pronounced.

\subsubsection{Osteoblast Proliferation}

The threshold alendronate concentration was particularly important for the controlledrelease alendronate-loaded films. The drug release profiles showed a burst of drug release on ,the first day. But unlike an in vivo system, where excess drug is distributed by the circulatory system, the drug concentration in the cell culture plate can accumulate, possibly to toxic levels. Therefore low concentrations of alendronate $(0.1,0.25$ and $0.5 \%)$ 
were used in the preparation of films for cell culture studies, and the media was changed regularly throughout the study.

The concentration of alendronate in the cell culture media was not determined by HPLC because a suitable procedure for extracting alendronate from biological media had not been developed and validated. Furthermore, in cell culture alendronate would be expected to chelate to calcium and other components of the media, reducing its bioavailability. The effective amount of alendronate in solution would therefore be quite different to what could be determined by HPLC.

The initial cell culture experiments were designed to visually observe the proliferation of osteoblasts on the films to ensure that there were no local toxicities and that the cells would adhere to the films normally and proliferate.

As seen in Figure 36, the sulfurhodamine B stain shows the morphology of the proliferating osteoblast cells under the rhodamine filter. The Hoechst stain labels only the nuclei, which were then visible under the DAPI filter. Counting the cells manually was found to be more accurate when only the nuclei were visible.

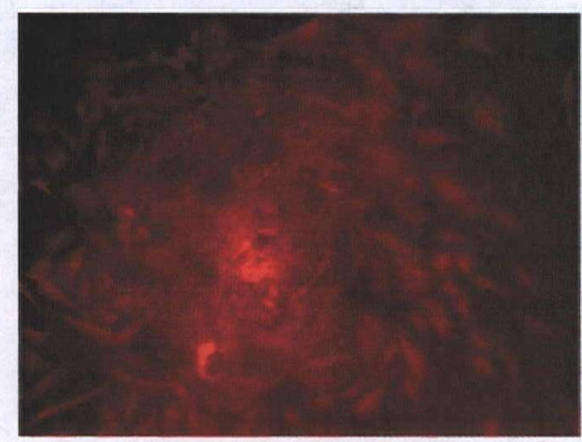

Rhodamine Filter

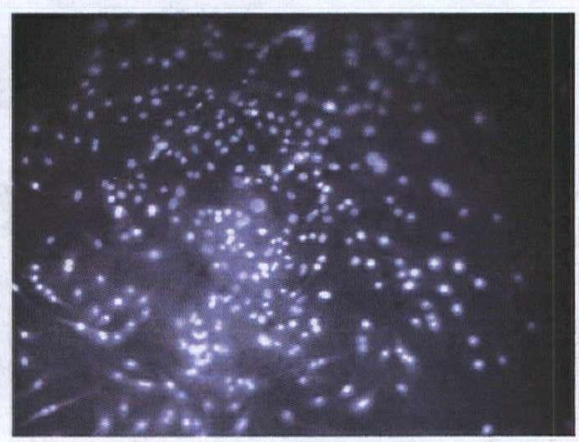

DAPI Filter

Figure 36 Fluorescence microscope images of rat osteoblasts on $0.25 \%$ alendronateloaded 10\% diblock in 85:15 PLGA Films, using the rhodamine (left) or DAPI (right) filters.

Figure 37 shows the number of osteoblast cells observed after 1,2, and 4 days. Osteoblast

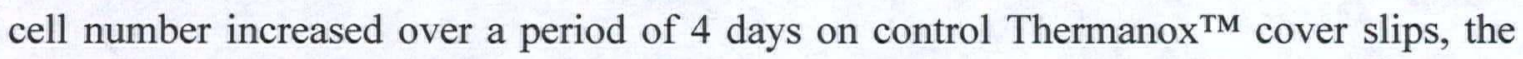
polymer-only films and the $0.25 \%$ alendronate-loaded polymer films. Cell proliferation on the $0.5 \%$ films was consistently low, indicating a potentially toxic concentration of alendronate, at least initially. The large error bars are due to wide variations in osteoblast 
populations on the films. Osteoblasts are known to prefer surfaces with variable topographies (Wieland et al. 2005; Owen et al. 2005), so the edges of the films, or any areas with bubbles or defects were frequently observed to be well populated; however, the smooth central areas of the films were often devoid of cells.

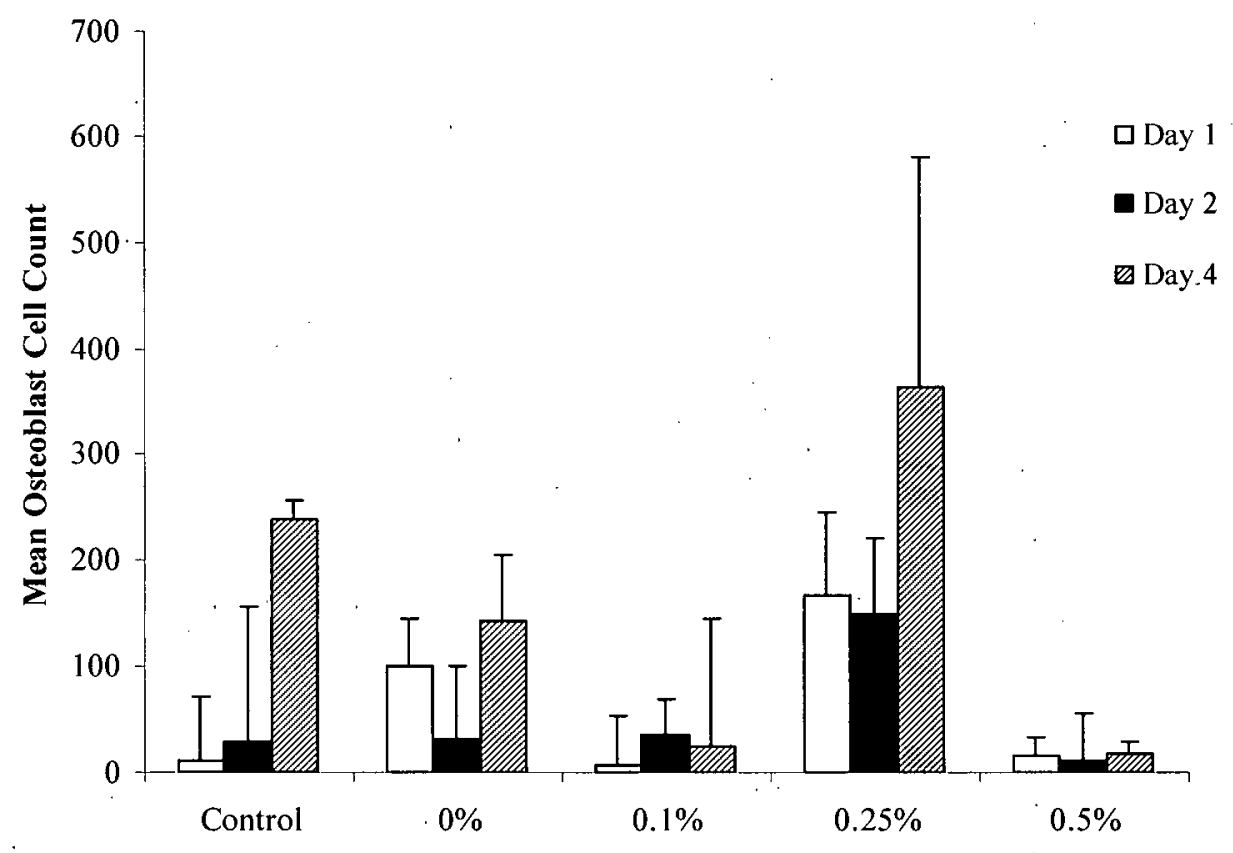

Figure 37 Osteoblast proliferation after 1,2 or 4 days incubation with control Thermanox ${ }^{\mathrm{TM}}$ cover slips or $10 \%$ diblock in 85:15 PLGA films loaded with $0,0.1,0.25$ or $0.5 \%$ alendronate. Proliferation is expressed as mean \pm SEM ( $N=3$ experiments) of stained osteoblasts visible per representative microscope image (10X magnification).

The cells were visually observed to adhere normally and proliferate on all surfaces except the $0.5 \%$ alendronate films. It was possible that the local alendronate concentrations reached toxic levels in the early time points due to the burst effect of drug release. In other studies that were followed out to 7 days, the osteoblast populations appeared to begin to recover after day 4 .

Osteoblast proliferation on films loaded with $0.25 \%$ alendronate was greater than proliferation observed on either the Thermanox ${ }^{\mathrm{TM}}$ control slides or the alendronate-free 
polymer controls. This effect might have been the result of optimal alendronate drug release, or possibly because the $0.25 \%$ alendronate films seemed to have a greater number of small contours and bubbles where the osteoblasts would congregate.

The manual counting method was lengthy and susceptible to bias in the choice of images. In addition, the duration of the proliferation experiments was limited, because the control cells became too numerous to count by day 7 . A second method for cell quantitation was desired.

\subsubsection{Cell Proliferation by MTS Assay}

The next series of experiments were quantitated using the 3-(4,5-dimethylthiazol-2-yl)-5(3-carboxymethoxyphenyl)-2-(4-sulfophenyl)-2H-tetrazolium, inner salt) or MTS assay to determine the number of viable cells colorimetrically. The MTS tetrazolium compound can be reduced by viable cells within a few hours to a coloured formazan product that absorbs at $492 \mathrm{~nm}$. The linear range of the assay was 0.2 to 1.1 absorbance units at $490 \mathrm{~nm}$.

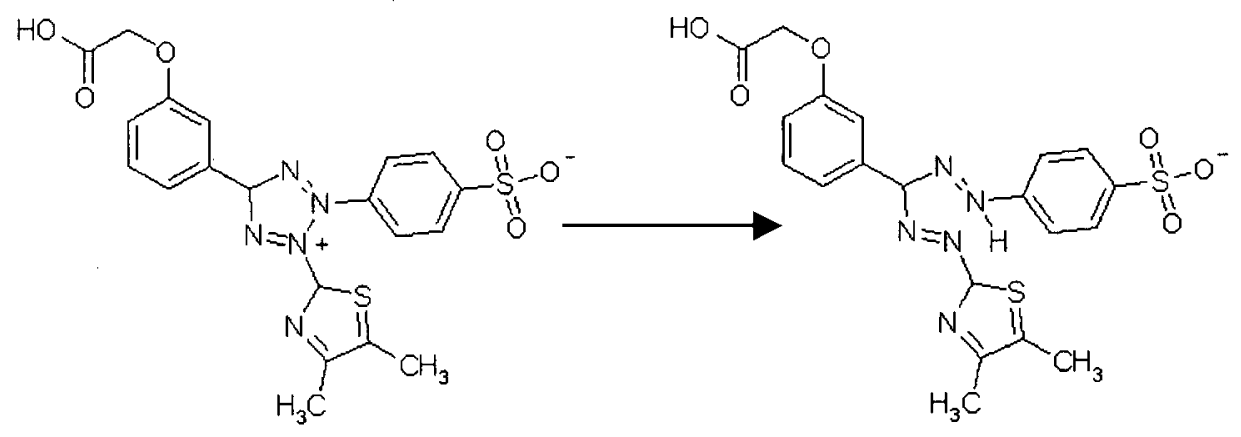

Figure 38 Chemical structure of MTS tetrazolium reagent being reduced to its formazan product

The proliferation experiments were repeated using the MTS assay. Using this assay, the quantities of proliferating cells on the films, as well as the quantities that had adhered to the sides of the wells were measured. This gave a measure of both the ability of cells to adhere to the polymeric films, as well as the effects of alendronate in solution. The data from 2 experiments are shown in Figure 39 and Figure 40. 
A)

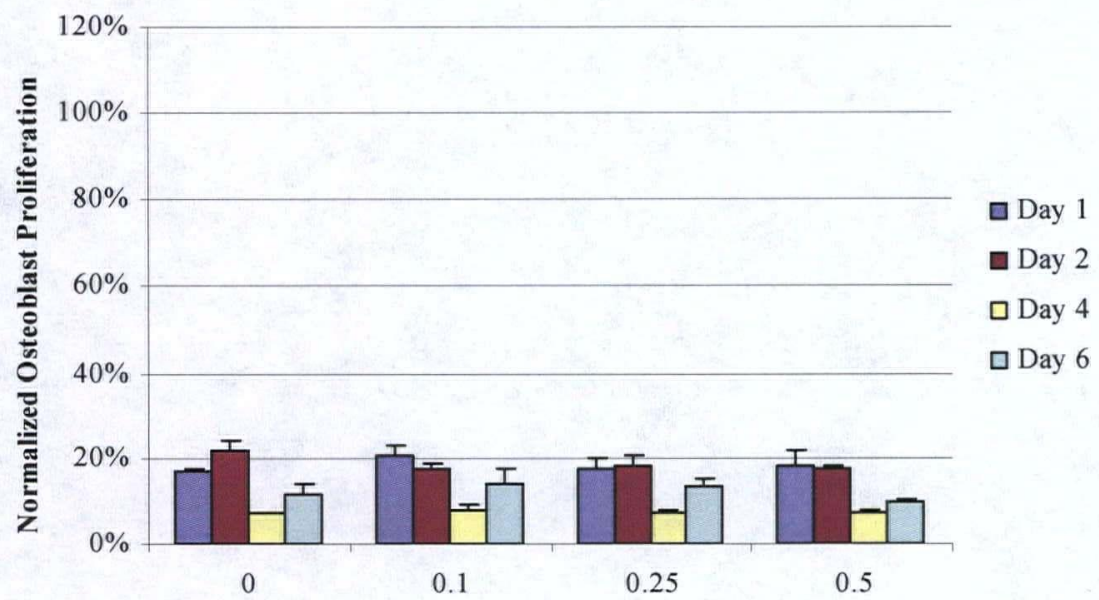

B)

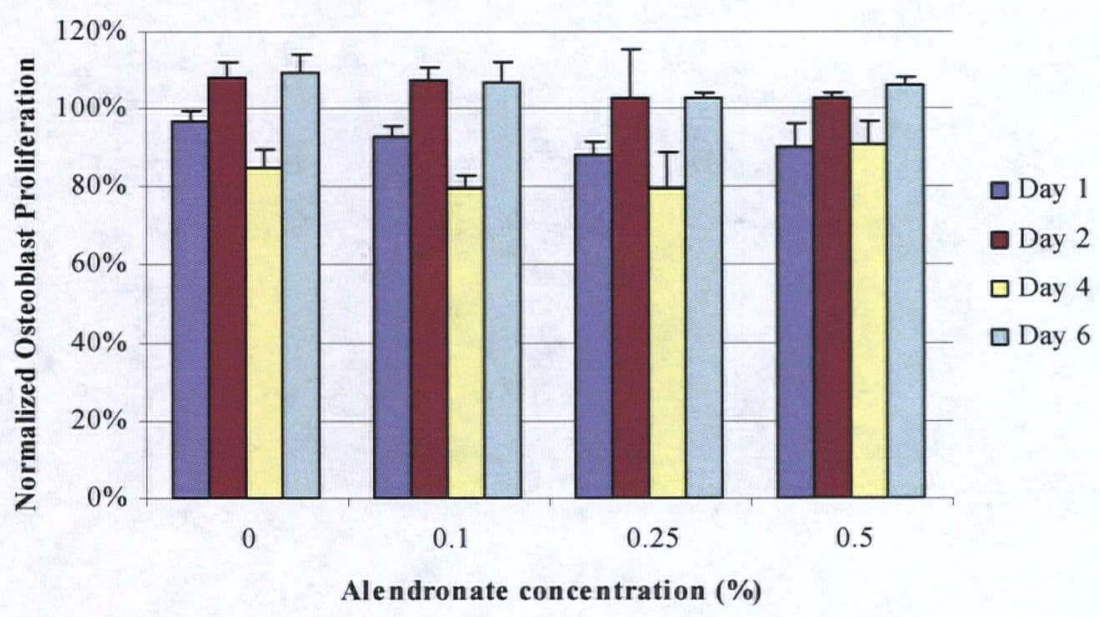

Figure 39 Osteoblast proliferation data from experiment 1 on $0,0.1,0.25$ and $0.5 \%$ alendronate-loaded 10\% diblock in 85:15 PLGA films after incubation at $37^{\circ} \mathrm{C}$ for $1,3,4$ or 6 days. Proliferation was measured by the MTS assay $(n=3)$ and normalized to untreated control wells. A) Osteoblast proliferation on films only, B) osteoblast proliferation on films and wells. 
A)

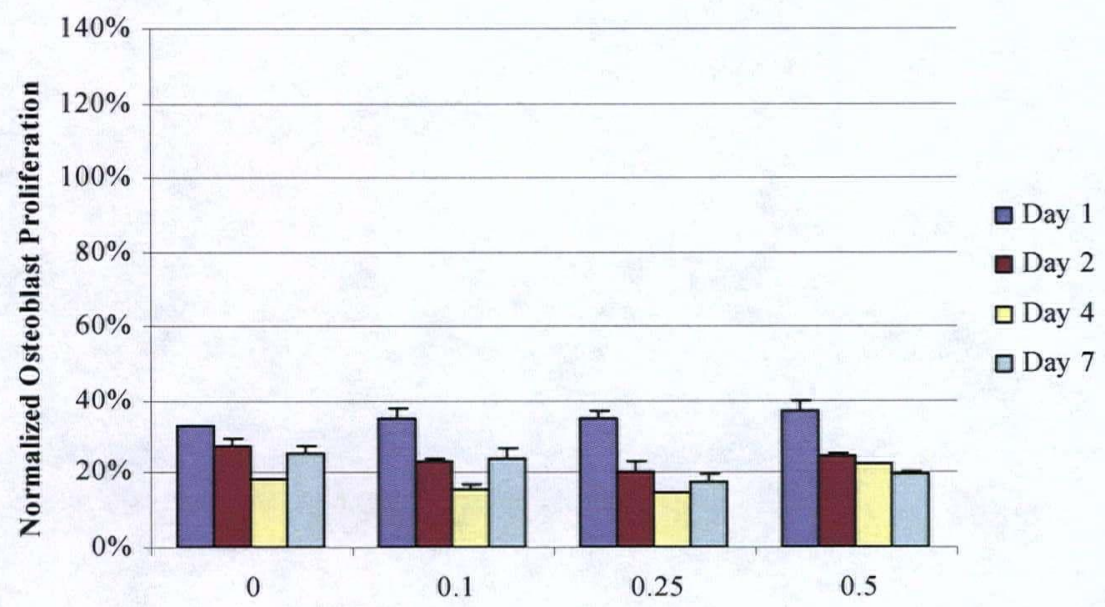

B)

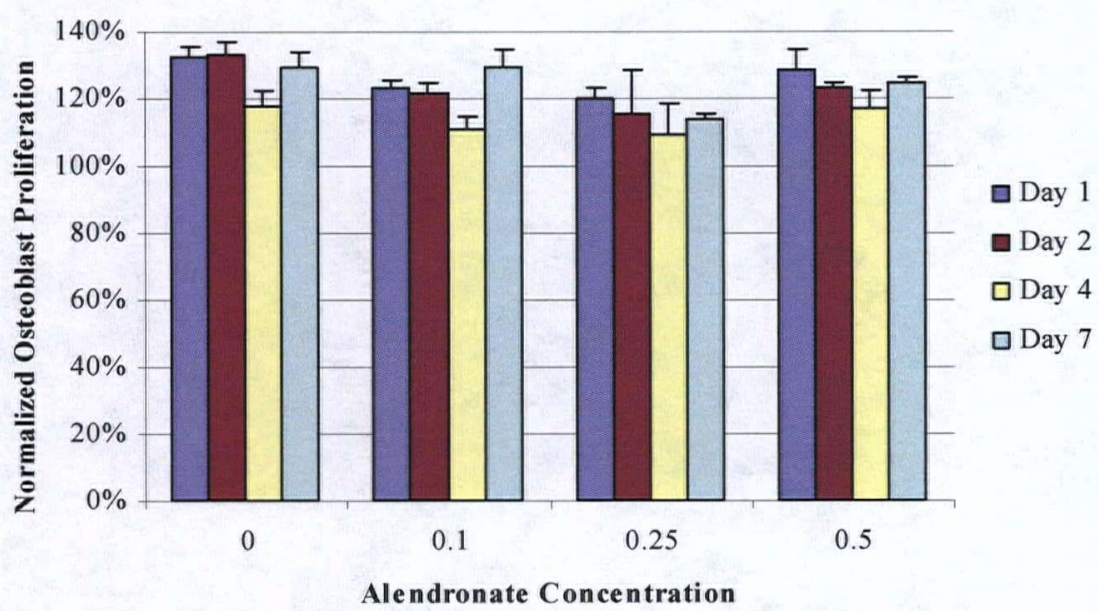

Figure 40 Osteoblast proliferation data from experiment 2 on $0,0.1,0.25$ and $0.5 \%$ alendronate-loaded 10\% diblock in 85:15 PLGA films after incubation at $37^{\circ} \mathrm{C}$ for $1,3,4$ or 7 days. Proliferation was measured by the MTS assay $(n=3)$ and normalized to untreated control wells. A) Osteoblast proliferation on films only, B) osteoblast proliferation on films and wells.

The MTS cell proliferation experiments did not support the earlier observations using manual counting. The inhibitory effect of $0.50 \%$ alendronate-loaded films was not observed; nor was the increased proliferation in the presence of $0.25 \%$ alendronateloaded films. The MTS experiments were performed on different batches of films, manufactured at lower temperatures to prevent small bubbles forming due to rapid 
evaporation of the solvent. It is possible that increased proliferation on the $0.25 \%$ alendronate-loaded films observed in Figure 37 could be explained by the different and more textured topography of the films used in these studies.

The MTS results do not show the increase in osteoblast proliferation with time seen in Figure 37 because the data have been normalized with respect to a set of control wells that did not contain polymer films. While there appeared to be a trend of decreasing osteoblast proliferation as a function of time for measurements on films only (Figure 39A and Figure 40A), it is not known whether these differences were significant based on only 2 experiments. On the other hand, in studies evaluating the osteoblast proliferation in both the films and the wells (Figure 39B and Figure 40B), there appeared to be no effect with incubation time.

An interesting trend of decreased osteoblast proliferation was noted day 4 in all studies, and at all concentrations. This appeared to be followed by recovery of the cells on day 6 or 7. The media was changed on days 1,2,4 and 7, and the alendronate burst phase in low concentration films lasted one day (Figure 30), so a toxic accumulation of alendronate was not likely. It remains to be determined whether this is a reproducible feature of osteoblast proliferation in these types of studies and what causes this effect.

\subsubsection{Future Experiments}

The MTS data for osteoblasts were inconclusive with regard to determining an optimal alendronate concentration for polymeric films. In future experiments, the effects of alendronate release on osteoclasts in addition to osteoblasts should be determined, although osteoclasts can be difficult to obtain and culture. The optimal alendronate concentration for osteoblasts is likely different from that of osteoclasts. And since a potential application for the polymer films is to act as a barrier between the bone and epithelial cells in periodontal applications, the effect on proliferation on epithelial cells might also be of interest.

After osteoblasts have proliferated to the point of confluence, they will begin to differentiate and secret bone matrix (Fleisch 1997). Other osteoblast studies typically include some experiments measuring the time to and extent of differentiation by measuring alkaline phosphatase activity and nodule formation. However, performing these experiments in the presence of bisphosphonates is complicated by the fact that the calcium ions essential for osteoblast differentiation will be chelated by the bisphosphonates in a concentration dependent manner (Peter et al. 2005b). While this effect is probably unimportant in vivo, it has been shown to be a factor in in vitro 
experiments. Including an additional chelator, such as EDTA or excess $\mathrm{Mg}^{2+}$ and $\mathrm{Zn}^{2+}$ ions might overcome the inhibitory effect of alendronate on alkaline phosphatase (Vaisman et al. 2005).

Finally, the affinity of osteoblasts for surface topography might be exploited by casting the polymer films into ridged or dimpled templates. A comparison of smooth and uneven surfaces would make an interesting study. 


\section{SUMMARY AND CONCLUSIONS}

A controlled-release drug delivery system for local delivery of alendronate has a number of potential applications, for which characterization of the quantity and rate of drug release was required. A sensitive fluoreșcence HPLC assay for alendronate was validated. The in vitro drug release profiles of several potential formulations of PLGA, alendronate and various release modulators and plasticizers were determined. The lead formulation of $0.25 \%$ alendronate in 85:15 PLGA containing 10\% diblock copolymer gave controlled release of drug over the expected healing period after surgery (2-4 weeks). This lead formulation may increase osteoblast proliferation over polymer alone, but this effect could not be confirmed using the MTS assay. 


\section{REFERENCES}

Al Deeb, S. K., Hamdan, I. I. and Al Najjar, S. M. Spectroscopic and HPLC Methods for the Determination of Alendronate in Tablets and Urine. Talanta, 2004, 64: 695702 .

Al Saffar, N. and Revell, P. A. Pathology of the Bone-Implant Interfaces. Journal of Long-Term Effects of Medical Implants, 1999, 9: 319-347.

Alexis, F. Factors Affecting the Degradation and Drug-Release Mechanism of Poly(Lactic Acid) and Poly[(Lactic Acid)-Co-(Glycolic Acid)]. Polymer International, 2005, 54: 36-46.

Allen, C., Han, J. N., Yu, Y. S., Maysinger, D. and Eisenberg, A. Polycaprolactone-BPoly(Ethylene Oxide) Copolymer Micelles as a Delivery Vehicle for Dihydrotestosterone. Journal of Controlled Release, 2000, 63: 275-286.

Altundal, H. and Gursoy, B. The Influence of Alendronate on Bone Formation After Autogenous Free Bone Grafting in Rats. Oral Surgery Oral Medicine Oral Pathology Oral Radiology and Endodontics, 2005, 99: 285-291.

Anderson, J. M. and Shive, M. S. Biodegradation and Biocompatibility of PLA and PLGA Microspheres. Advanced Drug Delivery Reviews, 1997, 28: 5-24.

Astrand, J. and Aspenberg, P. Topical, Single Dose Bisphosphonate Treatment Reduced Bone Resorption in a Rat Model for Prosthetic Loosening. Journal of Orthopaedic Research, 2004, 22: 244-249.

Baker, R. Diffusion Controlled Systems. Controlled Release of Biologically Active Agents. John Wiley and Sons, New York, 1987.

Bala, I., Hariharan, S. and Kumar Mnvr PLGA Nanoparticles in Drug Delivery: the State of the Art. Critical Reviews in Therapeutic Drug Carrier Systems, 2004, 21: 387422. 
Barrett, J., Worth, E., Bauss, F. and Epstein, S. Ibandronate: A Clinical Pharmacological and Pharmacokinetic Update. Journal of Clinical Pharmacology, 2004, 44: 951965 .

Bhadra, D., Bhadra, S., Jain, P. and Jain, N. K. Pegnology: a Review of PEG-Ylated Systems. Pharmazie, 2002, 57: 5-29.

Binderman, I., Adut, M. and Yaffe, A. Effectiveness of Local Delivery of Alendronate in Reducing Alveolar Bone Loss following Periodontal Surgery in Rats. Journal of Periodontology, 2000, 71: 1236-1240.

Bobyn, J. D., Hacking, S. A., Krygier, J. J., Harvey, E. J., Little, D. G. and Tanzer, M. Zoledronic Acid Causes Enhancement of Bone Growth Into Porous Implants. Journal of Bone and Joint Surgery-British Volume, 2005, 87B: 416-420.

Boulenc, X., Marti, E., Joyeux, H., Roques, C., Berger, Y. and Fabre, G. Importance of the Paracellular Pathway for the Transport of a new Bisphosphonate Using the Human CACO-2 Monolayers Model. Biochemical Pharmacology, 1993, 46: 1591-1600.

Burt, H. M., Zhang, X. C., Toleikis, P., Embree, L. and Hunter, W. L. Development of Copolymers of Poly(D,L-Lactide) and Methoxypolyethylene Glycol as Micellar Carriers of Paclitaxel. Colloids and Surfaces B-Biointerfaces, 1999, 16: 161-171.

Canadian Pharmacists Association Compendium of Pharmaceuticals and Specialties. Ottawa, 2005 (40th edition).

Cecchini, M. G., Felix, R., Fleisch, H. and Cooper, P. H. Effect of Bisphosphonates on Proliferation and Viability of Mouse Bone Marrow-Derived Macrophages. Journal of Bone and Mineral Research, 1987, 2: 135-142.

Center for Drug Evaluation and Research. Guidance for Industry: Dissolution Testing of Immediate Release Solid Oral Dosage Forms. 1997.

Cheng, A., Mavrokokki, A., Carter, G., Stein, B., Fazzalari, N. L., Wilson, D. F. and Goss, A. N. The Dental Implications of Bisphosphonates and Bone Disease. 
Australian Dental Journal, 2005, 50: S4-S13.

Chu, C. C. Biodegradable Polymeric Biomaterials: An Updated Overview. In: J. D. Bronzino (Ed) The Biomedical Engineering Handbook. CRC Press in cooperation with IEEE Press, Boca Raton, 2000.

Cooper, S. L., Visser, S. A., Hergenrother, R. W. and Lamba, N. M. K. Polymers. In: B. D. Ratner and A. S. Hoffman (Eds) Biomaterials Science: An Introduction to Materials in Medicine. Elsevier Academic Press, New York, 2004.

Cornell, C. N. Osteoconductive Materials and their Role as Substitutes for Autogenous Bone Grafts. Orthopedic Clinics of North America, 1999, 30: 591-598.

Daley-Yates, P. T., Gifford, L. A. and Hoggarth, C. R. Assay of 1-Hydroxy-3Aminopropylidene-1,1-Bisphosphonate and Related Bisphosphonates in HumanUrine and Plasma by High-Performance Ion Chromatography. Journal of Chromatography-Biomedical Applications, 1989, 490: 329-338.

DeMarco J.D., Biffar, S. E., Reed, D. G. and Brooks, M. A. The Determination of 4amino-1-hydroxybutane-1,1-diphosphonic acid Monosodium Salt Trihydrate in Pharmaceutical Dosage Forms by High-Performance Liquid Chromatography. Journal of Pharmaceutical and Biomedical Analysis 7[12], 1719-1727. 1989.

denHartigh, J., Langebroek, R. and Vermeij, P. Ion-Exchange-Liquid-Chromatographic Analysis of Bisphosphonates in Pharmaceutical Preparations. Journal of Pharmaceutical and Biomedical Analysis, 1993, 11: 977-983.

Duan, K., Fan, Y. W. and Wang, R. Z. Electrolytic Deposition of Calcium Etidronate Drug Coating on Titanium Substrate. Journal of Biomedical Materials Research Part B-Applied Biomaterials, 2005, 72B: 43-51.

Eberhardt, C., Schwarz, M. and Kurth, A. H. High Dosage Treatment of NitrogenContaining Bisphosphonate Ibandronate Is Required for Osseointegration of Cementless Metal Implants. Journal of Orthopaedic Science, 2005, 10: 622-626.

Endele, R., Loew, H. and Bauss, F. Analytical Methods for the Quantification of 
Ibandronate in Body Fluids and Bone. Journal of Pharmaceutical and Biomedical Analysis, 2005, 39: 246-256.

Ezra, A. and Golomb, G. Administration routes and delivery systems of bisphosphonates for the treatment of bone resorption. Advanced Drug Delivery Reviews, 2000, 42: 175-195.

Fan, Y. W., Duan, K. and Wang, R. Z. A Composite Coating by Electrolysis-Induced Collagen Self-Assembly and Calcium Phosphate Mineralization. Biomaterials, 2005, 26: 1623-1632.

Fleisch, H. Chemistry and Mechanisms of Action of Diphosphonates. In: S.Garattini (Ed) Bone Resorption, Metastasis and Disphosphonates. Raven Press, New York, 1985: 33-40.

Fleisch, H. Bisphosphonates in Bone Disease: From the Laboratory to the Patient, 3rd ed. Parthenon Publishing Group, New York, 1997.

Fleisch, H. Bisphosphonates: Mechanisms of Action. Endocrine Reviews, 1998, 19: 80100.

Flesch, G. and Hauffe, S. A. Determination of the Bisphosphonate Pamidronate Disodium in Urine by Pre-Column Derivatization With Fluorescamine, HighPerformance Liquid-Chromatography and Fluorescence Detection. Journal of Chromatography-Biomedical Applications, 1989, 489: 446-451.

Flesch, G., Tominaga, N. and Degen, P. Improved Determination of the Bisphosphonate Pamidronate Disodium in Plasma and Urine by Precolumn Derivatization With Fluorescamine, High-Performance Liquid-Chromatography and Fluorescence Detection. Journal of Chromatography-Biomedical Applications, 1991, 568: 261266.

Fox, T. G. Influence of Diluent and of Copolymer Composition on the Glass Transition Temperature of a Polymer System. Bull. Am. Phys. Soc., 1956, 1: 123.

Freiberg, S. and Zhu, X. Polymer Microspheres for Controlled Drug Release. 
International Journal of Pharmaceutics, 2004, 282: 1-18.

Fruijtier-Polloth, C. Safety Assessment on Polyethylene Glycols (Pegs) and Their Derivatives as Used in Cosmetic Products. Toxicology, 2005, 214: 1-38.

Garcia-Moreno, C., Serrano, S., Nacher, M., Farre, M., Diez, A., Marinoso, M. L., Carbonell, J., Mellibovsky, L., Nogues, X., Ballester, J. and Aubia, J. Effect of Alendronate on Cultured Normal Human Osteoblasts. Bone 22[3], 233-239. 1998.

Greenspan, S. L., Harris, S. T., Bone, H., Miller, P. D., Orwoll, E. S., Watts, N. B. and Rosen, C. J. Bisphosphonates: Safety and Efficacy in the Treatment and Prevention of Osteoporosis. American Family Physician, 2000, 61: 2731-2736.

Grubisic, Z., Rempp, P. and Benoit, H. A Universal Calibration for Gel Permeation Chromatography. Journal of Polymer Science Part B-Polymer Letters, 1967, 5: 753-\&.

Hammerle, C. H. F. and Jung, R. E. Bone Augmentation by Means of Barrier Membranes. Periodontology 2000, 2003, 33: 36-53:

Han, Y. H. R. and Qin, X. Z. Determination of Alendronate Sodium by Ion Chromatography with Refractive Index Detection. Journal of Chromatography A, 1996, 719: 345-352.

Higuchi, T. Rate of Release of Medicaments from Ointment Bases Containing Drugs in Suspension. Journal of Pharmaceutical Sciences, 1961, 50: 874-5.

Hillner, B. E., Ingle, J. N., Chlebowski, R. T., Gralow, J., Yee, G. C., Janjan, N. A., Cauley, J. A., Blumenstein, B. A., Albain, K. S., Lipton, A. and Brown, S. American Society of Clinical Oncology 2003 update on the role of bisphosphonates and bone health issues in women with breast cancer. J.Clin Oncol., 2003, 21: 4042-4057.

Hoffman, A. S. Classes of Materials Used in Medicine. In: B. D. Ratner and A. S. Hoffman (Eds) Biomaterials Science: An Introduction to Materials in Medicine. Elsevier Academic Press, New York, 2004. 
Hughes, D. E., Macdonald, B. R., Russell, R. G. G. and Gowen, M. Inhibition Of Osteoclast-Like Cell-Formation By Bisphosphonates In Long-Term Cultures Of Human-Bone Marrow. Journal of Clinical Investigation, 1989, 83: 1930-1935.

Hughes, D. E., Wright, K. R., Uy, H. L., Sasaki, A., Yoneda, T., Roodman, G. D., Mundy, G. R. and Boyce, B. F: Bisphosphonates Promote Apoptosis In Murine Osteoclasts In-Vitro And In-Vivo. Journal of Bone and Mineral Research, 1995, 10: 1478-1487.

Im, G. I., Qureshi, S. A., Kenney, J., Rubash, H. E. and Shanbhag, A. S. Osteoblast Proliferation and Maturation by Bisphosphonates. Biomaterials, 2004, 25: 41054115.

International Conference on Harmonization. ICH Topic Q2B: Validation of Analytical Procedures: Methodology. 1996.

Jackson, J. K., Skinner, K. C., Burgess, L., Sun, T., Hunter, W. L. and Burt, H. M. Paclitaxel-Loaded Crosslinked Hyaluronic Acid Films for the Prevention of Postsurgical Adhesions. Pharmaceutical Research, 2002, 19: 411-417.

Jackson, J. K., Smith, J., Letchford, K., Babiuk, K. A., Lindsay, M., Signore, P., Hunter, W. L., Wang, K. Y. and Burt, H. M. Characterization of Perivascular Poly (Lactic-Co-Glycolic Acid) Films Containing Paclitaxel. International Journal of Pharmaceutics, 2004, 283: 97-109.

Jain, R. A. The Manufacturing Techniques of Various Drug Loaded Biodegradable Poly(Lactide-co-Glycolide) (PLGA) Devices. Biomatérials, 2000, 21: 2475-2490.

Jeppsson, C., Astrand, J., Tagil, M. and Aspenberg, P. A Combination of Bisphosphonate and Bmp Additives in Impacted Bone Allografts. Acta Orthopaedica Scandinavica, 2003, 74: 483-489.

Jiang, W. L., Gupta, R. K., Deshpande, M. C. and Schwendeman, S. P. Biodegradable Poly(Lactic-Co-Glycolic Acid) Microparticles for Injectable Delivery of Vaccine Antigens. Advanced Drug Delivery Reviews, 2005, 57: 391-410. 
Jones, D. Pharmaceutical Applications of Polymers for Drug Delivery. Rapra Review Report 174. Rapra Technology Ltd., London, 2004.

Kajiwara, H., Yamaza, T., Yoshinari, M., Goto, T., Iyama, S., Atsuta, I., Kido, M. A. and Tanaka, T. The Bisphosphonate Pamidronate on the Surface of Titanium Stimulates Bone Formation around Tibial Implants in Rats. Biomaterials, 2005, 26: $581-587$.

Khang, G., Rhee, J. M., Jeong, J. K., Lee, J. S., Kim, M. S., Cho, S. H. and Lee, H. B. Local Drug Delivery System Using Biodegradable Polymers. Macromolecular Research, 2003, 11:207-223.

Kim, S. Y., Shin, I. G. and Lee, Y. M. Preparation and Characterization of Biodegradable Nanospheres Composed of Methoxy Poly(Ethylene Glycol) and Dl-Lactide Block Copolymer as Novel Drug Carriers. Journal of Controlled Release, 1998, 56: 197208.

Kinane, D. F. and Lindhe, J. Pathogenesis of Periodontitis. In: J. Lindhe, T. Karring and N. P. Lang (Eds) Clinical periodontology and implant dentistry. Blackwell Science, Oxford, 2000: 189-225.

King, L. E. and Vieth, R. Extraction and Measurement of Pamidronate from Bone Samples using Automated Pre-column Derivatization, High-Performance Liquid Chromatography and Fluorescence Detection. Journal of Chromatography BBiomedical Applications, 1996, 678: 325-330.

Kline, W. F. and Matuszewski, B. K. Improved Determination of the Bisphosphonate Alendronate in Human Plasma and Urine by Automated Precolumn Derivatization and High-Performance Liquid-Chromatography with Fluorescence and Electrochemical Detection. Journal of Chromatography-Biomedical Applications, 1992, 583: 183-193.

Kline, W. F., Matuszewski, B. K. and Bayne, W. F. Determination of 4-Amino-1Hydroxybutane-1,1-Bisphosphonic Acid in Urine by Automated Precolumn Derivatization with 2,3-Naphthalene Dicarboxyaldehyde and High-Performance Liquid-Chromatography with Fluorescence Detection . Journal of 
Chromatography-Biomedical Applications, 1990, 534: 139-149.

Kohn, J., Abramson, S. and Langer, R. Bioresorbable and Bioerodible Materials. In: B. D. Ratner and A. S. Hoffman (Eds) Biomaterials Science: An Introduction to Materials in Medicine. Elsevier Academic Press, New York, 2004.

Kovacevic, M., Gartner, A. and Novic, M. Determination of Bisphosphonate by Ion Chromatography-Inductively Coupled Mass Spectrometry. Journal of Chromatography a, 2004, 1039: 77-82.

Kuljanin, J., Jankovic, I., Nedeljkovic, J., Prstojevic, D. and Marinkovic, V. Spectrophotometric Determination of Alendronate in Pharmaceutical Formulations via Complex Formation with $\mathrm{Fe}(\mathrm{III})$ Ions. Journal of Pharmaceutical and Biomedical Analysis, 2002, 28: 1215-1220.

Kwong, E., Chiu, A. M. Y., McClintock, S. A. and Cotton, M. L. HPLC Analysis of an Amino Bisphosphonate in Pharmaceutical Formulations using Postcolumn Derivatization and Fluorescence Detection. Journal of Chromatographic Science, 1990, 28: 563-566.

Langer, R. New Methods of Drug Delivery. Science, 1990, 249: 1527-1533.

Langer, R. Drug Delivery and Targeting. Nature, 1998, 392: 5-10.

Laurell, L., Gottlow, J., Zybutz, M. and Persson, R. Treatment of Intrabony Defects by Different Surgical Procedures. A Literature Review. Journal of Periodontology, 1998, 69: 303-313.

Leis, H. J., Fauler, G. and Windischhofer, W. Use of O-18(3)-Clodronate as an Internal Standard for the Quantitative Analysis of Clodronate in Human Plasma by Gas Chromatography/Electron Ionisation Mass Spectrometry. Rapid Communications in Mass Spectrometry, 2004, 18: 2781-2784.

Lichtenberger, L. M., Romero, J. J., Gibson, G. W. and Blank, M. A. Effect of Bisphosphonates on Surface Hydrophobicity and Phosphatidylcholine Concentration of Rodent Gastric Mucosa. Digestive Diseases and Sciences, 2000, 
45: 1792-1801.

Liggins, R. T. and Burt, H. A. Paclitaxel-Loaded Poly(L-Lactic Acid) Microspheres 3: Blending Low and High Molecular Weight Polymers to Control Morphology and Drug Release. International Journal of Pharmaceutics, 2004, 282: 61-71.

Liggins, R. T. and Burt, H. M. Paclitaxel Loaded Poly(L-lactic acid) Microspheres: Properties of Microspheres made with Low Molecular Weight Polymers. International Journal of Pharmaceutics, 2001, 222: 19-33.

Liggins, R. T. and Burt, H. M. Polyether-Polyester Diblock Copolymers for the Preparation of Paclitaxel Loaded Polymeric Micelle Formulations. Advanced Drug Delivery Reviews, 2002, 54: 191-202.

Liggins, R. T. and Burt, H. M. Paclitaxel Loaded Poly(Lactic Acid) (Plla) Microspheres Ii. The Effect of Processing Parameters on Microsphere Morphology and Drug Release Kinetics. International Journal of Pharmaceutics, 2004, 281: 103-106.

Lin, J. H. Bisphosphonates: A Review of their Pharmacokinetic Properties. Bone, 1996, 18: $75-85$.

Lin, J. H., Chen, I. W. and Deluna, F. A. On the Absorption of Alendronate in Rats. Journal of Pharmaceutical Sciences, 1994, 83: 1741-1746.

Lin, J. H., Duggan, D. E., Chen, I. W. and Ellsworth, R. L. Physiological Disposition of Alendronate, A Potent Anti-Osteolytic Bisphosphonate, in Laboratory Animals. Drug Metabolism and Disposition, 1991, 19: 926-932.

Marshall, J. K. The Gastrointestinal Tolerability and Safety of Oral Bisphosphonates. Expert.Opin.Drug Saf, 2002, 1: 71-78.

Marx, R. E., Sawatari, Y., Fortin, M. and Broumand, V. Bisphosphonate-Induced Exposed Bone (Osteonecrosis/Osteopetrosis) of the Jaws: Risk Factors, Recognition, Prevention, and Treatment. Journal of Oral and Maxillofacial Surgery, 2005, 63: 1567-1575. 
Meraw, S. J: and Reeve, C. M. Qualitative Analysis of Peripheral Peri-Implant Bone and Influence of Alendronate Sodium on Early Bone Regeneration. Journal of Periodontology, 1999, 70: 1228-1233.

Meraw, S. J., Reeve, C. M. and Wollan, P. C. Use of Alendronate in Peri-Implant Defect Regeneration. Journal of Periodontology, 1999, 70: 151-158.

Millett, P. J., Allen, M. J. and Bostrom, M. P. G. Effects of Alendronate on ParticleInduced Osteolysis in a Rat Model. Journal of Bone and Joint Surgery-American Volume, 2002, 84A: 236-249.

Moore, J. W. and Flanner, H. H. Mathematical Comparison of Dissolution Profiles. Pharmaceutical Technólogy 20[6], 64-74. 1996.

Moore, W. R., Graves, S. E. and Bain, G. I. Synthetic Bone Graft Substitutes. ANZ Journal of Surgery, 2001, 71: 354-361.

Moreira, M. S., Katayama, E., Bombana, A. C. and Marques, M. M. Cytotoxicity Analysis of Alendronate on Cultured Endothelial Cells and Subcutaneous Tissue. A Pilot Study. Dental Traumatology, 2005, 21: 329-335.

.Muntoni, E., Canaparo, R., Della Pepa, C., Serpe, L., Casale, F., Barbera, S., Romano, P., Zara, G. P. and Eandi, M. Determination of Disodium Clodronate in Human Plasma and Urine Using Gas-Chromatography-Nitrogen-Phosphorous Detections: Validation and Application in Pharmacokinetic Study. Journal of Chromatography B-Analytical Technologies in the Biomedical and Life Sciences, 2004, 799: 133-139.

Nasr, H. F., Aichelmann-Reidy, M. E. and Yukna, R. A. Bone and Bone Substitutes. Periodontology 2000, 1999, 19: 74-86.

Ostovic, D. and Brenner, G. S. Development of Subcutaneous and Intramuscular Formulations of Calcium Alendronate Salts. Drug Development and Industrial Pharmacy, 1995, 21: 1157-1169.

Ostovic, D., Stelmach, C. and Hulshizer, B. Formation of a Chromophoric Complex 
between Alendronate and Copper (II) Ions. Pharmaceutical Research, 1993, 10: 470-472.

Owen, G. R., Jackson, J., Chehroudi, B., Burt, H. and Brunette, D. M. A PLGA Membrane Controlling Cell Behaviour for Promoting Tissue Regeneration. Biomaterials, 2005, 26: 7447-7456.

Park, J. H., Ye, M. L. and Park, K. Biodegradable Polymers for Microencapsulation of Drugs. Molecules, 2005, 10: 146-161.

Park, P. I. P. and Jonnalagadda, S. Predictors of Glass Transition in the Biodegradable Poly-Lactide and Poly-Lactide-co-Glycolide Polymers. Journal of Applied Polymer Science, 2006, 100: 1983-1987.

Park, Y. J., Lee, Y. M., Park, S. N., Lee, J. Y., Ku, Y., Chung, C. P. and Lee, S. J. Enhanced Guided Bone Regeneration by Controlled Tetracycline Release From Poly(L-Lactide) Barrier Membranes. Journal of Biomedical Materials Research, 2000, 51: 391-397.

Perugini, P., Genta, I., Conti, B., Modena, T. and Pavanetto, F. Long-term Release of Clodronate from Biodegradable Microspheres. Acta Orthopaedica Scandinavica 2[3], 10. 2001.

Peter, B., Gauthier, O., Laib, S., Bujoli, B., Guicheux, J., Janvier, P., Van Lenthe, G. H., Muller, R., Zambelli, P. Y., Bouler, J. M. and Pioletti, D. P. Local Delivery of Bisphosphonate From Coated Orthopedic Implants Increases Implants Mechanical Stability in Osteoporotic Rats. Journal of Biomedical Materials Research Part a, 2006, 76A: 133-143.

Peter, B., Pioletti, D. P., Laib, S., Bujoli, B., Pilet, P., Janvier, P., Guicheux, J., Zambelli, P. Y., Bouler, J. M. and Gauthier, O. Calcium Phosphate Drug Delivery System: Influence of Local Zoledronate Release on Bone Implant Osteointegration. Bone, 2005a, 36: 52-60.

Peter, B., Zambelli, P. Y., Guicheux, J. and Pioletti, D. P. The Effect of Bisphosphonates and Titanium Particles on Osteoblasts - an in Vitro Study. Journal of Bone and 
Joint Surgery-British Volume, 2005b, 87B: 1157-1163.

Piskin, E. Biodegradable Polymers as Biomaterials. Journal of Biomaterials SciencePolymer Edition, 1995, 6: 775-795.

Piskin, E., Kaitian, X., Denkbas, E. B. and Kucukyavuz, Z. Novel PDLLA/PEG Copolymer Micelles as Drug Carriers. Journal of Biomaterials Science-Polymer Edition, 1995, 7: 359-373.

Ptacek, P., Klima, J. and Macek, J. Determination of Alendronate in Human Urine as 9Fluorenylmethyl Derivative by High-Performance Liquid Chromatography. Journal of Chromatography B-Analytical Technologies in the Biomedical and Life Sciences, 2002, 767: 111-116.

Qin, X. Z., Tsai, E. W., Sakuma, T. and Ip, D. P. Pharmaceutical Application of Liquid Chromatography-Mass Spectrometry 2. Ion Chromatography Ion-Spray MassSpectrometric Characterization of Alendronate . Journal of Chromatography A, 1994, 686: 205-212.

Quitasol, J. and Krastins, L. Analysis of Pamidronate Disodium in Pharmaceutical Dosage Forms by Ion Chromatography. Journal of Chromatography A, 1994, 671: 273-279.

Raisz, L. G. Physiology and Pathophysiology of Bone Remodeling. Clinical Chemistry, 1999, 45: 1353-1358.

Ralston, S. The Bone Remodelling Cycle. http://www.abdn.ac.uk/medicine_therapeutics/bone/bone\%20anatomy\%20and\%2 Ocell\%20biology.hti, 2005.

Reed, D. G., Martin, G. P., Konieczny, J. M. and Brooks, M. A. The Determination of Alendronate Sodium in Tablets by Inductively-Coupled Plasma (ICP). Journal of Pharmaceutical and Biomedical Analysis, 1995, 13: 1055-1058.

Reszka, A. A. and Rodan, G. A. Nitrogen-Containing Bisphosphonate Mechanism of Action. Mini-Reviews in Medicinal Chemistry, 2004, 4: 711-719. 
Rodan, G. A. and Fleisch, H. A. Bisphosphonates: Mechanisms of Action. Journal of Clinical Investigation, 1996, 97: 2692-2696.

Rogers, M. J., Chilton, K. M., Coxon, F. P., Lawry, J., Smith, M. O., Suri, S. and Russell, R. G. G. Bisphosphonates Induce Apoptosis in Mouse Macrophage-Like Cells in Vitro by a Nitric Oxide-Independent Mechanism. Journal of Bone and Mineral Research, 1996, 11: 1482-1491.

Rosen S.L. Polymer Morphology, In "Fundamental Principles of Polymeric Materials". John Wiley \& Sons, Inc. New York, 1993.

Russell, R. G. G., Croucher, P. I. and Rogers, M. J. Bisphosphonates: Pharmacology, Mechanisms of Action and Clinical Uses. Osteoporosis International, 1999, 9: 66-80.

Sahni, M., Guenther, H. L., Fleisch, H., Collin, P. and Martin, T. J. Bisphosphonates Act on Rat Bone-Resorption Through the Mediation of Osteoblasts. Journal of Clinical Investigation, 1993, 91: 2004-2011.

Sakiyama, N., Kataoka, H. and Makita, M. Gas Chromatographic Analysis of 3-Amino1-Hydroxypropylidene-1,1-Bisphosphonate and Related Bisphosphonate as their N-Isobutoxycarbonyl Methyl Ester Derivatives. Journal of Chromatography A, 1996, 724: 279-284.

Sato, M., Grasser, W., Endo, N., Akins, R., Simmons, H., Thompson, D. D., Golub, E. and Rodan, G. A. Bisphosphonate Action - Alendronate Localization In Rat Bone And Effects On Osteoclast Ultrastructure. Journal of Clinical Investigation, 1991, 88: 2095-2105.

Sedlak, M. Recent Advances in Chemistry and Applications of Substituted Poly(Ethylene Glycol)S. Collection of Czechoslovak Chemical Communications, 2005, 70: 269291.

Shenderova, A., Burke, T. G. and Schwendeman, S. P. The Acidic Microclimate in Poly(Lactide-Co-Glycolide) Microspheres Stabilizes Camptothecins. Pharmaceutical Research, 1999, 16: 241-248. 
Shipman, C. M., Croucher, P. I., Russell, R. G. G., Helfrich, M. H. and Rogers, M. J. The Bisphosphonate Incadronate (Ym175) Causes Apoptosis of Human Myeloma Cells in Vitro by Inhibiting the Mevalonate Pathway. Cancer Research, 1998, 58: 5294-5297.

Skoglund, B., Holmertz, J. and Aspenberg, P. Systemic and Local Ibandronate Enhance Screw Fixation. Journal of Orthopaedic Research, 2004, 22: 1108-1113.

Sparidans, R. W. and den Hartigh, J. Chromatographic Analysis of Bisphosphonates. Pharmacy World \& Science, 1999, 21: 1-10.

Sparidans, R. W., den Hartigh, J., Beijnen, J. H. and Vermeij, P. Determination of Pamidronate in Urine by Ion-Pair Liquid Chromatography after. Derivatization with 1-Naphthylisothiocyanate. Journal of Chromatography B, 1997, 696: 137144.

Sparidans, R. W., den Hartigh, J., Beijnen, J. H. and Vermeij, P. Semi-Automatic Liquid Chromatographic Analysis of Pamidronate in Serum and Citrate Plasma after Derivatization with 1-Naphthylisothiocyanate. Journal of Chromatography B, 1998, 705: 331-339.

Sparidans, R. W., den Hartigh, J., RampKoopmanschap, W. M., Langebroek, R. H. and Vermeij, P. The Determination of Pamidronate in Pharmaceutical Preparations by Ion-Pair Liquid Chromatography after Derivatization with Phenylisothiocyanate. Journal of Pharmaceutical and Biomedical Analysis, 1997, 16: 491-497.

Sparidans, R. W., den Hartigh, J. and Vermeij, P. High-Performance Ion-Exchange Chromatography with In-Line Complexation of Bisphosphonates and their Quality Control in Pharmaceutical Preparations. Journal of Pharmaceutical and Biomedical Analysis, 1995, 13: 1545-1550.

Strickley, R. G. Solubilizing Excipients in Oral and Injectable Formulations. Pharmaceutical Research, 2004, 21: 201-230.

Suri, S., Monkkonen, J., Taskinen, M., Pesonen, J., Blank, M. A., Phipps, R. J. and Rogers, M. J. Nitrogen-Containing Bisphosphonates Induce Apoptosis of Caco-2 
cells In Vitro by Inhibiting the Mevalonate Pathway: a Model of BisphosphonateInduced Gastrointestinal Toxicity. Bone 29[4], 336-343. 2001.

Taha, E. A. and Youssef, N. F. Spectrophotometric Determination of Some Drugs for Osteoporosis. Chemical \& Pharmaceutical Bulletin, 2003, 51: 1444-1447.

Tenenbaum, H. C., Shelemay, A., Girard, B., Zohar, R. and Fritz, P. C. Bisphosphonates and Periodontics: Potential Applications for Regulation of Bone Mass in the Periodontium and Other Therapeutic/Diagnostic Uses. Journal of Periodontology, 2002, 73: 813-822.

Tengvall, P., Skoglund, B., Askendal, A. and Aspenberg, P. Surface Immobilized Bisphosphonate Improves Stainless-Steel Screw Fixation in Rats. Biomaterials, 2004, 25: 2133-2138.

Trombelli, L., Heitz-Mayfield, L. J. A., Needleman, I., Moles, D. and Scabbia, A. A Systematic Review of Graft Materials and Biological Agents for Periodontal Intraosseous Defects. Journal of Clinical Periodontology, 2002, 29: 117-135.

Tsai, E. W., Chamberlin, S. D., Forsyth, R. J., Bell, C., Ip, D. P. and Brooks, M. A. Determination of Bisphosphonate Drugs in Pharmaceutical Dosage Formulations by Ion Chromatography with Indirect UV Detection. Journal of Pharmaceutical and Biomedical Analysis, 1994, 12: 983-991.

Tsai, E. W., Ip, D. P. and Brooks, M. A. Determination of Alendronate in Pharmaceutical Dosage Formulations by Ion Chromatography with Conductivity Detection. Journal of Chromatography, 1992, 596: 217-224.

Twiss, I. M., Pas, O., Ramp-Koopmanschap, W., den Hartigh, J. and Vermeij, P. The Effects of Nitrogen-Containing Bisphosphonates on Human Epithelial (Caco-2) Cells, an In Vitro Model for Intestinal Epithelium. Journal of Bone and Mineral Research, 1999, 14 : 784-791.

Tzanavaras, P. D., Zacharis, C. K., Theodoridis, G. A., Kalaitzantonakis, E. A. and Voulgaropoulos, A. N. Normal Spectrophotometric and Stopped-Flow Spectrofluorimetric Sequential Injection Methods for the Determination of 
Alendronic Acid, an Anti-Osteoporosis Amino-Bisphosphonate Drug, in Pharmaceuticals. Analytica Chimica Acta, 2005, 547: 98-103.

Vaisman, D. N., Mccarthy, A. D. and Cortizo, A. M. Bone-Specific Alkaline Phosphatase Activity Is Inhibited by Bisphosphonates - Role of Divalent Cations. Biological Trace Element Research, 2005, 104: 131-140.

Vega, D., Baggio, R. and Garland, M. T. Monosodium 4-Amino-1-hydroxy-1,1butanediyldiphosphonate Trihydrate (Alendronate). Acta Crystallographica C52, 2198-2201. 1996.

Veronese, F. M. and Pasut, G. Pegylation, Successful Approach to Drug Delivery. Drug Discovery Today, 2005, 10: 1451-1458.

Vickers, M. Investigation of Sodium Alendronate Trihydrate (Form C). http://img.cryst.bbk.ac.uk/www/reports/alen/alend.htm, 2004.

Vitte, C., Fleisch, H. and Guenther, H. L. Biphosphonates Induce Osteoblasts to Secrete an Inhibitor of Osteoclast-Mediated Resorption. Endocrinology, 1996, 137: 23242333.

Von Knoch, F., Jaquiery, C., Kowalsky, M., Schaeren, S., Alabre, C., Martin, I., Rubash, H. E. and Shanbhag, A. S. Effects of Bisphosphonates on Proliferation and Osteoblast Differentiation of Human Bone Marrow Stromal Cells. Biomaterials, 2005, 26: 6941-6949.

Wang, F. J. and Wang, C. H. Etanidazole-Loaded Microspheres Fabricated by SprayDrying Different Poly(Lactide/Glycolide) Polymers: Effects on Microsphere Properties. Journal of Biomaterials Science-Polymer Edition, 2003, 14: 157-183.

Weidenauer, U., Bodmer, D. and Kissel, T. Microencapsulation of Hydrophilic Drug Substances Using Biodegradable Polyesters. Part I: Evaluation of Different Techniques for the Encapsulation of Pamidronate Di-Sodium Salt. Journal of Microencapsulation, 2003, 20: 509-524.

Weidenauer, U., Bodmer, D. and Kissel, T. Microencapsulation of Hydrophilic Drug 
Substances Using Biodegradable Polyesters. Part II: Implants Allowing Controlled Drug Release - a Feasibility Study Using Bisphosphonates. Journal of Microencapsulation, 2004, 21: 137-149.

Wieland, M., Textor, M., Chehroudi, B. and Brunette, D. M. Synergistic Interaction of Topographic Features in the Production of Bone-Like Nodules on Ti Surfaces by Rat Osteoblasts. Biomaterials, 2005, 26: 1119-1130.

Wise, L. M., Waldman, S. D., Kasra, M., Cheung, R., Binnington, A., Kandel, R. A., White, L. M. and Grynpas, M. D. Effect of Zoledronate on Bone Quality in the Treatment of Aseptic Loosening of Hip Arthroplasty in the Dog. Calcified Tissue International, 2005, 77: 367-375.

Wong, J. A., Renton, K. W., Crocker, J. F. S., O'Regan, P. A. and Acott, P. D. Determination of Pamidronate in Human Whole Blood and Urine by ReversedPhase HPLC with Fluorescence Detection. Biomedical Chromatography, 2004, 18: 98-101.

Yaffe, A., Fine, N., Alt, I. and Binderman, I. The Effect of Bisphosphonate on Alveolar Bone-Resorption Following Mucoperiosteal Flap Surgery in the Mandible of Rats . Journal of Periodontology, 1995, 66: 999-1003.

Yaffe, A., Iztkovich, M., Earon, Y., Alt, I., Lilov, R. and Binderman, I. Local Delivery of an Amino Bisphosphonate Prevents the Resorptive Phase of Alveolar Bone Following Mucoperiosteal Flap Surgery in Rats. Journal of Periodontology, 1997, 68: 884-889.

Yoshinari, M., Oda, Y., Inoue, T., Matsuzaka, K. and Shimono, M. Bone Response to Calcium Phosphate-Coated and Bisphosphonate-Immobilized Titanium Implants. Biomaterials, 2002, 23: 2879-2885.

Yoshinari, M., Oda, Y., Ueki, H. and Yokose, S. Immobilization of Bisphosphonates on Surface Modified Titanium. Biomaterials, 2001, 22: 709-715.

Yun, M. H. and Kwon, K. High-Performance Liquid Chromatography Method for Determining Alendronate Sodium in Human Plasma by Detecting Fluorescence: 
Application to a Pharmacokinetic Study in Humans. Journal of Pharmaceutical and Biomedical Analysis, 2006, 40: 168-172.

Zhang, X. C., Jackson, J. K. and Burt, H. M. Development of Amphiphilic Diblock Copolymers as Micellar Carriers of Taxol. International Journal of Pharmaceutics, 1996, 132: 195-206.

Zou, X. N., Xue, Q. Y., Li, H. S., Bunger, M., Lind, M. and Bunger, C. Effect .of Alendronate on Bone Ingrowth into Porous Tantalum and Carbon Fiber Interbody Devices - An Experimental Study on Spinal Fusion in Pigs. Acta Orthopaedica Scandinavica, 2003, 74: 596-603. 